\title{
Plasma-Sprayed and Sintered Silver-Based Antimicrobial Coatings for Industrial and Biomedical Application
}

\author{
by \\ Joseph Salvatore \\ A thesis submitted to the Faculty of Graduate and Postdoctoral Affairs in partial \\ fulfillment of the requirements for the degree of \\ Master of Applied Science \\ in \\ Biomedical Engineering \\ Carleton University \\ Ottawa, Ontario \\ (C) 2018 \\ Joseph Salvatore
}




\begin{abstract}
$\underline{\text { Abstract }}$
Bacteria are ever-present in many industries, especially food and water processing, and medicine. Bacteria can colonize the surfaces of equipment and implants, risking potential infection. An antimicrobial coating that could be applied to an alloy would prove invaluable in these industries. This thesis suggests using silver as an active antibacterial agent and details the experimental data and analysis of coatings produced via plasmaspraying and sintering. The coatings were applied to cobalt chromium, an alloy used in both industries. The plasma-sprayed coatings used cobalt chromium as a base metal, containing $0 \%, 2 \%$, and $5 \%$ silver by weight. The sintered coatings had a greater adhesion strength than the plasma-sprayed coatings (25.86 MPa versus $24.66 \mathrm{MPa}$ in the $2 \%$ silver coating). The plasma-sprayed coatings saw no leaching of silver in sterile water, and the $2 \%$ and $5 \%$ silver plasma-sprayed coatings reduced bacteria proliferation relative to the $0 \%(99.9 \%$ and $63.4 \%$ reduction $)$.
\end{abstract}




\section{$\underline{\text { Acknowledgements }}$}

Special thanks to Dr. Andrew Speirs, David Raude, Steve Truttman, Alex Proctor, Kevin Sangster, Ian Lloy, Jianqun Wang, Amanda Carroll, Dr. Alex Wong, Dr. Xiao Huang, and Cathy Xiao. I could not have done it without you.

This work was partially supported by a NSERC Engage Grant and by the industry partner, Kennametal Stellite, who supplied many of the test materials. 


\section{Table of Contents}

List of Figures .............................................................................................. vii

List of Tables .......................................................................................................... Xv

Chapter 1: Introduction ......................................................................................... 1

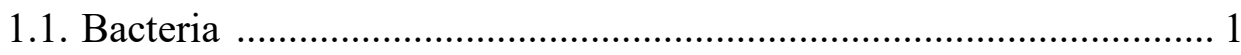

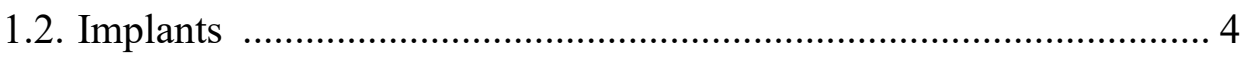

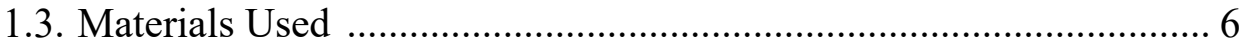

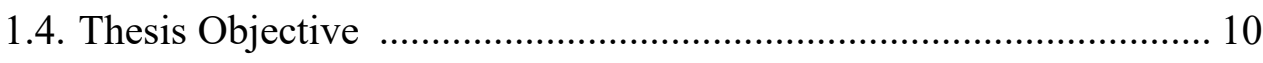

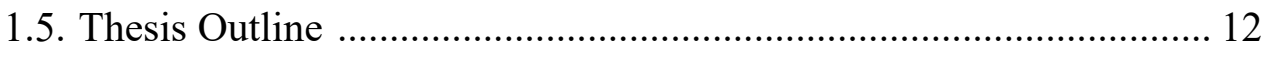

2. Chapter 2: Literature Review .......................................................................... 13

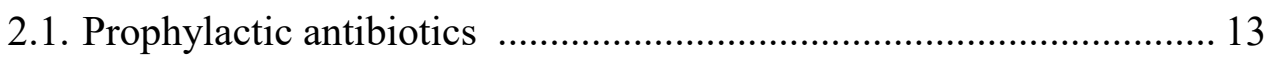

2.2. Infection Treatment …………………………………………….... 13

2.3. Material Surface Modifications ………………………….................. 14

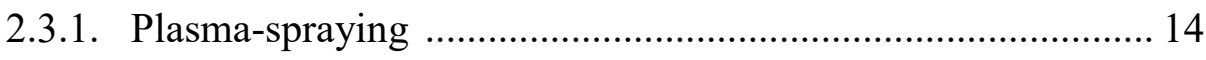

2.3.2. Sintered silver and titanium ………………….................... 15

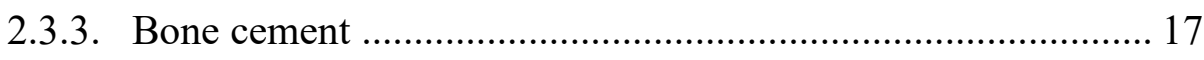

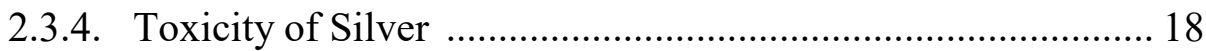

3. Chapter 3: Plasma-Sprayed Coatings ............................................................ 19

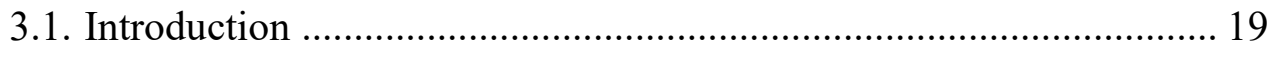

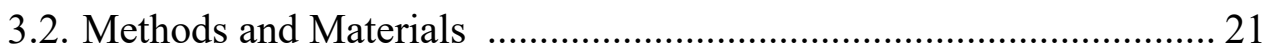

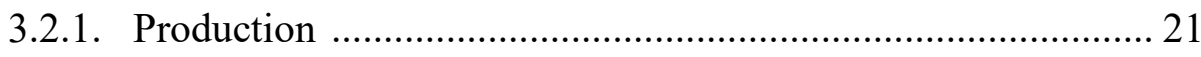

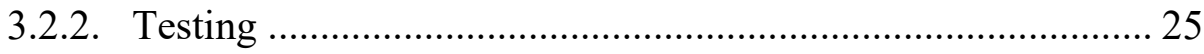

3.2.2.1. Scanning Electron Microscopy ........................................ 25 
3.2.1.2. Adhesion Strength .......................................................... 27

3.2.1.3. Silver Elution .............................................................. 30

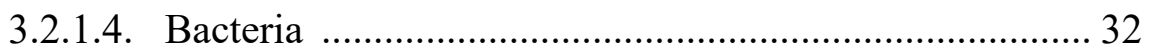

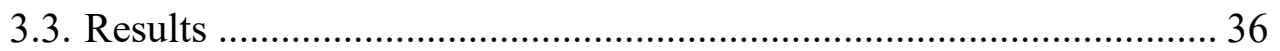

3.3.1. Scanning Electron Microscopy …………………………….... 36

3.3.1.1. Revisit after Bacteria Testing .......................................... 54

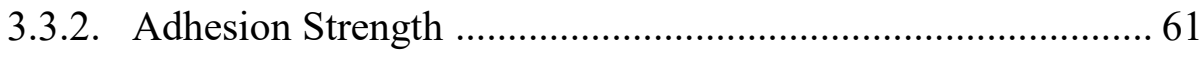

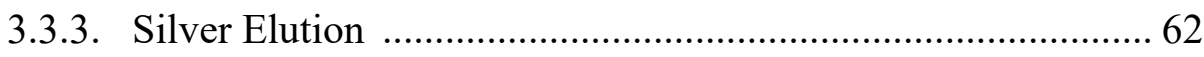

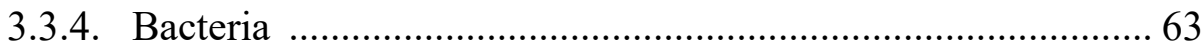

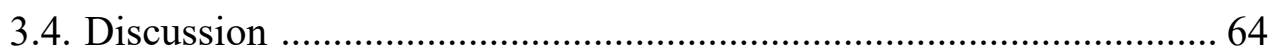

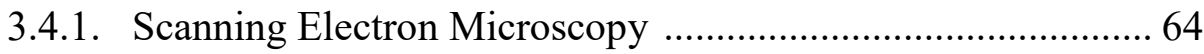

3.4.1.1. Revisit after Bacteria Testing ………………………...... 65

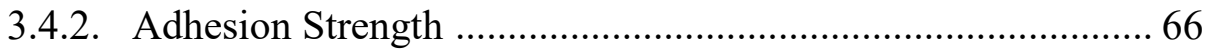

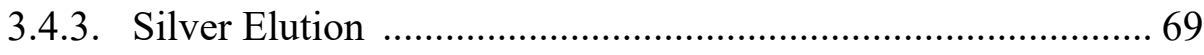

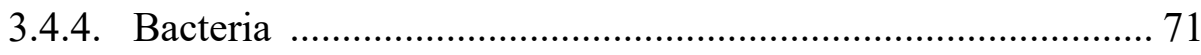

3.4.4.1. Uncoated Stellite vs. $0 \%$................................................ 77

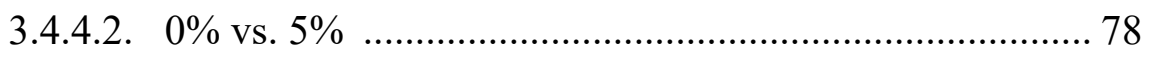

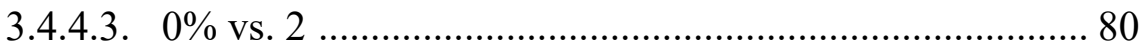

4. Chapter 4: Sintered Coatings ………………………….................................. 83

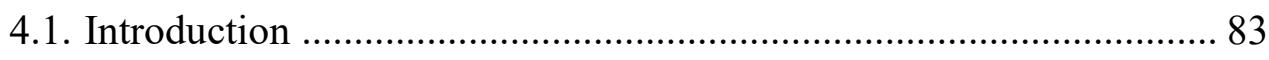

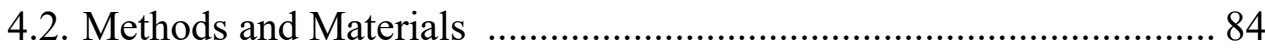

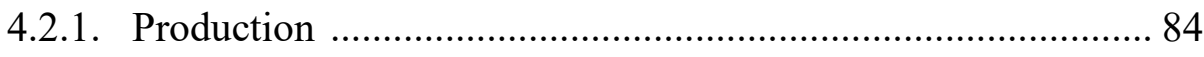

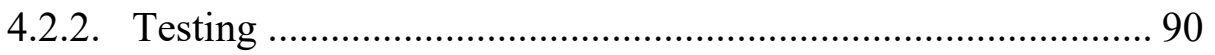


4.2.2.1. Scanning Electron Microscopy …………………............. 90

4.2.2.2. Adhesion Strength ........................................................... 90

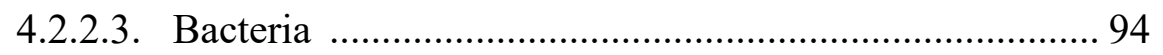

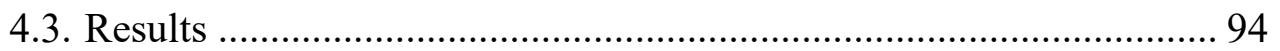

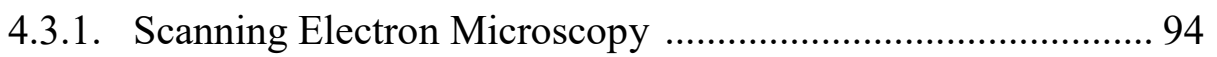

4.3.1.1. Revisit after Bacteria Testing ......................................... 104

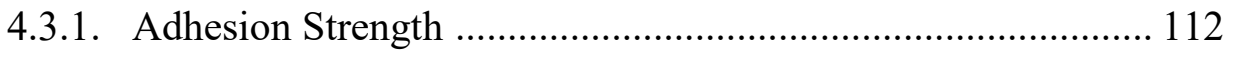

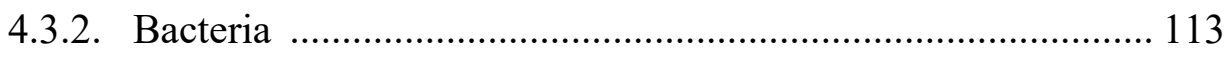

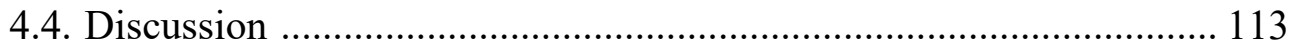

4.4.1. Scanning Electron Microscopy ………………....................... 113

4.4.1.1. Revisit after bacteria testing ........................................... 114

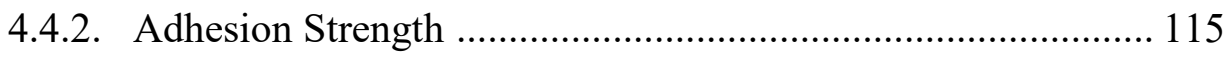

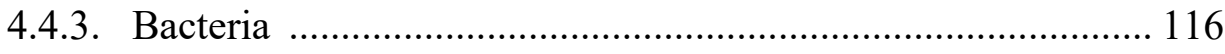

4.4.3.1. Uncoated Stellite vs. Sintered Titanium ........................ 118

4.4.3.2. Uncoated Stellite vs. Sintered Titanium + Silver .......... 118

5. Chapter 5: Discussion and Conclusions ....................................................... 120

6. Chapter 6: Contributions .............................................................................. 122

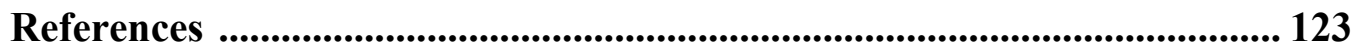




\section{List of Figures}

Figure 1: Left: Stellite coupons, Right: 316L steel coupons. One has been machined to fit a dowel pin for the adhesion test.

21

Figure 2: Two steel coupons with convex surfaces in contact to show the curvature. ..... 21

Figure 3: Left: Uncoated stainless-steel sample and one of each plasma-sprayed coupons. The silver concentrations were $0 \%, 2 \%$, and $5 \%$ by mass and are labeled accordingly. These coupons would later be viewed in the Scanning Electron Microscope. Right: Two plasma-sprayed Stellite coupons, showing the markings on the reverse...... 25

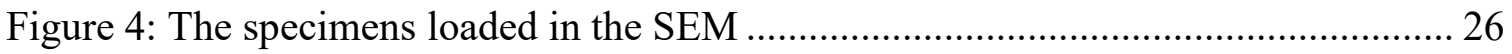

Figure 5: 5\% silver plasma-sprayed coupons shortly before being adhered together. Epoxy

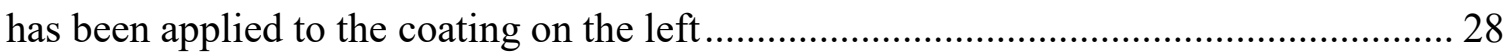

Figure 6: 5\% silver plasma-sprayed coupons in a steel vice before being loaded into the furnace to cure the epoxy

Figure 7: Vice containing plasma-sprayed coupons loaded into the furnace ................... 29 Figure 8: Plasma-sprayed coupons loaded in MTS frame for ASTM F1044.These were loaded in tension until failure.

Figure 9: A 2\% silver plasma-sprayed coating shortly after emersion in water for the elution test. 31

Figure 10: One of the vials of solution sent to Paracel Laboratories, Ltd. 32

Figure 11: Left: Bacteria culture on 316L steel with sterile water in the dish, Right: adding sterile water to several wells surrounding the coated area of a Stellite coupon 34 Figure 12: Rinsing a coupon with liquid broth to remove bacteria after incubating on the surface. This mixture was then plated. 35 
Figure 13: Dilutions testing of bacteria, with each dilution amount written near each dish. The $10^{-4}$ dilution was ultimately used to create countable bacteria colonies 35

Figure 14: A comparison of 316L steel at 1000x magnification using two different imaging modalities. Left: Backscatter Electron Imaging, Right: Secondary Electron Image. Backscatter imaging was used throughout the SEM study 36

Figure 15: uncoated Stellite coupon at 1000x magnification (backscatter image)..... 37 Figure 16: 0\% Silver plasma-sprayed coating at 2000x magnification. Left: Backscatter Electron Imaging, Right: Secondary Electron Imaging... 38 Figure 17: 2\% silver plasma-sprayed coating at 1000x magnification, Left: Backscatter Electron Imaging, Right: Secondary Electron Imaging. Note the brighter region in the backscatter image (circled in red), later identified as silver.This would be difficult to identify in the Secondary Electron image 39

Figure 18: 5\% silver plasma-sprayed coating at 1000x magnification. Left: Backscatter Electron Imaging, Right: Secondary Electron Imaging. The bright region in the backscatter image (circled in red) was later identified to be silver. 40 Figure 19:SEM images taken at 100x magnification. A: Uncoated 316L steel, B: 0\% silver plasma-sprayed, C: 2\% silver plasma-sprayed, D: 5\% silver plasma-sprayed. The bright regions of $\mathrm{C}$ and $\mathrm{D}$ (some marked with red arrows) are silver. 40 Figure 20: Elemental composition of 316L steel coupon, which is consistent with the alloy specifications 41

Figure 21: Elemental composition of Stellite coupon, which is consistent with the alloy

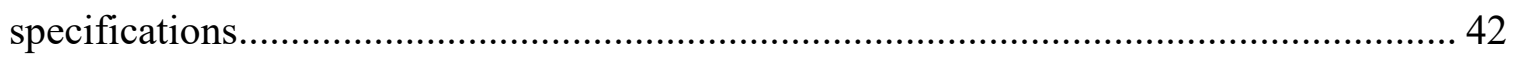
Figure 22: Elemental composition of $0 \%$ silver plasma-sprayed coating...................... 43 
Figure 23: Elemental composition of a bright region on $2 \%$ silver plasma-sprayed coating showing approximately $71 \mathrm{wt} \%$ silver. 44

Figure 24: Elemental composition of a dark region on $2 \%$ silver plasma-sprayed coating, showing to be consistent with the Stellite used 45

Figure 25: Cross-section of a $2 \%$ coating, with the interface marked with red arrows and some silver regions marked with blue arrows.................................................... 45

Figure 26: Elemental makeup of a 2\% silver coating cross-section ............................. 46

Figure 27: Elemental makeup of substrate under 2\% silver coating ............................. 47

Figure 28: Elemental map of $2 \%$ silver coating cross-section. A: Cobalt, B: Iron, C:

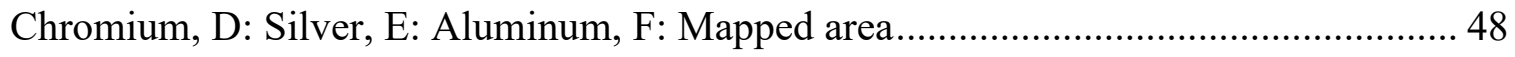

Figure 29: Elemental composition of a bright region on 5\% silver plasma-sprayed coating, indicating that it is silver.

Figure 30: Elemental composition of a dark region on 5\% silver plasma-sprayed coating, showing that it is consistent with the Stellite used

Figure 31: Cross-section of 5\% coating with the interface marked with red arrows and some silver regions marked with blue arrows . 50

Figure 32: Elemental makeup of 5\% coating cross-section. 51

Figure 33: Elemental makeup of substrate under 5\% coating 52 Figure 34: Elemental mapping of 5\% silver coating cross-section. A: Cobalt, B: Iron, C: Chromium, D: Silver, E: Aluminum, F: Mapped area.............................................. 53 Figure 35: Left: uncorroded edge of Stellite coupon, Right: corroded edge of Stellite. Arrows pointing to bright spots of interest, were beads of molybdenum. One found was tungsten 54 
Figure 36: Elemental composition of brighter region of uncorroded Stellite 55

Figure 37: Elemental composition of dark region in uncorroded Stellite, indicating that it is aluminum oxide 56

Figure 38: Elemental composition of a darker region on the corroded Stellite, which is also aluminum oxide 57

Figure 39: Elemental composition of a brighter region on the corroded Stellite. 57 Figure 40: Overall scan of uncorroded Stellite 58

Figure 41: Overall scan of corroded Stellite 58

Figure 42: Elemental composition of bright structure on corroded Stellite, which is largely comprised of molybdenum 59

Figure 43: Elemental composition of another bright structure on corroded Stellite, which is also molybdenum 60

Figure 44: Elemental composition of an amorphous bright structure on corroded Stellite determined to be tungsten 60 Figure 45:Plasma-sprayed coatings after being loaded until failure according to ASTM F1044. Left: 0\% silver, Center: 2\% silver, Right: 5\% silver. Each column was a pair adhered together. 61

Figure 46: The average ultimate stresses of each plasma-sprayed coating, plotted with standard deviation

Figure 47: Bacteria plates from: Left: uncoated 316L steel, Right: uncoated Stellite. These were used as the controls 63

Figure 48: Bacteria plates from: Left: $0 \%$ silver plasma sprayed coatings, Center: $2 \%$ silver, Right: 5\% silver 63 
Figure 49: Left: $2 \%$ silver coating after one week of submersion in distilled water, shortly before the solution was collected. Right: Two $2 \%$ silver coatings after two weeks of submersion. 70

Figure 50: Left: Corrosion on Stellite coupon that formed from autoclaving wiped off on glove, Right: comparison of uncorroded edge (left) and corroded edge (right). Oxidation from the "uncorroded" edge can be seen on the glove 71 Figure 51: Left: Stellite polished to 600 grit compared to untreated Stellite, Right: untreated Stellite compared with Stellite polished to 1200 grit. 73 Figure 52: $20 \mu 1$ of bacteria culture on a $2 \%$ silver coating (left) versus an uncoated $316 \mathrm{~L}$ steel coupon (right). This demonstrates the hydrophobic properties of the coating ......... 74 Figure 53: A dried culture that failed to yield any bacteria 76 Figure 54: Custom die used for sintering compaction. A Stellite coupon was loaded into the die and had titanium compacted on top with a punch (top right) ............................ 85 Figure 55: Titanium compaction in the die shortly after loading 85 Figure 56: The MTS frame used for titanium compaction with the die and punch setup 86 Figure 57: Titanium compactions after being removed from the die. Some loose powder would leak from one side of the compactions, and a best effort was made to brush it away without disturbing the compaction. 86 Figure 58: The tube furnace during a first stage sintering cycle. 87 Figure 59: Top: Sintered titanium coatings, Center: the same coupons after adding the silver slurry, Bottom: Sintered titanium and silver coatings. 89 
Figure 60: Sintered coatings before being loaded into SEM. An identical setup was used for the plasma-sprayed coatings. Left: failed compaction, Center: sintered titanium, Right: sintered titanium and silver 90

Figure 61: The sintered coatings used for the adhesion testing. Each coating was paired with the coating vertically adjacent 91

Figure 62: Sintered coating with applied epoxy 91 Figure 63: Sintered coupons clamped together before entering the furnace. Markings can be seen on the sides where they were measured to one inch. The epoxy was only applied to a one square inch area. 92 Figure 64: Sintered coupons set in yokes before being setup in the MTS frame. The same setup was used for plasma-sprayed coatings except the $316 \mathrm{~L}$ coupons used $5 / 8$ " dowels instead of bolts 93

Figure 65: Pair of sintered coatings loaded into the MTS frame 93 Figure 66: Failed titanium compaction at 1000x magnification, backscatter image 94 Figure 67: Sintered titanium at 1000x magnification. Some necks between titanium grains are marked with arrows. 95 Figure 68: Sintered titanium and silver at 1000x magnification. The large globular structures (marked with an arrow) and small bright spots (circled in red) were identified as silver. 96

Figure 69: Top left: Base Stellite coupon, Top right: failed titanium compaction, Bottom left: successful titanium compaction, bottom right: successful titanium compaction with

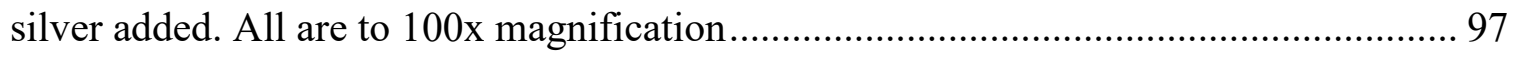

Figure 70: Point scan of unsuccessful titanium compaction 99 
Figure 71: Larger scan of unsuccessful titanium compaction 100

Figure 72: Sintered titanium elemental makeup showing significant amounts of cobalt and chromium 100

Figure 73: Elemental makeup of darker region in sintered titanium 101

Figure 74: Elemental makeup of bright structures on sintered titanium and silver 102

Figure 75: Elemental makeup of background of sintered titanium and silver, showing small amounts of silver. 103

Figure 76: Elemental makeup of another region in the background of sintered titanium and silver, also showing significant amounts of silver 104

Figure 77: Left: Ttitanium and silver sintered coating at 20x magnification, Right: same coating at 2000x magnification. This coating had not yet undergone ultrasonic cleaning. The bright areas in these images are silver 104

Figure 78: Left: Ultrasonically cleaned titanium and silver sintered coating at 20x magnification, Right: same coating at 2000x magnification. The bright areas in these images are silver 105

Figure 79: Elemental map of sintered titanium. A: Nitrogen, B: Oxygen, C: Titanium, D: Chromium, E: Cobalt 106

Figure 80: The test area of sintered titanium used for the elemental map in Figure 79 . 107 Figure 81: Elemental map of uncleaned sintered titanium and silver. A: Nitrogen, B: Oxygen, C: Titanium, D: Chromium, E: Cobalt, F: Silver. 108 Figure 82: The test area of uncleaned sintered titanium and silver used for the elemental map in Figure 81 109 
Figure 83: Elemental map of cleaned sintered titanium and silver. A: Sodium, B: Oxygen, C: Titanium, D: Chromium, E: Cobalt, F: Silver................................................ 110

Figure 84: The test area of cleaned sintered titanium and silver used for the elemental map

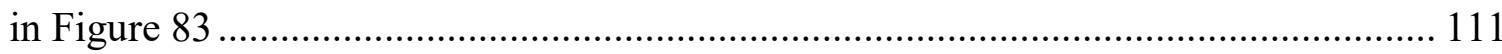

Figure 85: Sintered coupons after loading to failure according to ASTM F1044 „......... 112 Figure 86: Average shear strength and standard deviation of sintered coatings (blue) compared to plasma-sprayed coatings (grey) ....................................................... 112 Figure 87: Bacteria plates from: Left: sintered titanium coatings, Right: sintered titanium

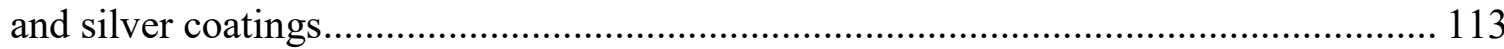
Figure 88: Left: Sintered titanium and silver coupon before ultrasonic cleaning, Right: same coupon after cleaning. 117 


\section{List of Tables}

Table 1: Composition of cobalt chromium alloy according to ASTM F75 ..............22

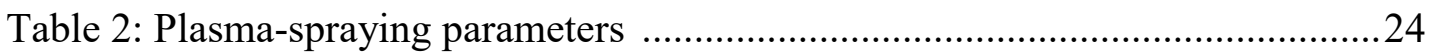

Table 3: Colony counts of each countable plate from the plasma-sprayed coatings 67 


\section{Chapter 1: Introduction}

\section{$\underline{1.1 . \text { Bacteria }}$}

Bacteria are a ubiquitous part of life, existing on almost every single surface humans come into contact with. Most bacteria that people come into contact with is harmless, and the immune system is capable of preventing infections before they start. The skin is able to block bacteria from entering the body, so most infections begin with bacteria crossing this barrier. Bacteria entering the body through the digestive tract and open wounds are significantly more likely to lead to an infection ${ }^{1,2}$. The immune system can directly attack bacteria within the body, but this is not guaranteed to prevent illness.

Eating and drinking is one of the most vulnerable activities humans perform, as foreign material is directly introduced to the internal body. The stomach uses strong acids to degrade consumed material, which also kills most bacteria. Some bacteria have adapted to survive this process, allowing them to infect humans ${ }^{3}$. E. coli is one of the most notorious examples of this, with periodic outbreaks occurring in the developed world ${ }^{4-6}$. In many of these cases, the bacteria contaminate foods that are not cooked, such as fresh fruits and vegetables. This can result in entire food supply chains being disrupted until all of the potentially contaminated food is disposed of ${ }^{7}$. E. coli can also contaminate water sources, rendering all water unfit for consumption. One of the most publicized examples of this was in Walkerton, $\mathrm{ON}$, where as many as 2,000 people became ill due to the consumption of by water contaminated with E. coli and other pathogens ${ }^{8}$. Fully cooked food products are also not completely safe from some bacteria. In 2008, an outbreak of listeriosis resulted in the deaths of 22 people, and likely resulted from the packaging process ${ }^{9}$. Bacteria can also be spread through cross-contamination. Poultry is well known to harbor salmonella, and 
that fully cooking the meat will kill the bacteria. The bacteria can survive on surfaces and can spread when the contaminated surface is not properly disinfected. Should the bacteria spread to food products that are consumed raw or are already cooked, a consumer is at significant risk of food poisoning ${ }^{10}$.

When people become seriously ill from an infection, they are usually brought to a hospital. While this provides them with the care they need, patients with infections risk infecting others around them. Some hospitals specialize their services, but most will provide care to a wide variety of illnesses ${ }^{11}$. Patients with serious infections can be found within the same facilities as those who are immunocompromised and/or recovering from surgery. Steps are taken to minimize infection risk, including separate floors and wings for infectious diseases and isolating the most severely ill patients ${ }^{12}$. There is always risk of diseases spreading through hospitals via the movement of people and supplies. The Center for Disease Control has estimated that as many as $4 \%$ of hospital patients in the United States will contract an infection from the hospital ${ }^{13}$.

Some illnesses have become particularly common for hospital patients. C. difficile predominantly infects the intestines and is frequently contracted shortly after completing a course of antibiotics. Antibiotics have a side effect of killing off the intestinal bacteria that aid humans in digestion, and these bacteria compete with C. difficile. Some strains of C. difficile have become resistant to some frequently used antibiotics, enabling them to survive and flourish after the other bacteria are killed off ${ }^{14}$.

Infection by staphyloccus aureus bacteria ("staph infections") are also especially common in hospitals. Staph infections are easily spread between people, where skin-toskin contact can result in contracting the infection ${ }^{15}$. There are a wide variety of strains of 
the staphylococcus bacteria, many of which are becoming resistant to antibiotics. One of the most notorious strains is Methicillin-resistant Staphylococcus aureus, or MRSA, which has developed resistance to $\beta$-lactam antibiotics ${ }^{16}$. These antibiotics are some of the most commonly used broad-spectrum antibiotics and prevent bacterial proliferation by interfering with the cell wall synthesis process ${ }^{17}$. Penicillin and its derivatives fall under this category of antibiotics. Treatment of MRSA must be aggressive and early, otherwise the infection can be fatal. New strains of MRSA have developed that show resistance to other antibiotics, including vancomycin and tetracyclines ${ }^{18}$.

Vancomycin-resistant Enterococcus (VRE) are also becoming increasingly problematic in the healthcare industry. The genus enterococcus is frequently found in the intestines of humans and other animals and are generally harmless and potentially helpful in aiding digestion. Some strains are pathogenic to humans, and the most notorious are resistant to vancomycin. Vancomycin is commonly used to treat skin infections, which is how VRE most commonly spreads in hospitals ${ }^{19}$.

Bacterial infections begin with the bacteria passing defensive barriers setup by the body. The skin and mucus membranes are physical barriers to keep bacteria from entering the host ${ }^{20}$. Surgical procedures generally need to bypass these barriers to access the body, potentially introducing bacteria. Once in the host, bacteria generally try to adhere to an organ or surface and begin to reproduce, forming colonies. These colonies can then form biofilms, which act as their own defensive barrier against the host's immune system. These biofilms can also prevent antibiotics from reaching the colony thus reducing treatment efficacy $^{20}$, so antibiotic intervention needs to begin as early as possible. 
Bacteria colonization is not limited to the field of medicine. Some species, such as E. coli, are capable of adhering to metallic surfaces ${ }^{21}$. This is relevant to medicine in implanted devices and is also a major concern in food processing and water treatment. The continuous development of these strains has created a need for novel and effective methods of killing bacteria in a wide variety of applications.

\subsection{Implants}

Joint replacement surgeries are becoming routine procedures in the western world, where they are used to treat severe arthritis and certain fractures. Cartilage wear can lead to friction between bones in a joint, resulting in pain and inflammation. Elderly patients, particularly those with osteoporosis, are susceptible to fractures at joints and may be unable to fully heal from them ${ }^{22}$. By replacing the afflicted bone with synthetic materials, the patient's quality of life can be improved. From 2014-2015, 51,272 hip replacements and 61,421 knee replacements were performed in Canada alone ${ }^{23}$. These are the two most common joints to be replaced, though most joints can be replaced. A joint replacement procedure involves removing bone material surrounding the joint and then fitting an implant to perform the functions of the joint. The implant components are composed of metal alloys and polymers. For example, in a knee replacement surgery parts of the distal femur, proximal tibia, and posterior patella are resected. The femoral and tibial components are anchored in the medullary canals, which may require reaming to make space. The implants are often fixed with bone cement to improve the overall integrity of the implant ${ }^{24}$.

One of the major concerns with performing a joint replacement is the risk for postoperative infection. Like all surgery, joint replacements are at risk of becoming infected. Joint replacements are at particular risk due to the nature of the procedure ${ }^{25,26}$. 
One common method of bacterial infection control is laminar airflow, where air is continuously moved over the surgical site to reduce bacteria present. The efficacy is currently under debate ${ }^{27,28}$, however, these systems are frequently used in joint replacement procedures. Over the past few decades, there has been a shift in surgical techniques from open surgery to as minimally invasive as possible ${ }^{29}$. Laparoscopic techniques and robotic surgery have become standard procedure in operating rooms. Reducing the size of the opening used for surgery improves recovery time ${ }^{30}$ and reduces infection risk ${ }^{31}$, as the patient is less exposed to the outside world. Joint replacements are limited in this aspect as direct access to a joint is required ${ }^{24}$. Furthermore, large sections of bone need to be removed, and most implants are comprised of no more than a few components ${ }^{24}$.

Infections are a serious concern for all implants, including joint replacements. The body of the patient is already under significant stress recovering from the surgery, and an infection can lead to various complications. An infection in the bone tissue surrounding a joint replacement can weaken this tissue leading to loosening of the implant ${ }^{32}$. It is critical that the supporting tissue adheres to the implant to maintain stability. When this happens, a revision surgery is often necessary ${ }^{23}$. The implants are often removed and replaced, requiring further removal of bone material to anchor the new joint replacement. This creates significantly greater trauma and there is risk of even further infection ${ }^{33}$.

Shortly before major surgery, most patients are given antibiotics, regardless of any preexisting infections ${ }^{34}$. The half-lives of these medications are on the order of hours, so this is done within an hour prior to the first incision being performed. In many cases, the course of antibiotics continues after the surgery, and can continue for up to several days ${ }^{35}$. This is done to prevent an infection from starting while the patient is most vulnerable. Patients 
recovering from surgery are also generally kept isolated from other hospital patients for a period of time, so they can be monitored by nurses. This also reduces the risk of infection from outside sources ${ }^{36}$. The surgical site is closely monitored, and any signs of infection are immediately reported and addressed. Treatment usually consists of more aggressive and specific antibiotics but could require further surgical intervention if the infection spreads beyond the wound surface ${ }^{37}$. Infections of joint replacements are especially problematic as previously stated, so surgical options are frequently used at the first indication of periprosthetic infection ${ }^{25}$. The general concept is to remove tissue that is infected, thoroughly irrigate the area and to implant a material that gradually releases antibiotics in the local surroundings. This leaves the existing implant in place, to prevent the need for a revision surgery. The most common form of this is known as "the DAIR procedure", standing for Debridement, Antibiotics, Irrigation, and Retention ${ }^{25}$. This procedure needs to be done in the early stages of an infection to prevent significant damage to the surrounding tissue. Alternatively the implant can be replaced with another that uses acrylic bone cement loaded with vancomycin or gentomycin antibiotics ${ }^{38}$. Furthermore, colonies of bacteria can form a biofilm, a barrier that protects the bacteria from the immune system and antibiotics ${ }^{26}$. Should a biofilm form on an implant, the treatment becomes significantly more difficult, and can require a revision surgery ${ }^{23}$.

\subsection{Materials Used}

The ideal materials for food processing, water treatment, and joint replacements share many characteristics. Many industrial applications require materials that can handle significant, cyclic loading over the span of years without wear ${ }^{39}$. Joint replacements need 
to handle cyclic load cycles for the rest of the life of the patient ${ }^{40,41}$, as revision surgeries should be avoided whenever possible. They all need to be biologically inert, as to not contaminate food and water supplies, or harm patients ${ }^{42-45}$. This includes being resistant to corrosion, as oxides can affect surrounding materials and can be a potential health risk. All three of these applications involve aqueous solutions, increasing the likelihood of corrosion $^{40-45}$. The materials used also need to be able to withstand thorough cleaning methods to prevent bacterial growth. Water supplies are most commonly chlorinated ${ }^{46}$, and food processing equipment is commonly cleaned with a range of sanitizing agents ${ }^{47}$. Quaternary ammonium and sodium hypochlorite are both frequently used in industrial applications ${ }^{47}$. Joint replacements are most commonly autoclaved immediately before being implanted, as this is the general practice hospitals use with surgical equipment ${ }^{48}$. Much like with antibiotics, these cleaning techniques are less effective on bacteria that have already formed biofilms ${ }^{49-52}$. This is generally not a concern with joint replacements at this stage, as most implants arrive directly from the manufacturer, are autoclaved, and then immediately implanted. Food processing and water treatment equipment are often used continuously, allowing for bacteria to proliferate if not regularly maintained $\mathrm{d}^{46,47}$.

In many cases, stainless-steel is selected. Steel is relatively inexpensive and easily accessible, and by the addition of chromium, corrosion resistant. Stainless-steel alloys can be further specialized by the addition of other metals. Cobalt chromium is also frequently used, especially in the medical field ${ }^{53}$. This family of alloys is also highly corrosion resistant ${ }^{42,43}$ and well suited for cyclic loading ${ }^{54}$. Cobalt chromium contains less magnetic material than stainless-steel, reducing artifacts in imaging techniques. It is also used in industrial applications, especially those with high levels of wear ${ }^{55}$, though it is significantly 
more expensive than steel. Titanium has similar properties to cobalt chromium and is also used for a variety of functions. Titanium also promotes adhesion of bone tissue to the implant surface ${ }^{56}$, making it particularly useful in joint replacements.

The surfaces of these materials can be specialized for various functions. Titanium oxide can be directly applied to the surface of a joint replacement to encourage osseointegration and create a rougher texture to reduce implant migration. Food processing equipment can be made to be more wear resistant, nonstick, or corrosion resistant, depending on the use $\mathrm{e}^{57}$. This is done through a variety of methods, with plasma-spraying and sintering being two of the most common coating techniques in metallurgy.

Plasma-spraying is a process where an extremely high temperature (on the order of $3,000 \mathrm{~K})$ jet of plasma is used to heat and propel powdered metal onto a desired substrate. The powder is injected near the jet of plasma and a rough, even surface is formed on the substrate. The process allows for metals of varying melting temperatures to be combined into a single coating ${ }^{58}$.

Sintering involves heating a fine powder of metal to a temperature under the melting point. The powder is usually compacted before being heated to reduce porosity in the final component, with a binder to maintain this structure until it is heated. The binder evaporates as the material is heated, and some external air pressure can be applied to the compaction ${ }^{59}$. Sintering at ambient air pressure is known as "pressureless sintering" $"$. The heating of the powder allows the beads to form small connections, called "necks"61. The structure is generally very porous, though allowing larger necks to form will reduce the porosity. The size of the necks is influenced by the sintering temperature and duration ${ }^{61}$. This large porosity translates to a large surface area, promoting better osseointegration ${ }^{62}$ and allowing 
for drug delivery in joint replacements. Sintering is best performed with metals that are of a similar melting point. If different materials are used, the metal with the lower melting point would melt before the other metal can start to form necks. This can be circumvented by repeating the sintering process at lower temperatures, though it would result in different material properties ${ }^{63}$.

Stainless-steel and cobalt chromium are commonly used substrates in plasmaspraying $^{64,65}$ and sintering ${ }^{66,67}$. Coatings and surface modifications of these materials are actively being explored for a variety of purposes, including antimicrobial applications. The development of a general-purpose antimicrobial coating would prove valuable to the fields of industrial application and biomedical implants.

A number of metals in the forms of ions and nanoparticles can potentially disrupt cellular functions. Silver, copper, and zinc have all been reported as potentially viable methods of killing bacteria ${ }^{68-70}$. Copper surfaces have been used since ancient times and are found to be effective in killing bacteria ${ }^{69}$. The copper functions as an antiseptic in the form of copper ions. The ions themselves can interfere with cellular functions via redox reactions, and $\mathrm{Cu}^{+}$reacts with hydrogen peroxide to form hydroxyl radicals that can cause significant damage. It is also believed that copper may compete with other metal ions for sites in forming proteins, rendering the protein inactive. Though not fully understood exactly how copper functions, the effects are well documented ${ }^{69}$. One of the main drawbacks of using metal ions in killing bacteria is that they are indiscriminant in targeting cells and can negatively affect host tissues ${ }^{70}$. Silver ions have been found to be more effective at treating infections in lower doses than copper, reducing the cytotoxic effects on human cells ${ }^{70}$. 
The antimicrobial properties of silver have been well documented, though its mechanism is not as well understood as copper ${ }^{68}$. Silver ions have been found to successfully lead to cell death in bacteria when applied to the surface of substrates ${ }^{71}$. One of the main advantages to silver is that the amount of silver required to be cytotoxic to human cells is significantly greater than what is required to kill bacteria. Most metal ions behave in this way, but silver is particularly viable in this respect ${ }^{70}$.

One other important factor in medical implants is the structure of the surface. Nanostructures along the surface can potentially disrupt cell adhesion and using hydrophobic materials can further decrease the possibility ${ }^{72}$. The structure of the surface can have a significant impact on the ability of bacteria to colonize.

Coatings on orthopedic implants have been applied for decades and are usually composed of hydroxyapatite (HA) or titanium ${ }^{71,73}$. HA is a large component of bone mineral, making it as suitable material to bridge the metallic implant to the surrounding bone. HA can be relatively porous, allowing for osseointegration and drug delivery ${ }^{73}$. Titanium, specifically titanium oxide, actively promotes osseointegration and is inert to other biological processes ${ }^{74}$. These coatings are often applied via plasma-spraying ${ }^{74}$. However, these have been developed for their qualities related to bone adhesion, and do not prevent bacterial infection

\subsection{Thesis Objective}

The goal of this thesis is to develop an antimicrobial coating that can be applied to cobalt-chromium and steel alloys that are typically used in food processing and water treatment equipment, as well as joint replacement implants. Cobalt-chromium alloys have 
high strength and high corrosion and wear resistance. Using the active antimicrobial agents only as a coating would minimize cost of materials while also using a load-bearing substrate that is well-suited for implants and industrial purposes. The coating would need to be composed of biologically inert materials, as the ultimate use would be in food processing, water treatment, and biomedical applications. The coating would need to be strong enough to not easily be separated from the substrate. This would require strength in both the coating adhesion and in the material properties of the coating itself. The coating needs to be effective in preventing microbe colonization on the surface, and at the same time be minimally damaging to host tissues in the body. The coating would ideally not depend on antibiotics, which are eluted from the surface until no drug remains to provide infection control. The nanostructure of the surface would also ideally reduce the chances of bacterial colonization.

This thesis evaluated coatings manufactured using two different methods: plasmaspraying, and pressureless sintering. Silver was added to the coating as an antimicrobial agent. The coatings were tested for mechanical strength, material leaching properties, and antimicrobial effectiveness. 


\subsection{Thesis outline}

Chapter 2 of this thesis is a review on current metallurgical methods of producing antimicrobial surfaces. This primarily focuses on industrial applications and metallic implants, but also expands to the materials surrounding a joint replacement, namely bone cement. Chapter 3 presents an experimental study of plasma-sprayed coatings developed for industrial and biomedical applications. The surface characteristics, adhesion properties, silver elution, and antimicrobial properties were all tested. The viabilities of these coatings are also assessed. Chapter 4 details similar experiments with sintered titanium coatings containing silver. The development of the coatings is outlined, and the surface characteristics, adhesion properties, and antimicrobial properties were tested. The viability of this method is discussed. Chapter 5 concludes this thesis with the overall findings of the studies. Conclusions regarding the effectiveness of the coatings are presented, and recommendations are made for future work. 


\section{Chapter 2: Literature Review}

\subsection{Prophylactic Antibiotics}

As previously mentioned, there is debate regarding the use of prophylactic antibiotics in medicine. Though valuable in preventing certain infections in early recovery, prophylactic antibiotic use can result in later infections, notably C. difficile ${ }^{75}$. This is particularly common with strains that are resistant to the antibiotics used. Kuong et al. explored prophylactic antibiotics in joint replacements and other procedures ${ }^{76}$. They found that the general recommendation is to give all joint replacement patients prophylactic antibiotics, with more specialized antibiotics for immunocompromised patients and those with a history of periprosthetic infections. The authors mention concerns with bacteria such as C. difficile, noting that the risk is relatively low as narrow-spectrum antibiotics are used $^{76}$.

\subsection{Infection Treatment}

When a patient is presenting with a periprosthetic infection, treatment needs to begin as soon as possible to preserve the joint. Otto-Lambertz et al. detailed the criteria for diagnosis and the resulting treatment used ${ }^{77}$. The authors thoroughly discuss the diagnosis criteria and known risk factors for periprosthetic infection, however, some details are not included in the treatment method should the implant be salvageable. The process is commonly known as "the DAIR procedure" 25 , however it is not mentioned by name. The authors also did not include any mention of the irrigation component of the process, an important step in ensuring that as much bacteria is removed as possible. This potentially 
raises concerns about the efficacy of periprosthetic infection treatment if the standard procedure is not fully known to some.

\subsection{Material Surface Modifications}

The surface modification of surgical and industrial alloys could potentially reduce bacterial growth. Govindarajan et al. reviewed a variety of surface modifications that were of interest in stent design ${ }^{78}$, which can use the same materials as joint replacements and industrial applications. The major focus was on bacteria migration and adhesion, with largely inconclusive results. The authors also documented coatings achieved through chemical alterations and the addition of bioactive compounds. The translation of these methods to the larger surfaces of joint replacements and industrial machinery is unclear, but a potentially viable method of reducing bacteria growth.

\subsubsection{Plasma-Spraying}

The plasma-spraying process is heavily dependent on the parameters set. One important factor in plasma-spraying is the position of the substrate relative to the plasma jet. The distance that the heated powder needs to travel influences particle temperature, velocity, and distribution. Afzal et al. performed plasma-spraying of $\mathrm{WC}-12 \% \mathrm{Co}$ cermet onto stainless steel at varying spraying distances, finding significant effects on coating thickness, surface roughness, and porosity ${ }^{79}$. Increasing spraying distance decreased coating thickness, increased surface roughness, and decreased porosity. The interface between substrate and coating also appeared to weaken with an increase in spraying distance. This was all done while maintaining other parameters as constant ${ }^{79}$. 
The geometry of the plasma torch also has substantial influence over the results. Shockwaves can be generated in the nozzle which can disrupt plasma flow and lead to inconsistencies in coating properties ${ }^{80}$. Different designs can be used to reduce shockwaves, one of which is involving a Laval nozzle, where the internal channel tapers and widens to accelerate the gas ${ }^{80}$. The design can be further altered to improve certain measures, such as overspraying ${ }^{81}$. Shockwaves hold merit in cold spraying, as it is used to accelerate and heat powder in lieu of a plasma jet ${ }^{82}$.

Plasma-spraying has been used for some time in orthopedic implants as an alternative to requiring bone cement to achieve implant fixation. Luckey et al. explored the surface interactions between plasma-sprayed cobalt chrome and bone ${ }^{83}$. The methods used created a coating approximately $100 \mu \mathrm{m}$ thick with crevices up to $50 \mu \mathrm{m}$ deep ${ }^{83}$. To create more porous coatings, hydroxyapatite is frequently used ${ }^{84}$. Generally, plasma-sprayed surfaces are rough unless finished, which aids in increasing friction with surrounding bone ${ }^{83}$.

Fielding et al. were able to demonstrate the use of plasma-sprayed silver as an antiseptic agent $^{71}$. The silver was added to HA powder during the plasma-spraying process, but this mixture was found to harm both Pseudomonas aeruginosa and human cells. The group was able to negate this by adding strontium oxide to the mixture. Together, the mixture killed nearly all bacteria cells present, without killing the human cells. It is unclear what the health risks would be by implanting this in a patient, as strontium is a bone-seeking element ${ }^{71}$.

\subsubsection{Sintered Silver and Titanium}

Sintering is generally performed under pressure to make the alloy more solid and rigid. This can be achieved through traditional sintering or spark plasma sintering ${ }^{85}$. Pressureless 
sintering is performed at ambient air pressure, keeping the structure more porous. E. Champion reviewed the sintering of several ceramics, which is procedurally identical to sintering metal ${ }^{86}$. Altering the temperature and duration of the sintering process, and the material properties of the powder can affect the results. When necking occurs, some materials will flow from one bead to another, making the distribution uneven ${ }^{86}$.

Chen et al. explored the properties of sintered silver and titanium alloys, finding that they were highly effective in reducing bacteria colony counts ${ }^{87}$. Silver powder was sintered with powdered titanium to form an alloy. The gradual release of silver ions into surrounding fluids would provide antibacterial properties. One of the most notable findings from their research was that reducing the size of the silver particles increased the antibacterial properties of the alloy. Larger diameter silver particles $(75 \mu \mathrm{m})$ had limited antibacterial properties, whereas using smaller particles $(10 \mu \mathrm{m})$ were able to achieve up to a $99.99 \%$ antibacterial rate when making up $5 \%$ of the alloy by weight. This appears to reflect previous findings involving silver nanoparticles and silver ions. The alloys produced were tested as singular pieces, and not as a coating on some substrate. Since this creates a new alloy, extensive mechanical, biocompatibility, and toxicity testing would be required to meet stringent regulatory requirements for medical devices. The sintering process would make the structure significantly more porous than a cast alloy, potentially compromising the strength of the material. This alloy is successful in killing bacteria, however it is unclear if it would be suitable for bearing large loads ${ }^{87}$. This might not be usable in joint replacements, since these would undergo thousands of load cycles every day. 


\subsubsection{Bone Cement}

It is possible to include silver in the cement used to secure implants to the surrounding bone $^{88}$. The main mechanism for this involves silver slowly leaching from the cement structure to maintain some level of silver ions in the surrounding fluid. The levels of silver would not elevate the amount present in the body beyond a significant threshold, so there is little cytotoxic risk ${ }^{88}$. Cellular activity by Staphylococcus aureus was reduced by $98 \%$ when introduced to the silver-laced bone cement. The cement is a potentially viable method of introducing silver and other compounds, as it is a highly porous and biointegrated compound. However, there are a number of potential complications resulting from the use of bone cement, and it is not used with every joint replacement implant. Though rare, Bone Cement Implantation Syndrome (BCIS) is a potentially life-threatening condition that suddenly appears during joint arthroplasty. The patient would experience a quick onset of hypoxia, and potentially cardiac arrest. BCIS is not exclusively seen during the phase of bone cement application and the mechanism is not fully understood ${ }^{89}$. It is believed that the pressures in the intramedullary canal during implantation can cause an embolus to form. This pressure is further increased by the presence of largely incompressible bone cement, which is already expanding as the compounds that form it react. There are particular risk factors associated with BCIS, and a patient with these may be given an implant that does not use bone cement ${ }^{90}$. An ideal antimicrobial agent to treat periprosthetic implants would not depend on the use of bone cement, since bone cement is not used on every implant. 


\subsubsection{Toxicity of Silver}

Like many metals, silver is toxic to human cells in sufficient doses. The toxicity of silver is dependent on the form it is in, as found by Milić et al. ${ }^{91}$. Silver ions require one fifth the concentration that silver nanoparticles need to be harmful to mammalian kidney cells $(5 \mathrm{mg} / \mathrm{L}$ versus $25 \mathrm{mg} / \mathrm{L})$. The group found that the concentrations needed would require that the tissue is in close contact with large amounts of silver or accumulates silver

over time $^{91}$. This is largely not a concern with water treatment or food processing, as oral introduction of silver requires significantly greater concentrations to damage tissues ${ }^{92}$. The cytotoxicity of silver needs to be carefully considered when producing implants containing the material. 


\section{Chapter 3: Plasma-Sprayed Coatings}

\subsection{Introduction}

Plasma-spraying is a potentially viable method of developing a variety of material surface characteristics. The powder used is quickly heated and then cools on the surface of the substrate, forming a strong physical connection. Plasma-spraying is also an efficient method of producing these desired properties, as only a small volume of material is needed to produce the desired effect. Powders can be homogenous or a mix of various materials and will result in an even coating ${ }^{58}$.

As the name suggests, plasma-spraying depends on the use of a plasma jet to heat and accelerate the coating material onto a target substrate. This is commonly performed by producing "arc plasma". A cathode is surrounded by an anode, forming the shape of a nozzle. A gap between the cathode and anode is filled with a carrier gas, typically argon or nitrogen, along with hydrogen. A high power electric current on the order of $80-100 \mathrm{~kW}$ is sent through the system, where it arcs through the gap. This quickly heats the gas to tens of thousands of Kelvin. Gas is forced toward the arc from behind the cathode, which is heated and then ejected out the nozzle. This produces the plasma torch used to create the coatings ${ }^{93}$.

Outside the plasma-producing nozzle is a second nozzle that sprays powdered material into the plasma jet. This is done perpendicular to the direction of plasma flow. The powdered material is quickly heated and accelerated towards a substrate. The substrate or the plasma jet can be moved over time to fully coat the substrate to specifications ${ }^{93}$.

The plasma-spraying process can be altered to produce different results. Typically, plasma-spraying is performed without any changes to the surrounding atmosphere, 
however it can be performed at lower pressure or in a vacuum. This is done primarily with oxygen in mind, as oxidation may disturb some surfaces ${ }^{93}$. As previously mentioned, altering various conditions of the torch can affect the results. The surface characteristics of the coating is highly dependent on the parameters used, so consistency between production runs is imperative.

This method of production can be used to introduce silver to the surface of alloys. Silver powder can be mixed with the substrate alloy in powder form to maintain the properties of the alloy, while adding the benefits of silver ${ }^{71}$. Kennametal Stellite was interested in applying silver to the surface of their cobalt chromium alloys, which are primarily used for industrial food processing and water treatment. Silver would be used as an antibacterial agent, while preserving the corrosion resistance of cobalt chromium. Cobalt chromium alloys are also used in medical devices ${ }^{53}$, making this proposed coating valuable to the field of biomedical engineering as well.

The coating needs to demonstrate mechanical soundness and antibacterial properties. One primary concern is the coating shearing from the surface of the substrate, so adhesion strength must be found and compared with previously developed coatings. Numerous coatings prevent bacterial proliferation by gradually releasing silver ions into the surrounding fluids, so this property needs to be tested for as well. A coating with the desired properties could be useful for the industry and would be recommended for further testing. 


\subsection{Methods and Materials}

\subsubsection{Production}

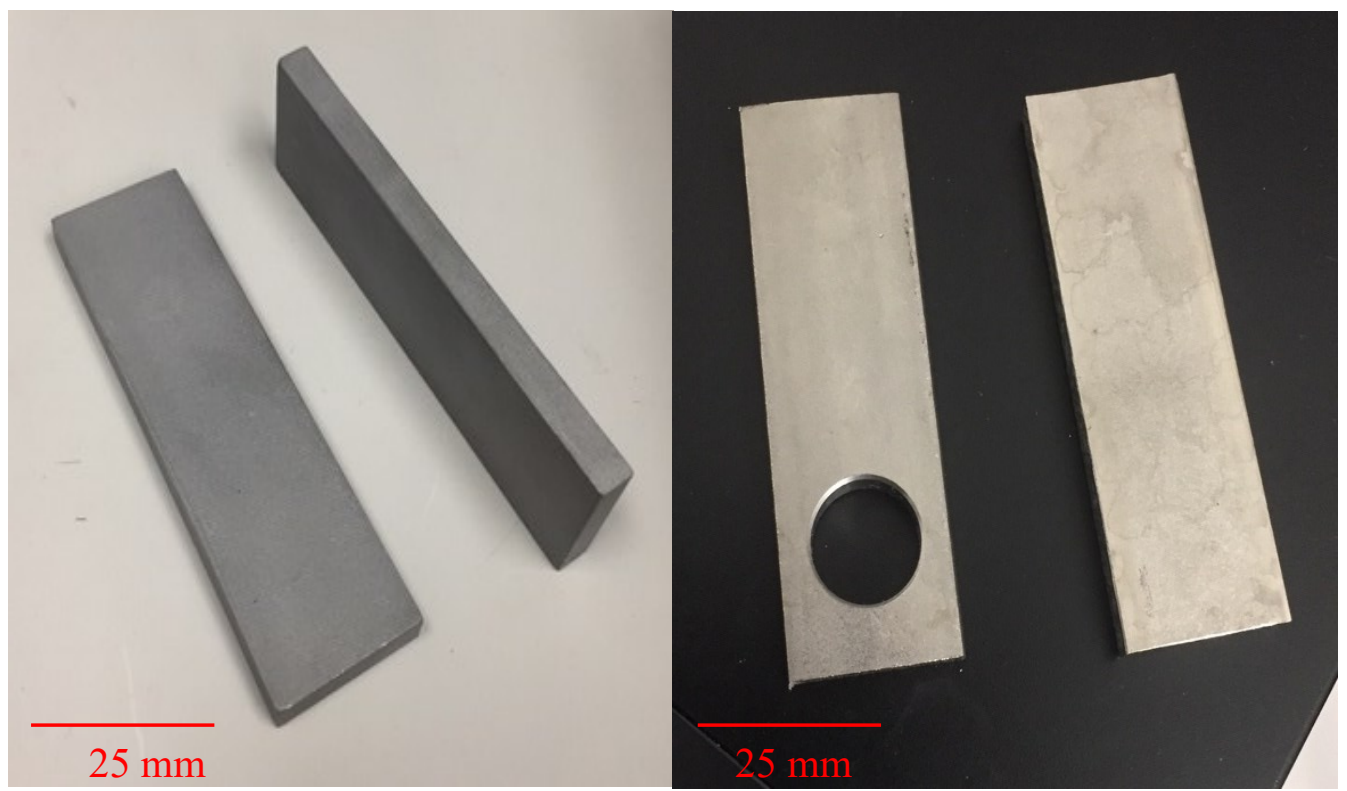

Figure 1: Left: Stellite coupons, Right: $316 \mathrm{~L}$ steel coupons. One has been machined to fit a dowel pin for the adhesion test.

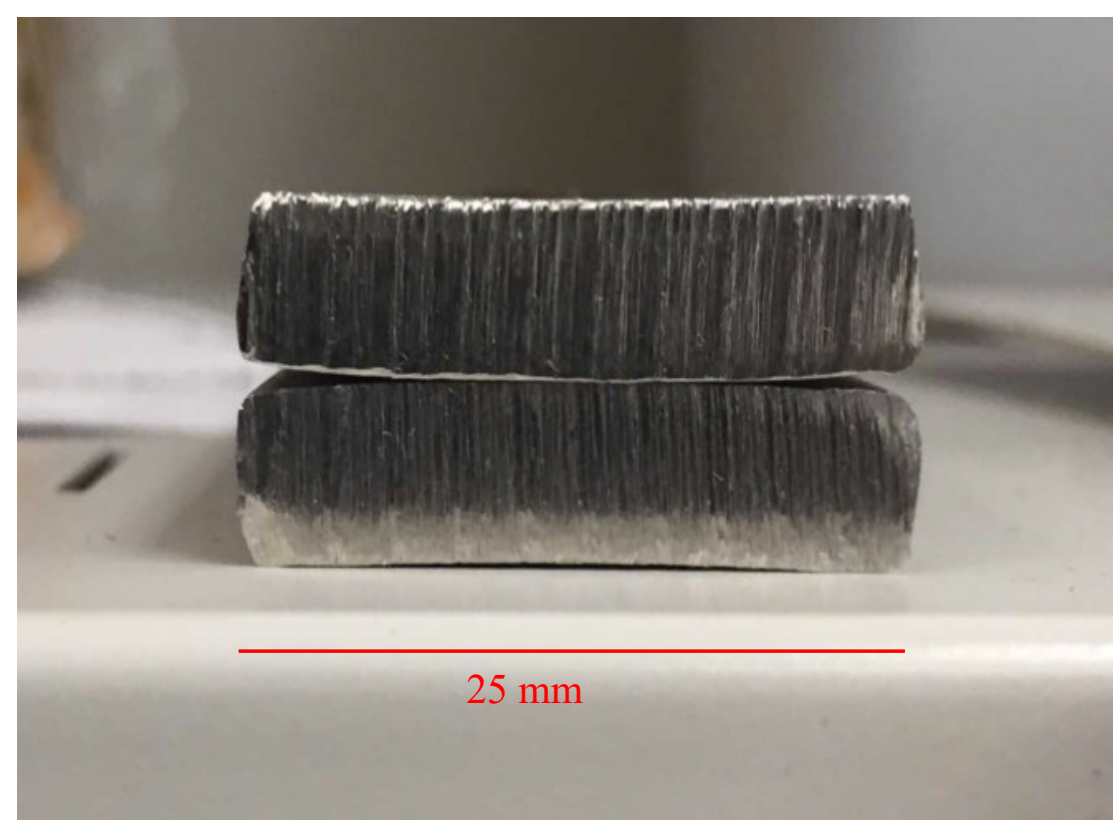

Figure 2: Two steel coupons with convex surfaces in contact to show the curvature. 


\begin{tabular}{|l|l|l|}
\hline Element & Minimum Composition \% & Maximum Composition \% \\
\hline Chromium & 27.00 & 30.00 \\
\hline Molybdenum & 5.00 & 7.00 \\
\hline Nickel & N/A & 0.50 \\
\hline Iron & N/A & 0.75 \\
\hline Carbon & N/A & 0.35 \\
\hline Silicon & N/A & 1.00 \\
\hline Manganese & N/A & 1.00 \\
\hline Tungsten & N/A & 0.20 \\
\hline Phosphorus & N/A & 0.020 \\
\hline Sulfur & N/A & 0.010 \\
\hline Nitrogen & N/A & 0.25 \\
\hline Aluminum & N/A & 0.10 \\
\hline Titanium & N/A & 0.10 \\
\hline Boron & N/A & 0.010 \\
\hline Cobalt & Balance & Balance \\
\hline
\end{tabular}

To test the coatings, Stellite (cobalt chromium) test coupons were used as a substrate. These were supplied by Kennametal Stellite (Belleville, ON), and conformed to ASTM Standard F75, commonly used in medical devices. The composition of the alloy can be found in Table 1. The coupons were 1 "x 3.5 " $\times 0.25$ " and were produced by investment casting. Some coupons included a $9 / 16$ " hole drilled at one end for mounting according to ASTM F1044 standards, leaving approximately 0.25 " of material on each side ${ }^{95}$. The test coupons were left unpolished except for the interior of the drilled hole, likely resulting from the machining process. A test coupon can be seen in Figure 1 .

Due to production delays by Kennametal, stainless-steel test coupons were used to test the plasma sprayed coatings. 316L stainless-steel was selected for its frequent use in implants ${ }^{96,97}$. The steel was left unhardened. These coupons were supplied by Metal Pros and measure 1 " 33 " $\times 0.25$ ". A 5/8" hole was drilled in test coupons that were used for adhesion testing. These coupons can also be seen in Figure 1. This size hole was selected 
to fit the dowels that were part of the load frame fixtures. The machining was performed at the Carleton University Mechanical and Aerospace Engineering Machine Shop with carbide drill bits. However, the Stellite coupons were drilled by Kennametal, as there was concern that the harder material would damage the drill bits used at Carleton University.

One concern noted with the 316L steel coupons was that they were slightly warped, as seen in Figure 2. This was primarily a concern for the adhesion test, which requires that the two coupons lay flush with each other ${ }^{95}$. This was later addressed during the plasma spraying process.

The plasma spraying process was performed at Vac Aero in Bocherville, Quebec, and done using the parameters listed in Table 2. The substrate was coated in a mixture of Stellite F75 and Atomized Silver Powder 451 purchased from Technic, Inc. The mixtures used included $0 \%, 2 \%$, and 5\% silver powder by weight. The Stellite has a powder size of $53 \mu \mathrm{m}$ diameter and the silver powder is composed of silver spheres with a diameter of $32-$ $45 \mu \mathrm{m}^{98}$. The $0 \%$ silver coating was produced to test how the addition of silver would influence the results. This was done primarily with the bacterial tests in mind. The modification of surface structure can influence how effectively bacteria can colonize the surface $^{78}$. The antimicrobial properties of the plasma-sprayed coatings independent from the silver need to be characterized to better understand the efficacy of silver in the coatings. The $0 \%$ mixture was only sprayed onto the Stellite coupons and the $2 \%$ and $5 \%$ were only sprayed onto the steel coupons. This was due to a communication error with Vac Aero, however it was later determined that this would not affect the results of the bacterial testing. The bacteria are affected by the composition of the surface they are in contact with, and the substrate does not have any influence should the coating prevent contact. Each coupon 
has a coated area of 1 square inch at the end to a thickness of approximately $150 \mu \mathrm{m}$. The thickness chosen is comparable to other plasma-sprayed coatings found on orthopedic implants, which commonly range from $50-250 \mu \mathrm{m}$ thick $^{99}$. The primary focus of this study was the antibacterial properties of the coating, which entirely depend on the surface characteristics. The thickness was not believed to have any effect on the coating as long as it was mechanically sound. For the coupons with drilled holes, this was done at the end opposite of the hole. The plasma-spraying was performed without optimization of spray parameters for mechanical properties or porosity. The focus of this study was the antibacterial efficacy of the coating, which depends on surface properties. Figure 3 shows three coupons post-spraying, including an uncoated steel coupon on the far left. The $0 \%$, $2 \%$, and $5 \%$ silver coatings were labeled with a 0,2 , and 5 , respectively.

\begin{tabular}{|l|l|}
\hline Plasma Torch & Oerlikon Metco 3MB \\
\hline Anode & GE \\
\hline Stand Off Distance & $4.0 \pm 0.5 \mathrm{in}$. \\
\hline Arc Current & $425 \pm 10 \mathrm{~A}$ \\
\hline Voltage & $63 \pm 3 \mathrm{~V}$ \\
\hline Primary Arc Gas Flow (Ar) & $115 \pm 5 \mathrm{SCFH}$ \\
\hline Secondary Arc Gas Flow $\left(\mathrm{H}_{2}\right)$ & $15.5 \pm 2 \mathrm{SCFH}$ \\
\hline Powder Feed Rate & $4.0 \pm 0.5 \mathrm{lbs}$ \\
\hline
\end{tabular}

Table 2: Plasma-spraying parameters

As previously mentioned, there was some curvature observed in the stainless-steel samples. To circumvent this issue the coating was applied on the concave side of half the specimens and on the convex side of the remaining specimens. The uncoated side of each 
coupon was marked with a black " $\mathrm{X}$ ", as noted in Figure 3. This way, there were pairs of coupons that had complimentary surfaces for the adhesion strength test.

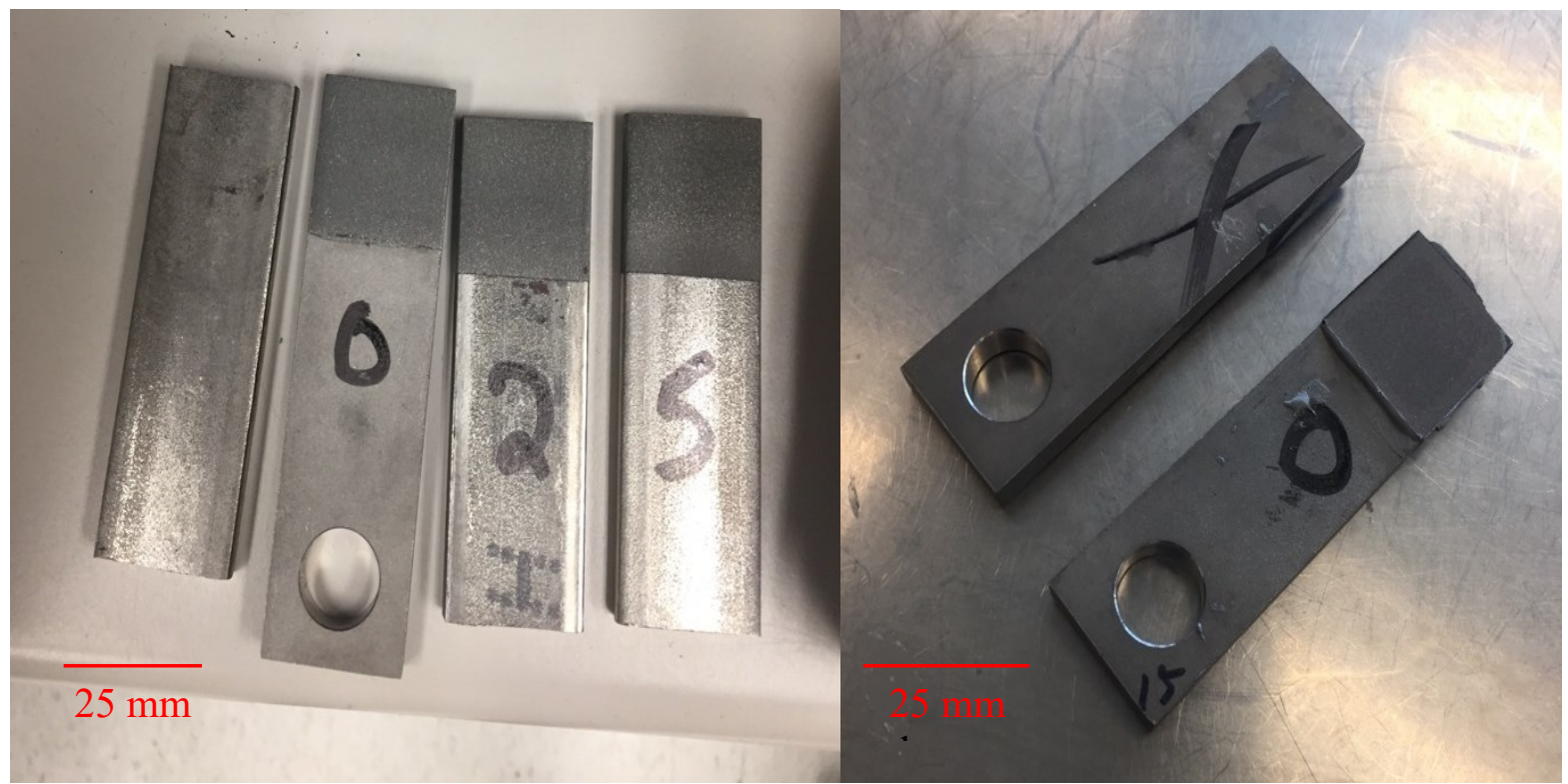

Figure 3: Left: Uncoated stainless-steel sample and one of each plasma-sprayed coupons. The silver concentrations were $0 \%, 2 \%$, and $5 \%$ by mass and are labeled accordingly. These coupons would later be viewed in the Scanning Electron Microscope. Right: Two plasma-sprayed Stellite coupons, showing the markings on the reverse

\subsubsection{Testing}

\subsubsection{Scanning Electron Microscopy}

Scanning electron microscopy was performed at the Carleton University Nano Imaging Facility. A Tescan Vega-II XMU SEM was used for all imaging purposes. The test samples were cleared of dust with compressed air and then adhered to a disk that was set in the SEM (Figure 4). A strip of copper foil was used to calibrate the SEM and confirm proper operation. Coupons from each test group were imaged at varying magnifications. Backscatter Electron Imaging was used to determine the composition of the surfaces. Backscatter Imaging detects electrons that are reflected back by atoms on the surface of a structure. Heavier atoms reflect more electrons, generating a greater signal, producing greater image intensity at the corresponding location in the image. Backscatter imagery 
does not produce the same resolution as Secondary Electron Imaging, but this difference is negligible at the magnification used and the secondary electron modality does not allow for composition testing.

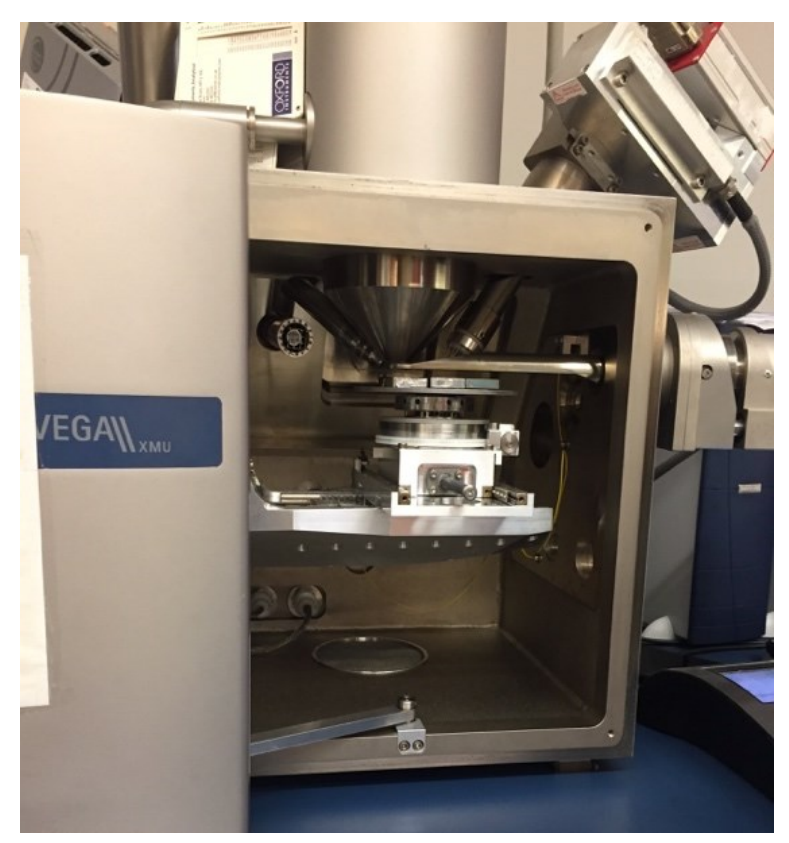

Figure 4: The specimens loaded in the SEM

The compositions of the coatings were determined via backscatter spectroscopy. It should be noted that the values found are approximate, and in most cases, the values found were not normalized to $100 \%$. This was intentionally done to get a more accurate representation of the composition. Flat surfaces were normalized to $100 \%$, since the deviation from this should have been minimal. The detector in the SEM is set in such a way that a perfectly level surface would yield a total count of $100 \%$. A surface angled toward the detector would reflect a larger number of electrons into the detector, increasing the total count to over $100 \%$. The opposite is also true, and pits in the surface would trap electrons, lowering the total count. The topography of a scanned area was considered when reviewing the output to determine if the results were valid. In most of these analyses were done to confirm the assumed makeup. For example, the Stellite alloy used was 
approximately two parts cobalt, one-part chromium, with a small amount of molybdenum and other trace elements ${ }^{94}$. Any significant deviation from this would indicate that the test coupons had some inherent flaw. The other area of interest was proving that there was silver present on the surface of the coatings that could come into contact with microbes.

To get a cross-section view of the coatings, a $2 \%$ and a $5 \%$ coating were cut. The coated area was cut in half, and the cut side of the smaller piece was polished to 1200 grit. This was then imaged via SEM. Elemental mapping was also used during the imaging process to better define the coating-substrate interface.

During the bacteria testing, it was discovered that uncoated Stellite coupons would corrode on all sides except one. The SEM was revisited to explore this (see Section 3.3.1.1.).

\subsubsection{Adhesion Strength}

The adhesion strength of the coatings was tested according to ASTM F1044 except where noted. As previously mentioned, the stainless-steel coupons were drilled with a $5 / 8$ " hole instead of a 9/16" due to a lack of available dowels at the time, and the alteration was decided to have a minimal effect on the results. Custom loading yokes were machined from O1 tool steel purchased from Metal Pros with the expectation that they could be used in future tests. Bolts of diameter $9 / 16$ " were ultimately used as dowels for the Stellite coupons.

Pairs of coupons were bonded together with Permabond ${ }^{\circledR}$ ES550 epoxy. 1 square inch of each coupon was bonded, covering the entire area of the plasma sprayed coatings. Both coupons in each pair had the same surface coating composition. The surface area of the 
coating was 1 square inch, so only the coatings were in contact with the epoxy. Any excess epoxy was removed.

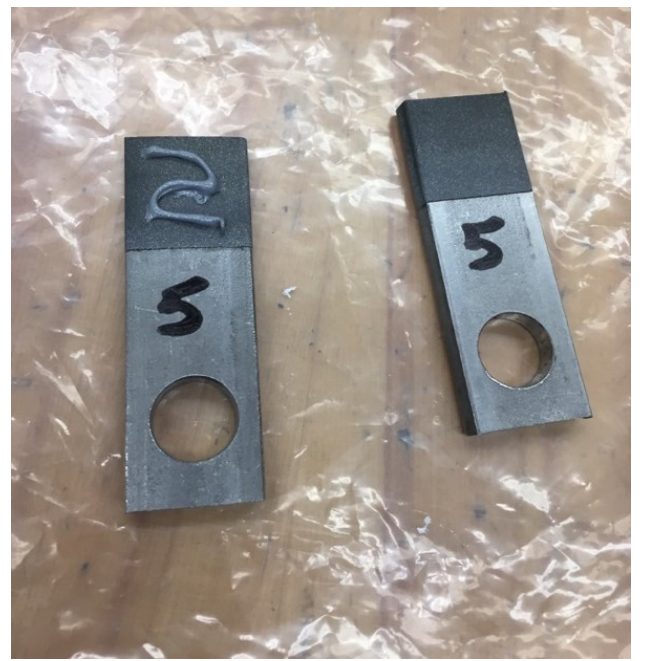

Figure 5: 5\% silver plasma-sprayed coupons shortly before being adhered together. Epoxy has been applied to the coating on the left

The plasma sprayed coupons were loaded into a vice in groups of 3 (Figure 6), and this assembly was placed in a Cole-Parmer StableTemp furnace. The samples were cured at $150^{\circ}$ Celsius for 60 minutes (Figure 7). They were then removed and allowed to cool to room temperature.

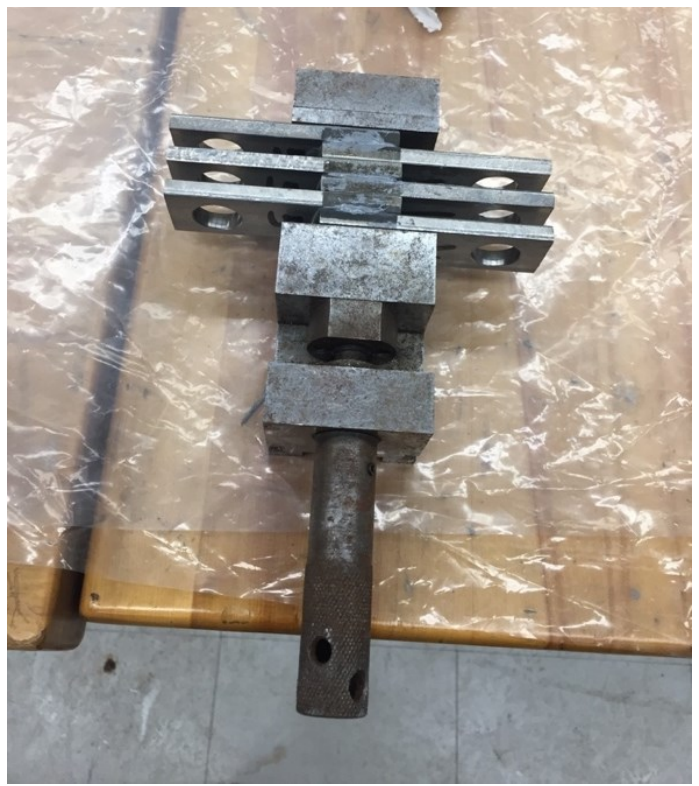

Figure 6: 5\% silver plasma-sprayed coupons in a steel vice before being loaded into the furnace to cure the epoxy. 


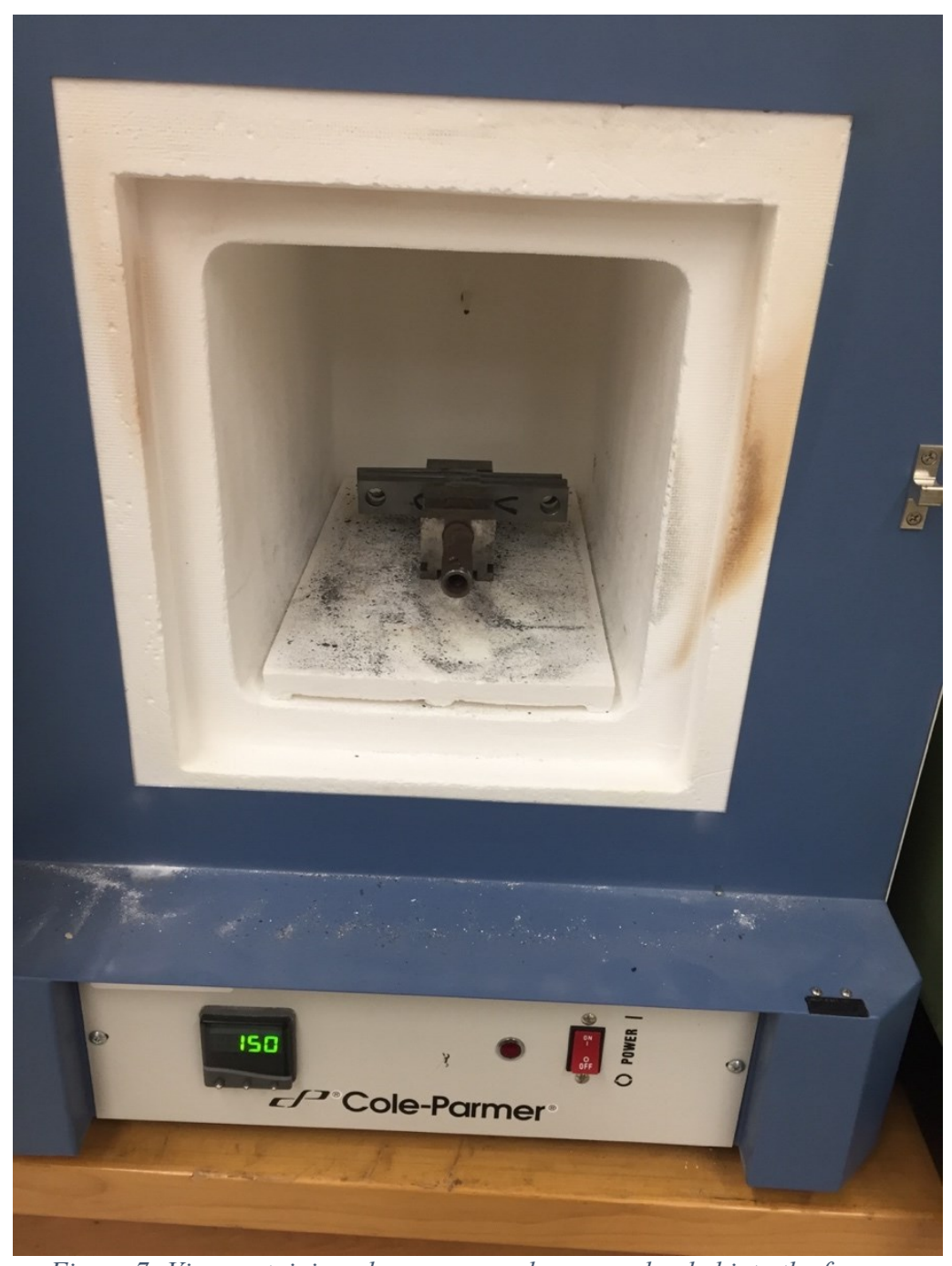

Figure 7: Vice containing plasma-sprayed coupons loaded into the furnace

The shear testing was performed on a MTS 810 Material Test System with 647 SideLoading Hydraulic Wedge Grips. The pairs of coupons were set in the yokes and then loaded into the frame as seen in Figure 8. The rig was set to have some slack before starting the load cycle to maintain consistency between tests. The loader was set to displace at a constant rate of $1 \mathrm{~mm} / \mathrm{minute}$ until failure of the coating. The data was recorded at a frequency of $100 \mathrm{~Hz}$ and was exported as an Excel file. The force value recorded at time of failure was used to calculate the ultimate stress, with each surface was assumed to be 1 in $^{2}$. 


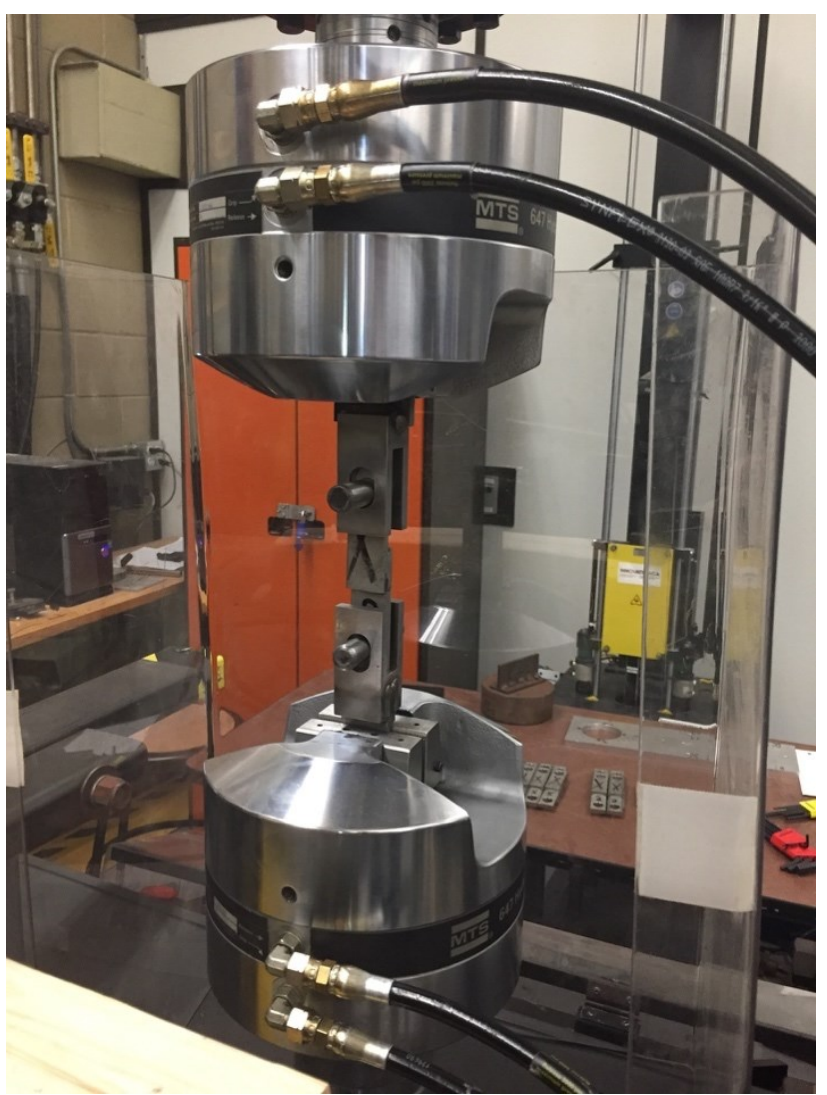

Figure 8: Plasma-sprayed coupons loaded in MTS frame for ASTM F1044.These were loaded in tension until failure.

\subsubsection{Silver Elution}

Leaching tests were performed to assess whether silver would leave the coating surface when exposed to a liquid. The leaching tests were performed over the span of two weeks on the $2 \%$ and $5 \%$ silver plasma sprayed coatings. A total of four coupons were tested from each of these groups. Each coupon was submerged in $100 \mathrm{ml}$ of distilled water and were stored in glass containers with silicone lids (Click Clack product number 423206). Distilled water was used to best reflect to potential use of the coatings in water processing facilities. Tap water was considered, however the variance in tap water composition would make the test difficult to replicate. The containers were thoroughly cleaned before use and were 
rinsed with ethanol. They were rinsed again with distilled water before the coupons were placed inside.

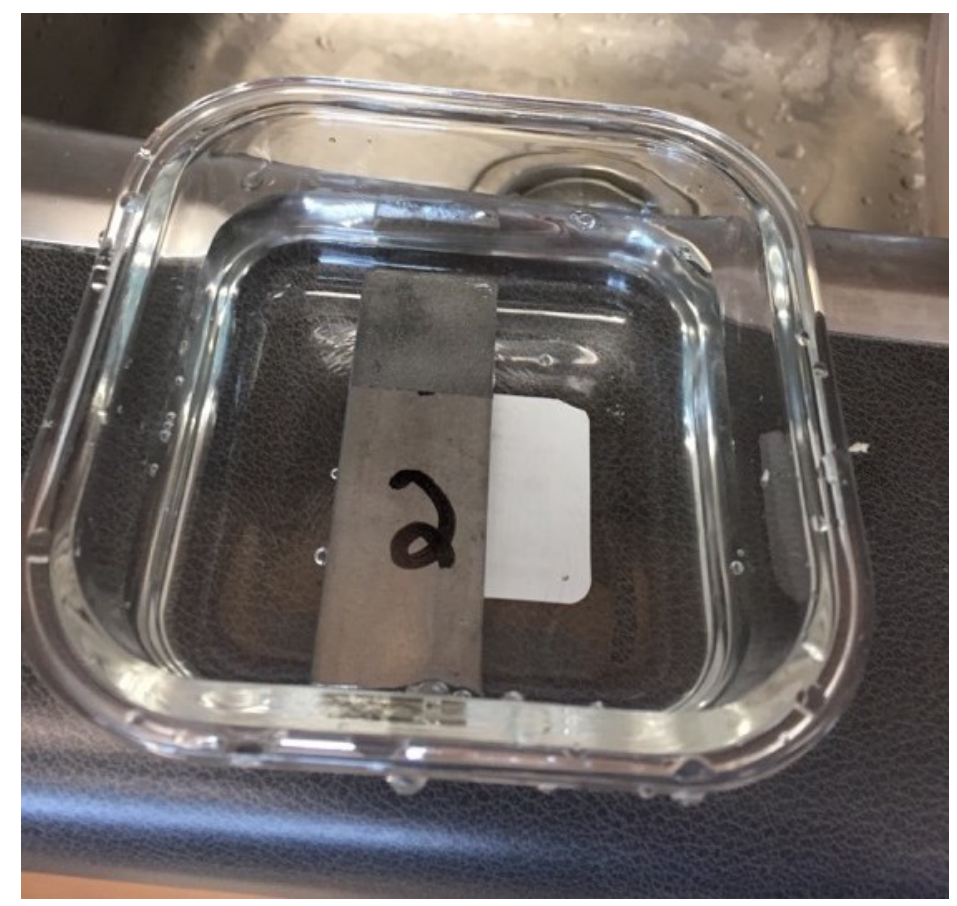

Figure 9: A 2\% silver plasma-sprayed coating shortly after emersion in water for the elution test.

After one week had elapsed, the solution from four of the containers was collected, two from each group. This was done by gently shaking the container to mix the solution and then pouring the solution directly into the vials without removing the coupons. The goal of this was to not contaminate the solution in the process of trying to first remove the coupon. The vials used were provided by Paracel Laboratories, Ltd. (Figure 10), who assessed silver concentration in the solution using mass spectrometry. The remaining coupons were left submerged for a total of two weeks. The vials from both time durations were given to Paracel Laboratories, Ltd. at the same time. The plasma-sprayed coatings were being considered for potential industrial application, where contact with water would be more commonplace. 


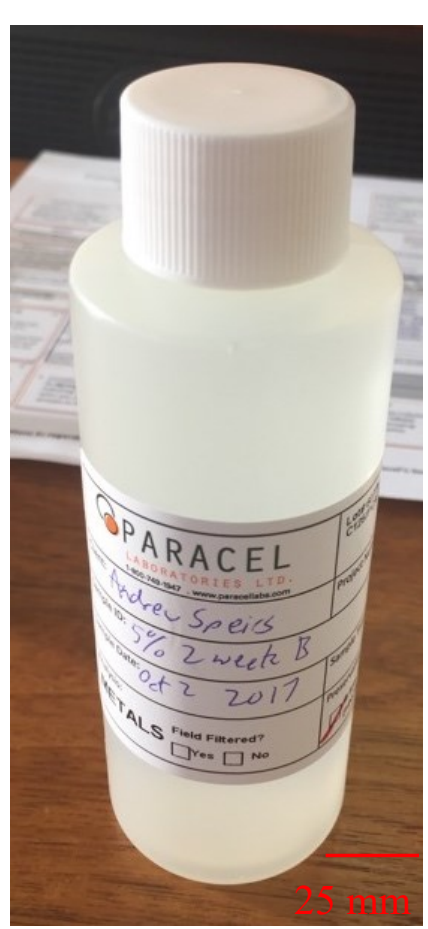

Figure 10: One of the vials of solution sent to Paracel Laboratories, Ltd.

\section{$\underline{\text { 3.2.2.4. Bacteria }}$}

The effectiveness of the coatings for preventing bacterial colonization was tested by exposing the coatings to E. coli bacteria. Bacterial testing was performed in the lab of Dr. Alex Wong. The MG1655 strain of E. coli was chosen due to its accelerated growth rate. This reduced the timescale of each trial to allow for more testing.

Before being autoclaved, the coupons were cleaned in a Fisher Scientific FS110D ultrasonic cleaner. This was done to loosen any potential contaminants and residues leftover from the manufacturing processes. The coupons were placed in such a way that they would not make direct contact with each other to ensure that they were fully cleaned. The coupons were cleaned for 60 minutes and immediately dried afterwards.

The coupons were autoclaved in empty pipette boxes in a Steris Amsco Lab 250 autoclave. The pipette boxes were chosen because they easily fit two coupons at a time and 
were known to be safe to use in the autoclave. The coupons were placed with the test surface upside down to prevent corrosion in the Stellite samples. This was also done with the uncoated stainless-steel coupons to keep conditions consistent between groups. All samples underwent a 20 -minute liquid cycle at $121^{\circ}$ Celsius at 18 psi.

Originally there was a proposal to submerge the coupons in a bacteria-containing solution inside of a centrifuge tube, but the coupons were only partially coated in the test materials, making it difficult to confirm bacterial growth only on the coating.

After cooling from the autoclave, the coupons were transferred to individual containers. The stainless-steel coupons were placed in 3" petri dishes, and the Stellite coupons were set in individual tip boxes that had gone through the autoclave. The Stellite coupons did not fit in the petri dishes. Each sample had $50 \mu 1$ of MG1655 culture placed on the test surface, and $1 \mathrm{ml}$ of sterile water was added to the container (Figure 11). This was done to prevent desiccation. The petri dish had water added near the edge of the dish, and the tip boxes had the water spread amongst several wells near the bacteria. The location of the bacteria was marked with an " $\mathrm{X}$ " on the petri dishes and tip boxes containing uncoated specimens to ensure that the bacteria could be located after incubation. The containers were sealed with parafilm and allowed to incubate for 24 hours at $37^{\circ} \mathrm{C}$. 


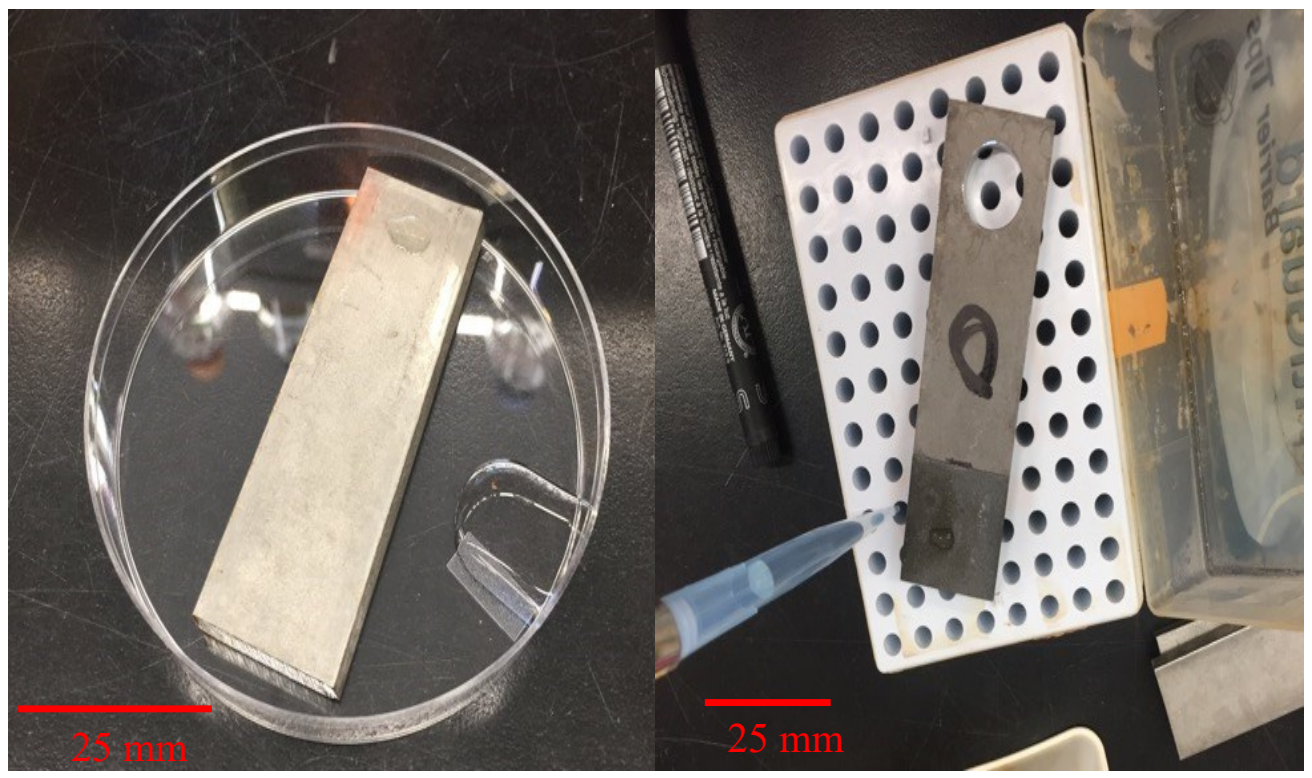

Figure 11: Left: Bacteria culture on 316L steel with sterile water in the dish, Right: adding sterile water to several wells surrounding the coated area of a Stellite coupon

After the incubation period passed, the bacteria culture was rinsed from the coupon. $1 \mathrm{ml}$ of liquid broth was passed over the bacteria via pipette and drained into a previously unused petri dish (Figure 12). The runoff was mixed with a pipette, and $100 \mu 1$ of this fluid was collected. This was then diluted to $10^{-4}$ and $100 \mu$ of this was plated on agar. The dilution was selected during pilot runs where it was found that this dilution would produce a reasonable number of countable colonies (Figure 13). Sterile glass beads were used to spread the dilution over the plate, and these were incubated for 24 hours at $37^{\circ} \mathrm{C}$. After this period passed, the colonies were counted and imaged. 


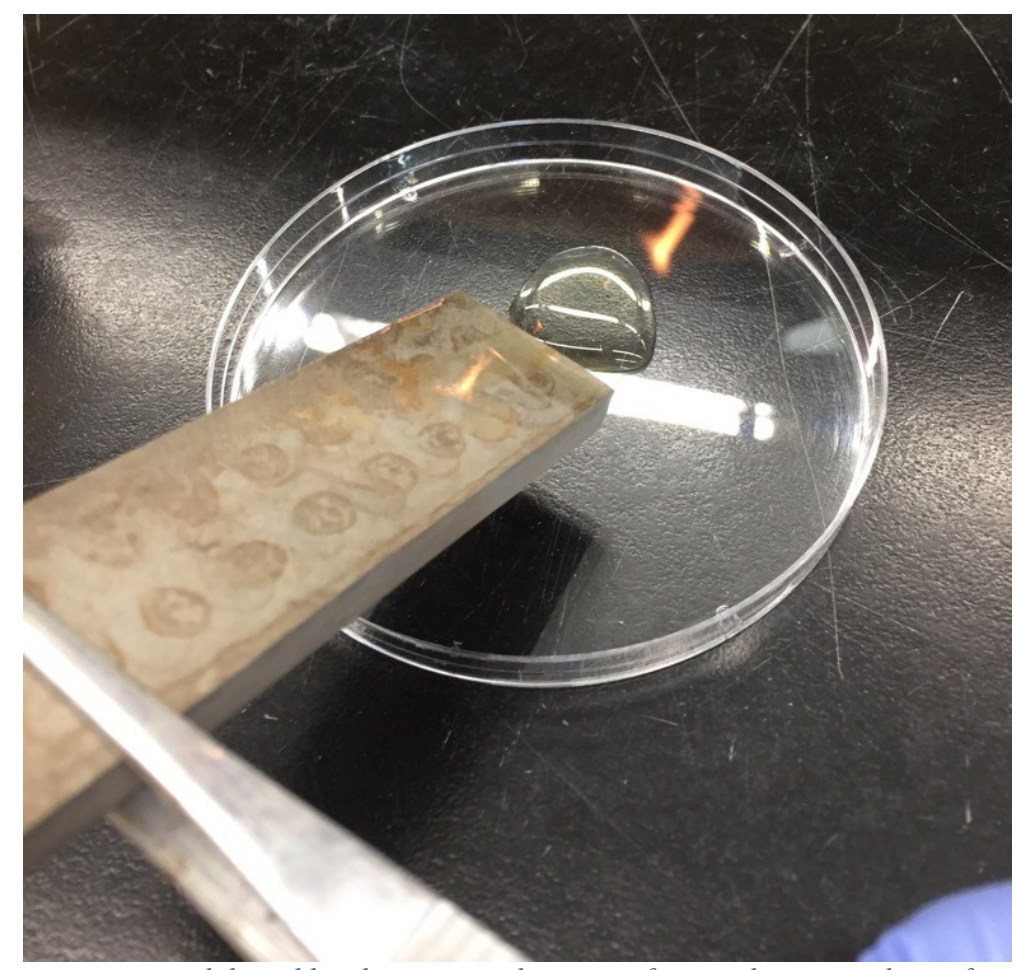

Figure 12: Rinsing a coupon with liquid broth to remove bacteria after incubating on the surface. This mixture was then plated

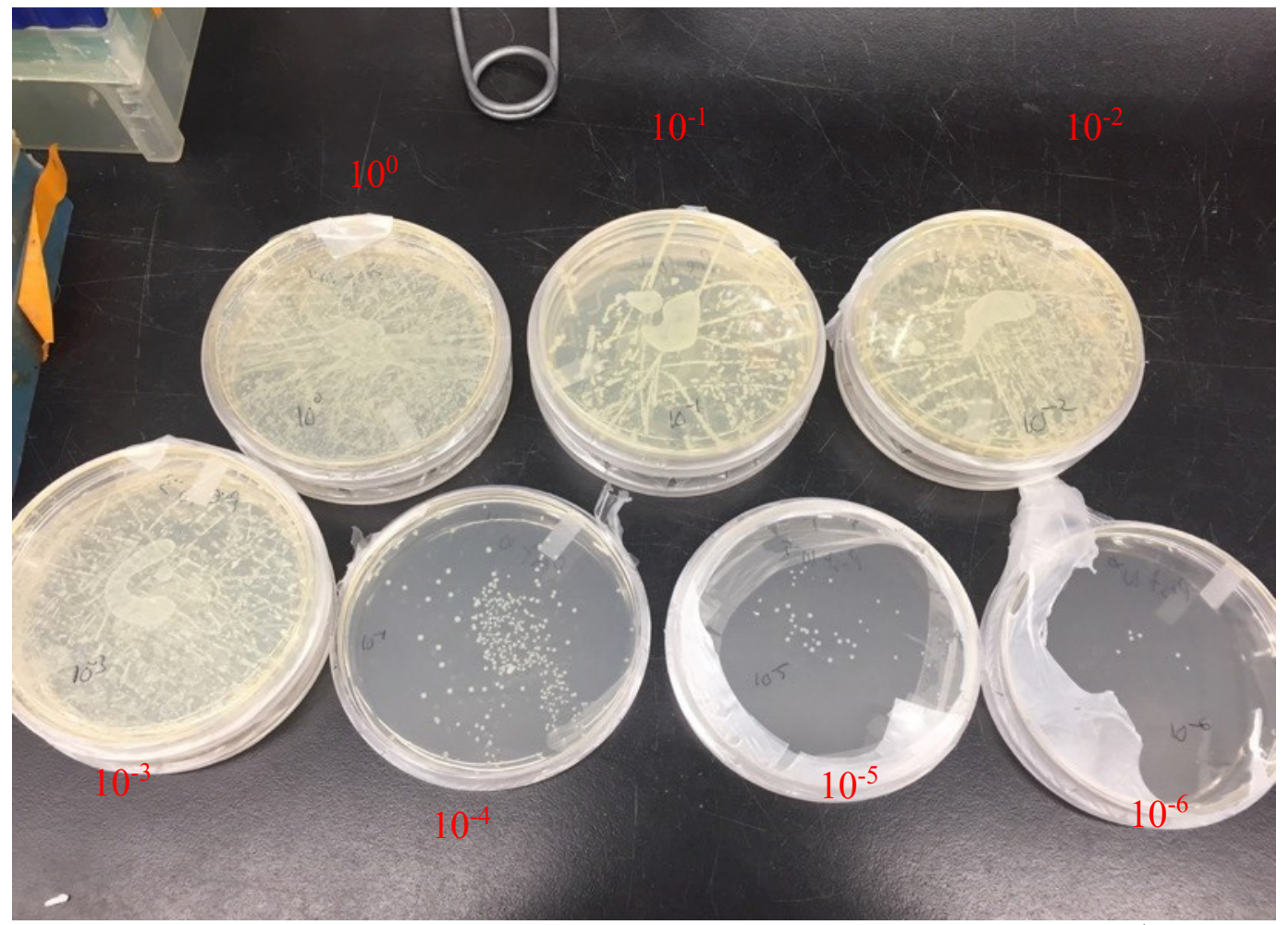

Figure 13: Dilutions testing of bacteria, with each dilution amount written near each dish. The 10-4 dilution was ultimately used to create countable bacteria colonies 
The bacteria testing of all specimens was completed in two separate rounds of testing. The uncoated Stellite coupons, along with the three plasma sprayed groups, were done first. The uncoated $316 \mathrm{~L}$ steel were tested immediately after. Both rounds included one of the uncoated materials as controls, since they are both known to harbor bacterial colonies on their surfaces ${ }^{100}$. The same vial of bacteria culture was used in both rounds, and all tip boxes were autoclaved between rounds.

\subsection{Results}

\subsubsection{Scanning Electron Microscopy}

Images from scanning electron microscope showed the microstructures of the surfaces (Figure 14Figure 30). Figure 20Figure 30 also include the elemental composition of the surfaces. These images showed that silver was present in substantial quantities for all plasma-sprayed coatings containing silver.

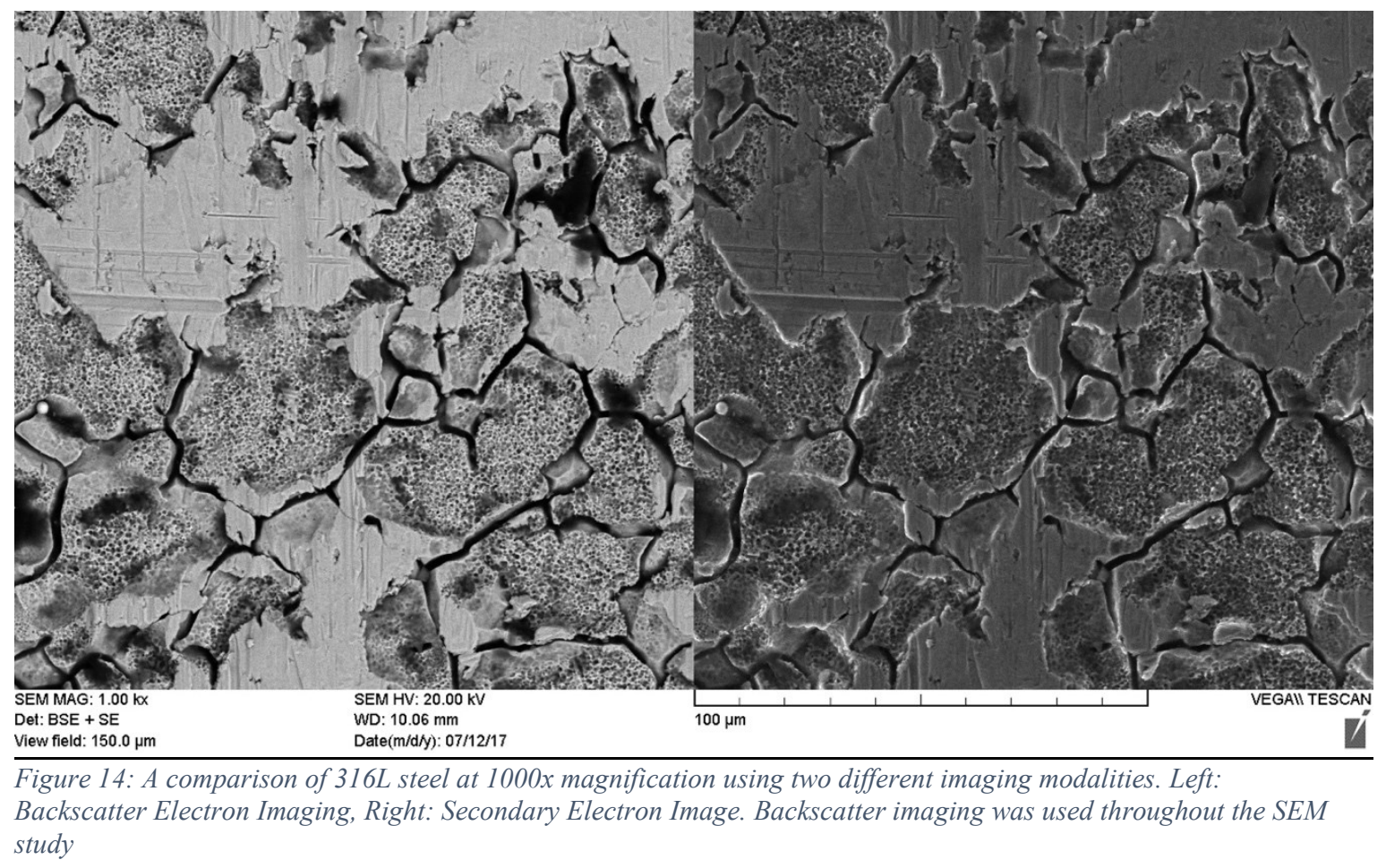


The surface of the stainless-steel coupons is very smooth, even when magnified 1000x (Figure 14). Some minute cracks are visible, but they appear to be no more than a few micrometers across. There are some darker areas in the image where the structure has small pits in it, but these are relatively small.

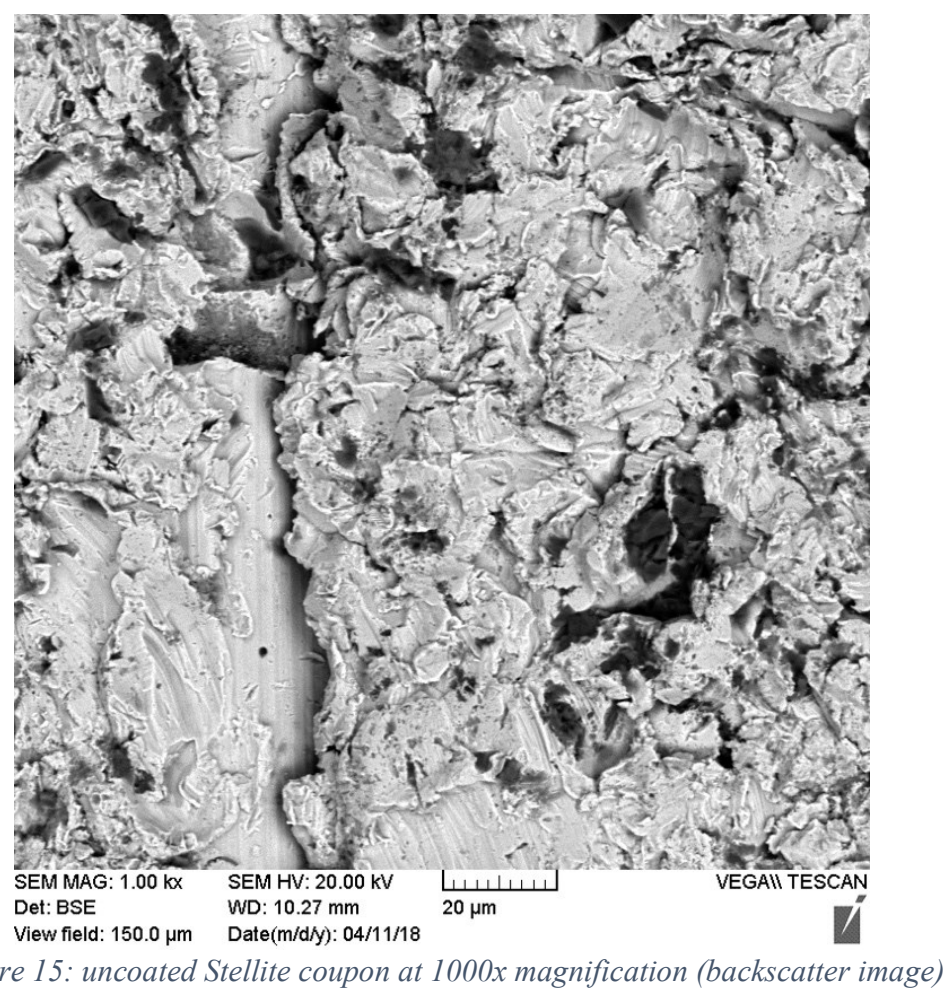

The surface of the Stellite coupon is noticeably rougher than the surface of the stainless-steel (Figure 15). This is likely due to the fact that the Stellite coupons were not polished or finished after casting. The surface is not porous, and is relatively homogenous, as seen in the backscatter image. 


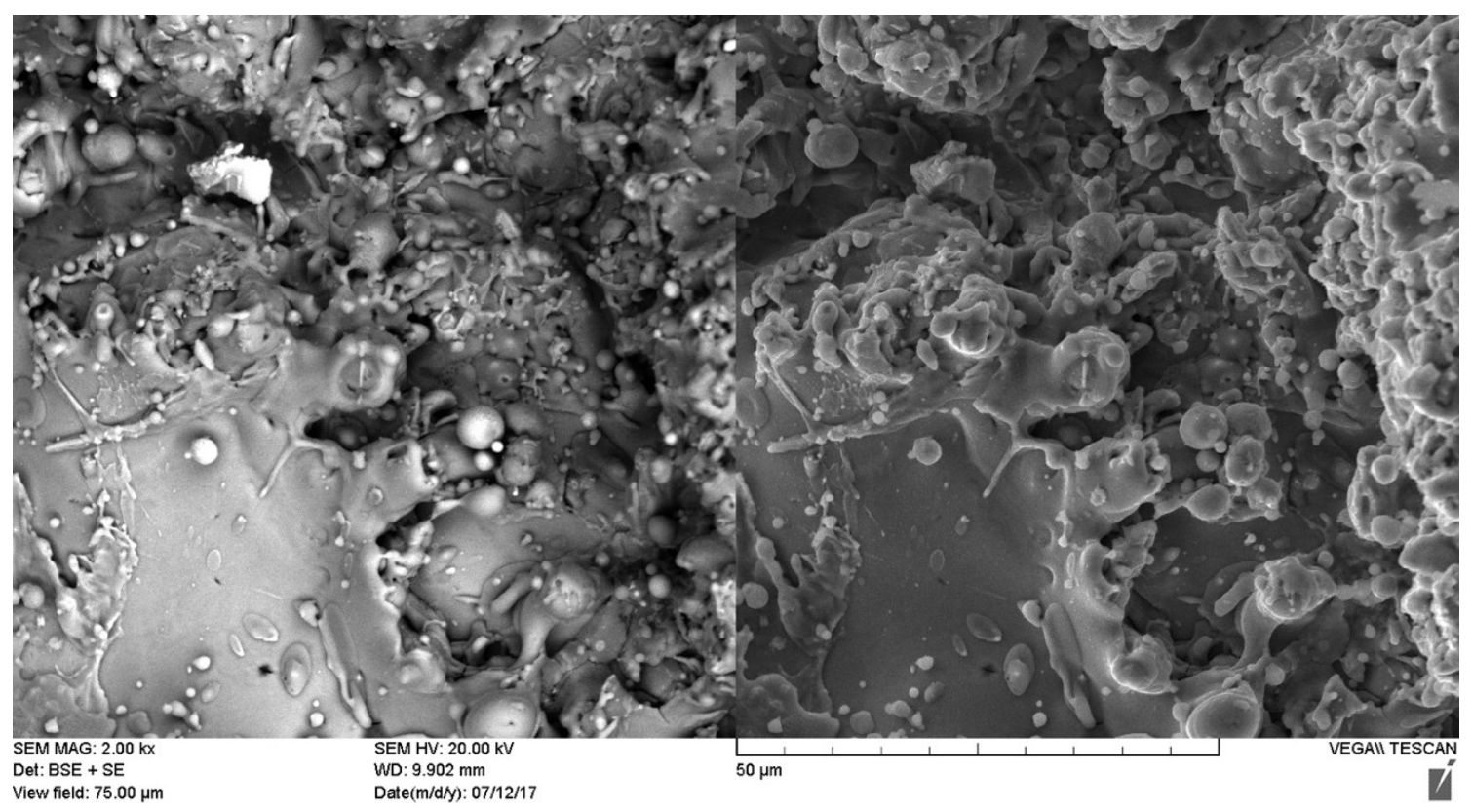

Figure 16: 0\% Silver plasma-sprayed coating at 2000x magnification. Left: Backscatter Electron Imaging, Right:

Secondary Electron Imaging

The $0 \%$ silver plasma sprayed coating appears to be significantly rougher than the uncoated areas (Figure 16). A significant number of small globular structures can be found within the coating. It should be noted that the $1000 \mathrm{x}$ magnification image taken of this coating was accidentally taken at 2000x and was not noticed until after imaging was completed. The overall structure is significantly rougher than the uncoated Stellite, though it cannot be described as "porous". There are a few dark spots visible but otherwise the gradient is largely even. 


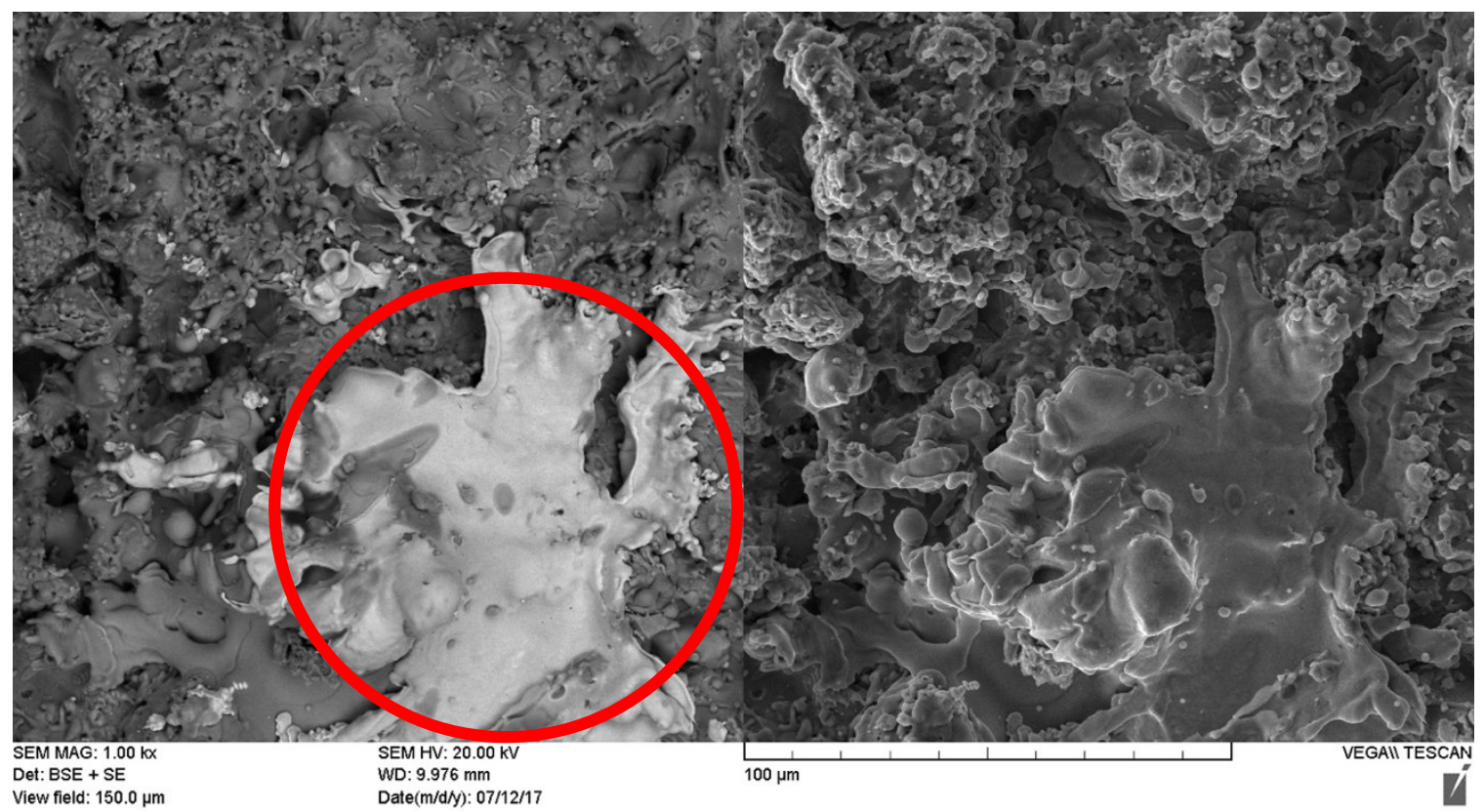

Figure 17: 2\% silver plasma-sprayed coating at 1000x magnification, Left: Backscatter Electron Imaging, Right:

Secondary Electron Imaging. Note the brighter region in the backscatter image (circled in red), later identified as silver.This would be difficult to identify in the Secondary Electron image

The $2 \%$ silver plasma-sprayed coating has a similar appearance to the $0 \%$ in terms of topography, with the exception of some smooth sections that are noticeably brighter in the backscatter image (Figure 17). These sections are approximately $100 \mu \mathrm{m}$ in diameter and are irregular in geometry. The 5\% silver plasma-sprayed coatings have a near identical appearance to the $2 \%$ silver coatings, however they have an increased number of these smooth regions (Figure 18). These were identified as possibly being silver, seeing that silver has a significantly greater atomic number (47) than cobalt (27) and chromium (24). Cobalt and chromium would appear similar in backscatter imagery, and silver would appear significantly brighter. This was later tested via backscatter spectroscopy. 


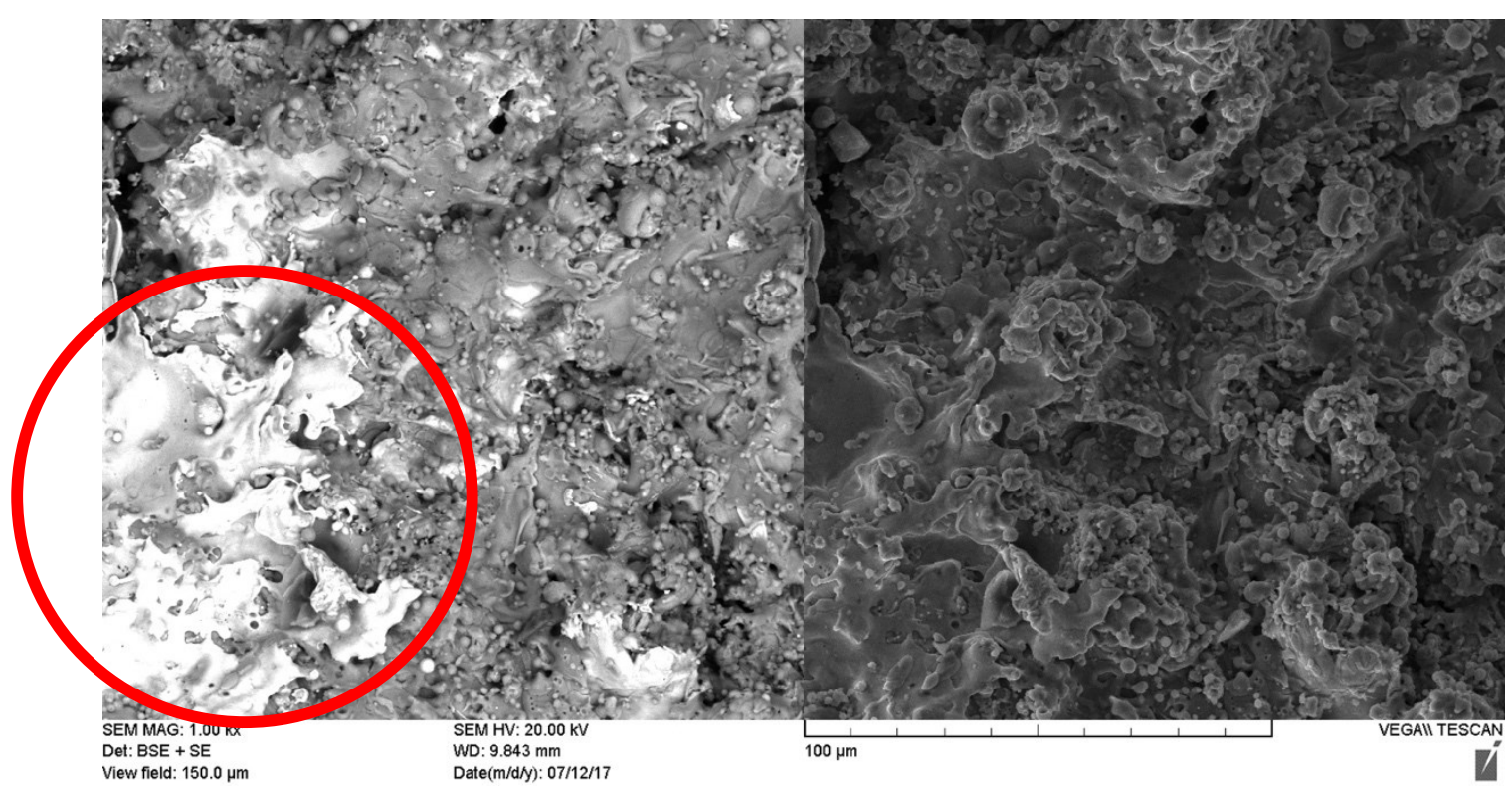

Figure 18: 5\% silver plasma-sprayed coating at 1000x magnification. Left: Backscatter Electron Imaging, Right: Secondary Electron Imaging. The bright region in the backscatter image (circled in red) was later identified to be silver.
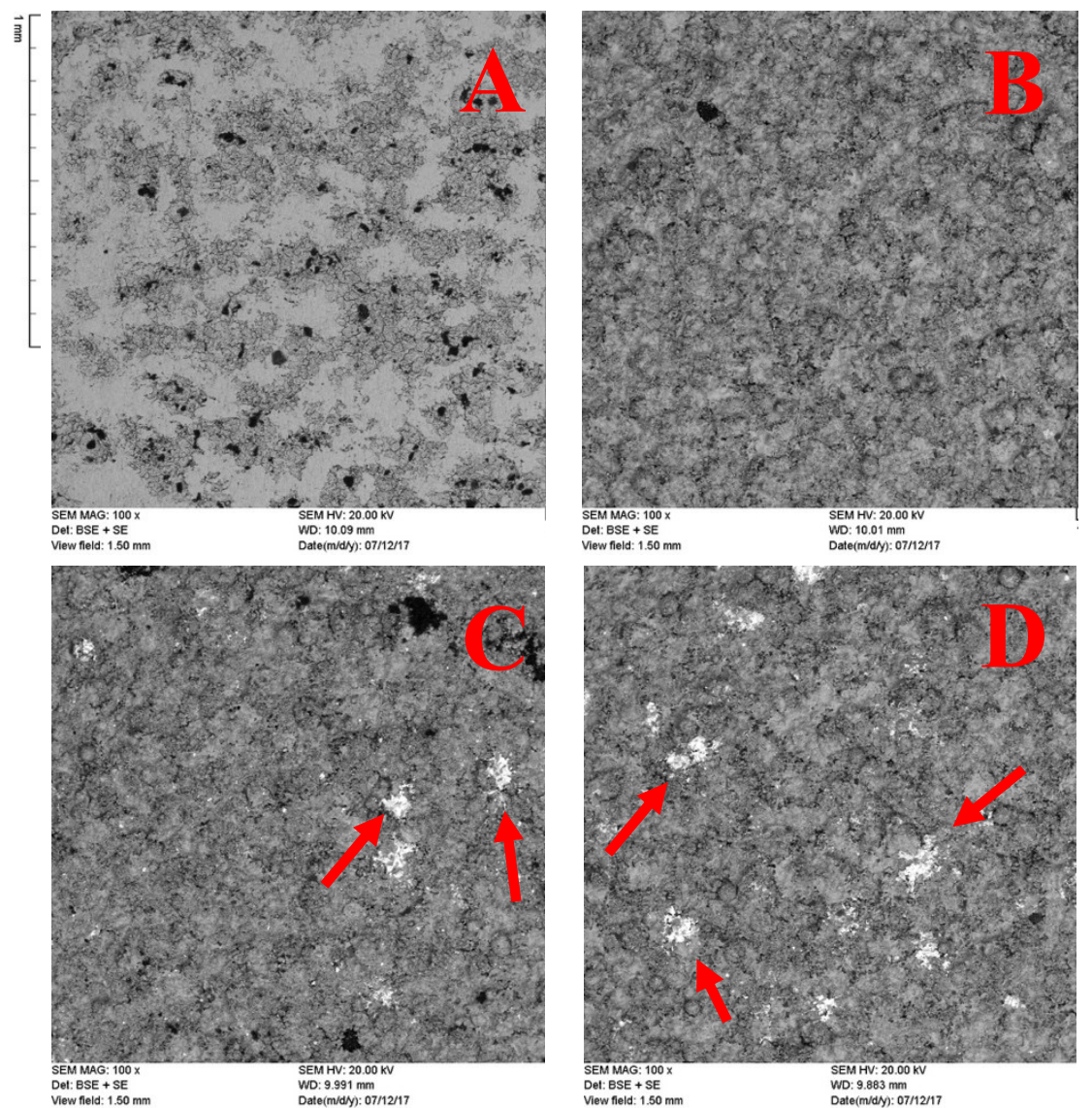

Figure 19:SEM images taken at 100x magnification. A: Uncoated 316L steel, B: 0\% silver plasma-sprayed, C: 2\% silver plasma-sprayed, D: $5 \%$ silver plasma-sprayed. The bright regions of $C$ and $D$ (some marked with red arrows) are silver. 
When compared to the plasma-sprayed coatings, as seen in Figure 19, the stainlesssteel appears to be very smooth, though it is not as uniform in appearance as the plasmasprayed coatings. When viewed at 100x magnification (Figure 19B), the plasma-sprayed material appears to be relatively homogenous in makeup. The coating containing silver (Figure 19C,D) have an identical appearance to the $0 \%$ coating with the addition of silver, which appear as bright regions.
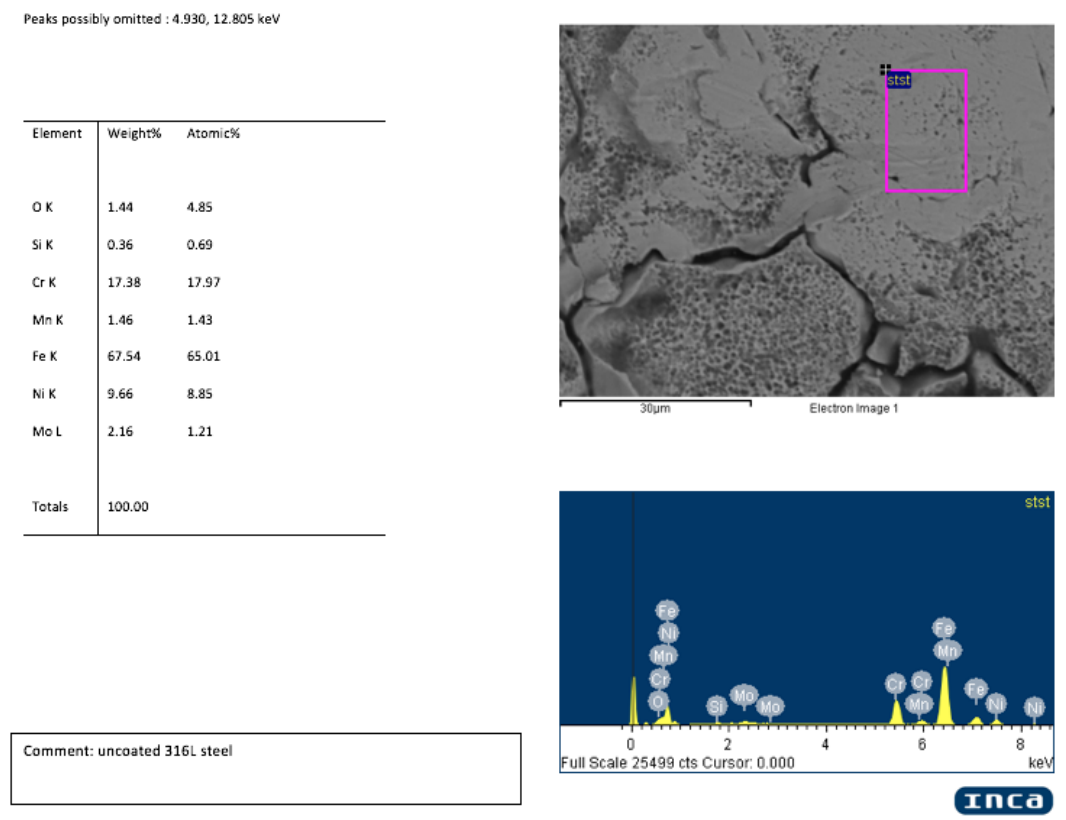

Figure 20: Elemental composition of 316 L steel coupon, which is consistent with the alloy specifications

The first composition determined via backscatter spectroscopy was on the uncoated stainless-steel and can be seen in Figure 20. 316L steel is primarily made of iron, and also contains approximately $17 \%$ chromium and $12 \%$ nickel by weight, along with some trace materials $^{101}$. The spectrum analysis found the surface to be primarily iron, and $17.38 \%$ chromium and $9.66 \%$ nickel by weight, with some trace materials. The steel composition assessed from this surface is consistent with $316 \mathrm{~L}$, although the nickel content is slightly below the minimum of $10 \%$. 
There is curiously a relatively large amount of oxygen present at $1.44 \%$ of the weight. This could partially be explained by the area inside the SEM not being a perfect vacuum, but it is also possible that there is a small amount of oxidation present on the surface. There was no observable iron oxide on the coupon before being placed in the SEM.

The elemental makeup of the Stellite coupon (Figure 21) confirms the alloy, with the exception of significant levels of oxygen. The coupons are not polished, possibly making them more susceptible to oxidation.

Spectrum processing :
No peaks omitted
\begin{tabular}{l|ll}
\hline Element & Weight\% & Atomic\% \\
CK & 9.98 & 25.46 \\
OK & 11.42 & 21.87 \\
Al K & 6.55 & 7.44 \\
Si K & 2.44 & 2.66 \\
Cr K & 23.80 & 14.02 \\
Fe K & 1.13 & 0.62 \\
Co K & 51.59 & 26.81 \\
Mo L & 3.52 & 1.12 \\
Totals & 110.43 & \\
\hline
\end{tabular}
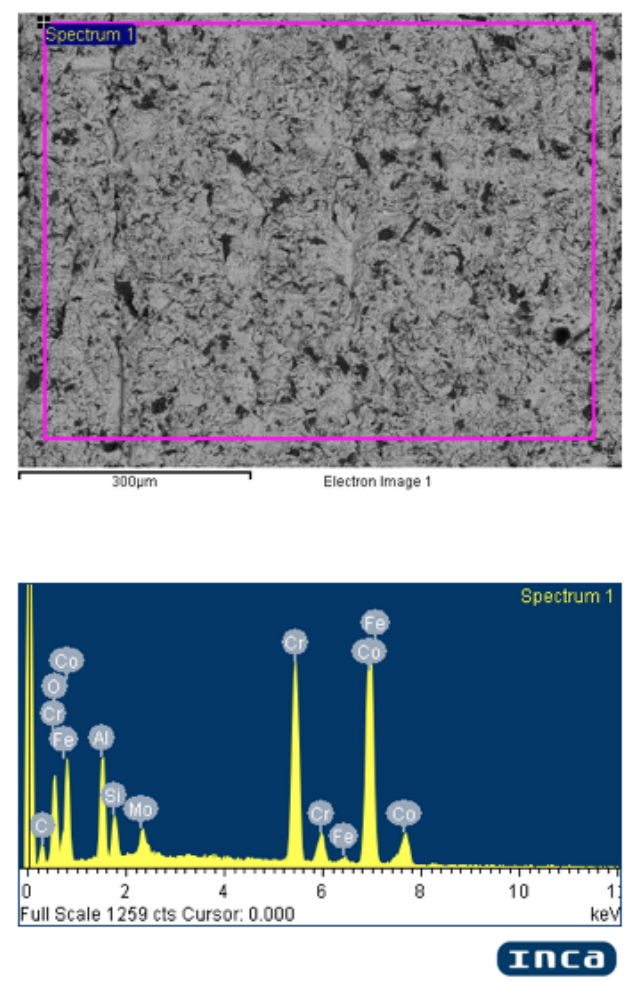

Figure 21: Elemental composition of Stellite coupon, which is consistent with the alloy specifications 

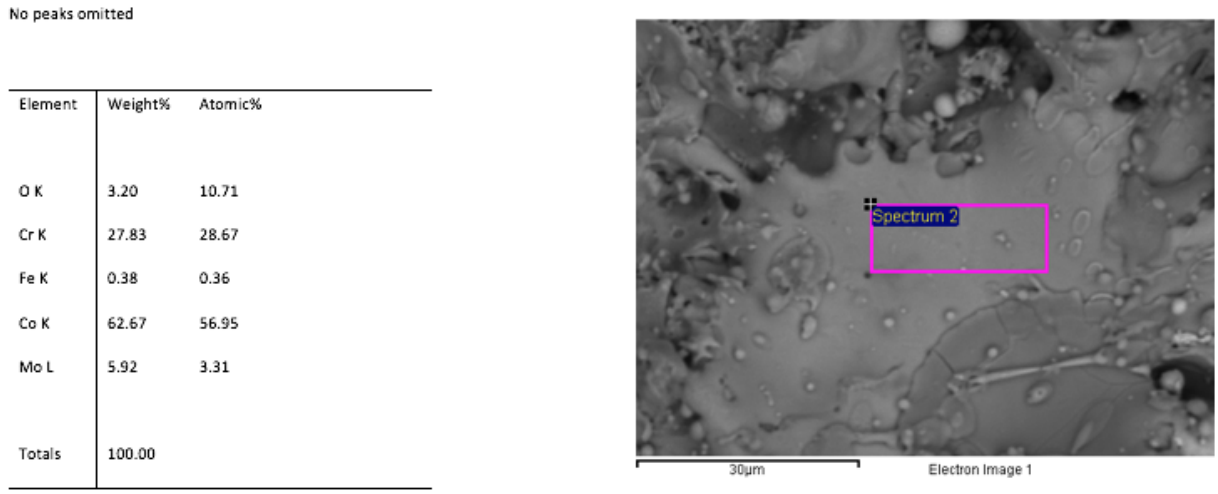

Comment: $0 \%$ Ag plasma sprayed coating

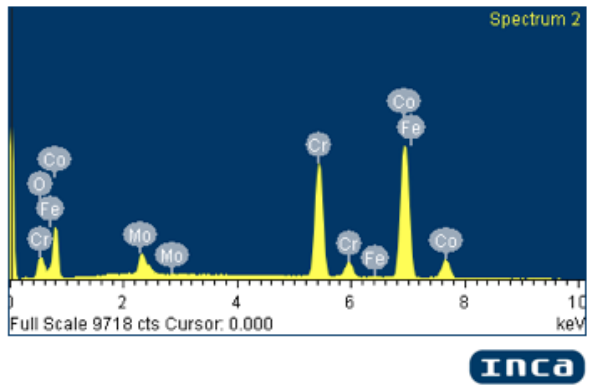

Figure 22: Elemental composition of $0 \%$ silver plasma-sprayed coating

The surface of the $0 \%$ silver plasma-sprayed coating (Figure 22) was found to have approximately a 2-1 ratio of cobalt to chromium, which is expected in the alloy of Stellite used in the plasma-sprayed powder. There is also a significant amount of molybdenum in the alloy, which is expected. This also proves that the alloy did not separate during the plasma-spraying process, as the surface has the same makeup as the total alloy. 

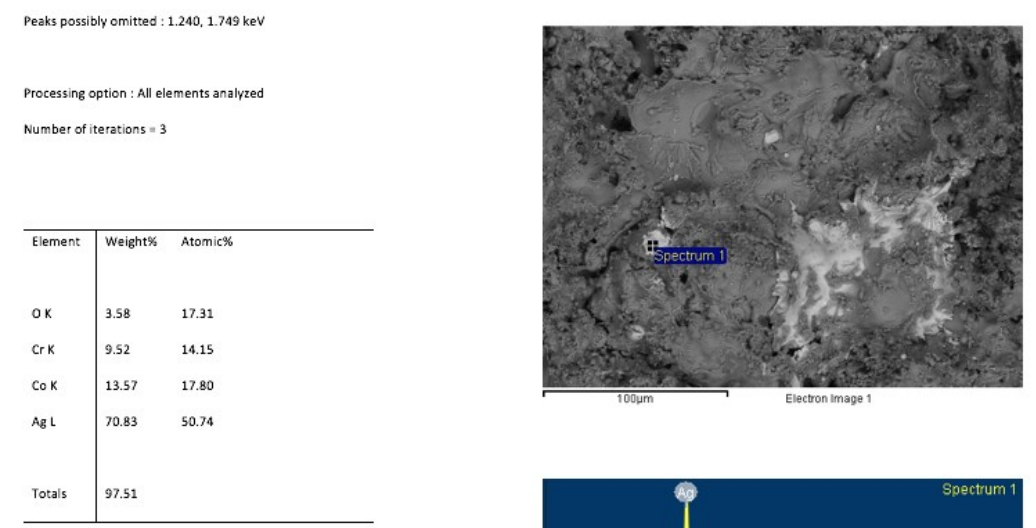

Comment: $2 \%$ Ag plasma sprayed coating

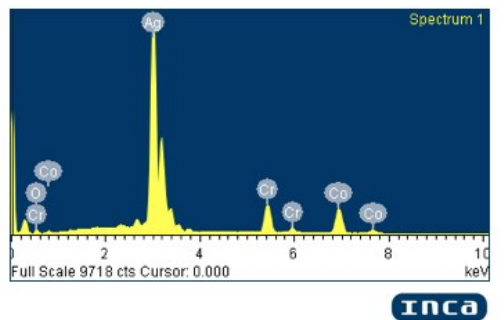

Figure 23: Elemental composition of a bright region on 2\% silver plasma-sprayed coating showing approximately 71 $w t \%$ silver

Figure 23 Figure 24 show two different spectrum analyses of the $2 \%$ silver plasmasprayed coating. The brighter region was speculated to be silver, since silver has an atomic number significantly greater than cobalt and chromium. The results show that the tested area in Figure 23 is primarily silver, with small amounts of cobalt and chromium present as well. The other scan of the coating was performed on a region not containing any bright spots, and no silver was detected. This region also has approximately a 2-1 ratio of cobalt to chromium, which is expected in the alloy used. Curiously there is a significantly greater amount of oxygen present in this area than a comparable region in the $0 \%$ silver plasmasprayed coating. 

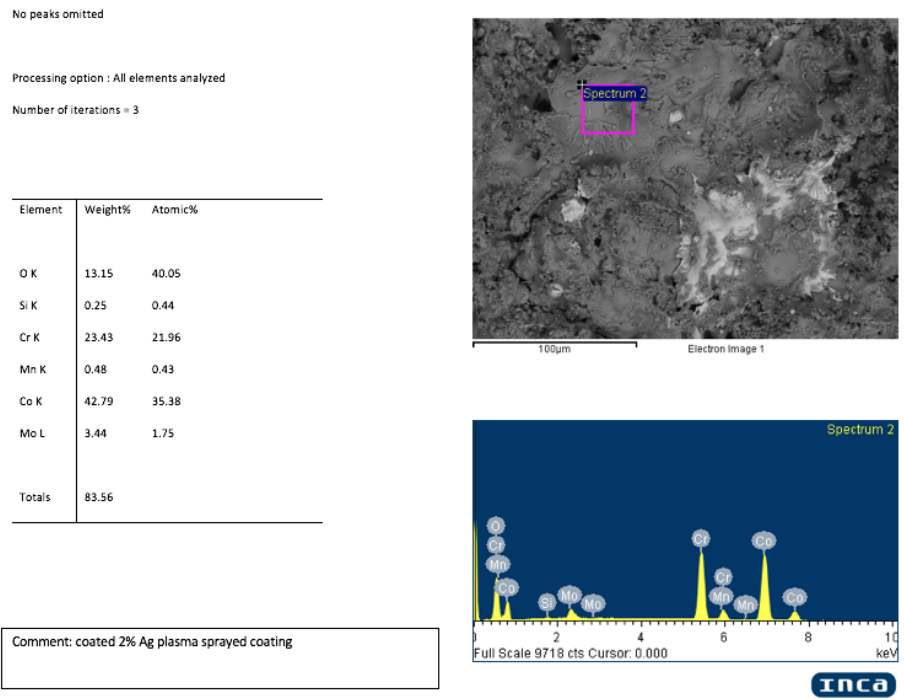

Figure 24: Elemental composition of a dark region on 2\% silver plasma-sprayed coating, showing to be consistent with the Stellite used

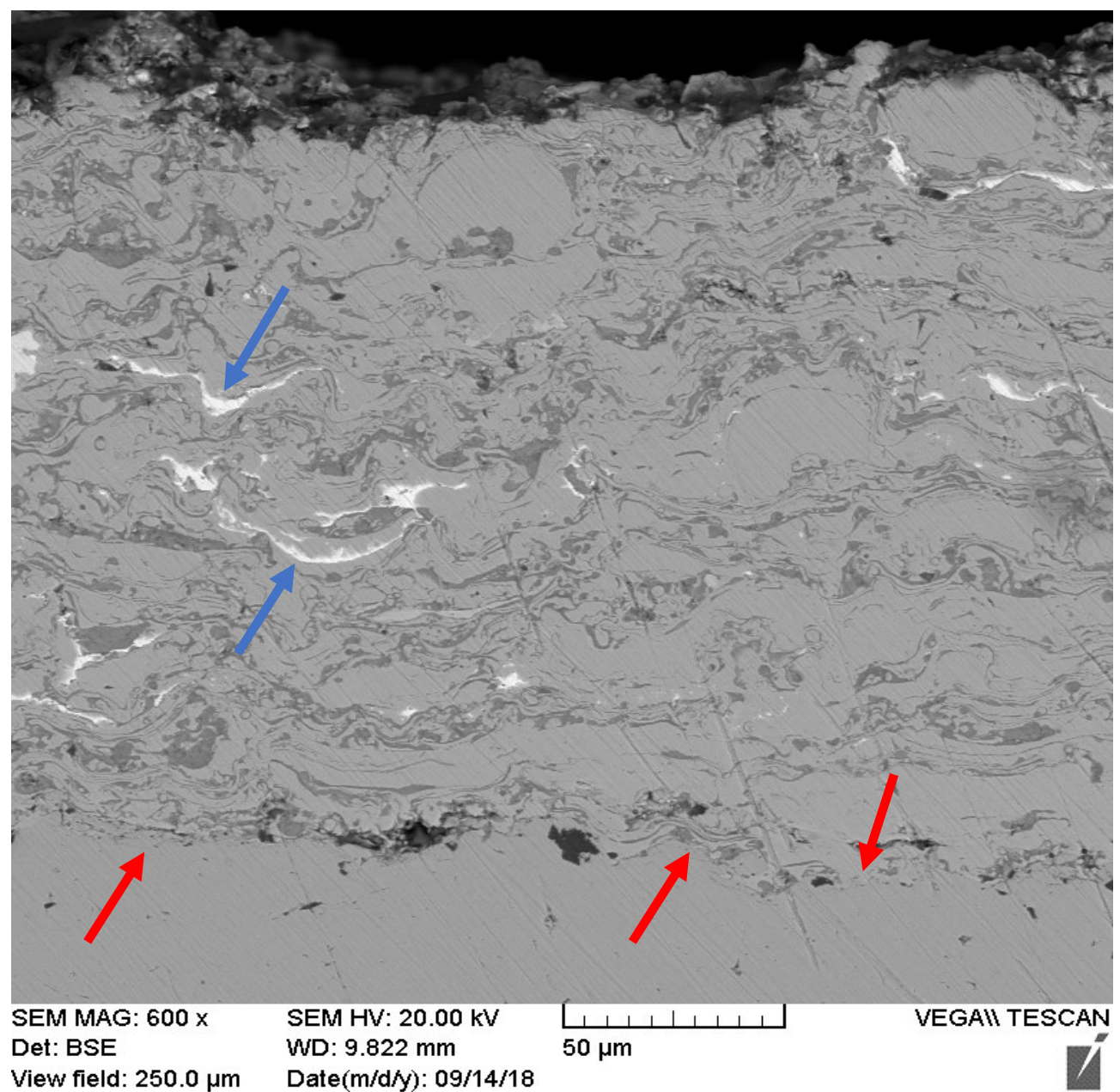

Figure 25: Cross-section of a 2\% coating, with the interface marked with red arrows and some silver regions marked with blue arrows 
The cross-section of the $2 \%$ coating (Figure 25 ) shows that the coating is very solid in composition, with no significant spaces in the material. The bright regions of silver are scattered throughout this cross-section and is seen at various depths of the coating. The interface between the coating and substrate is pointed to with an arrow, and it is clear that there is a strong bond between the materials. Dark pockets of aluminum are visible at the surface interface in significantly greater amounts than what is seen throughout the coating. Figures 26 and 27 show the elemental makeup of the two regions, which show expected levels of chromium, cobalt, iron, and silver.

No peaks omitted

\begin{tabular}{l|ll}
\hline Element & Weight\% & Atomic\% \\
& & \\
CK & 3.63 & 12.72 \\
OK & 9.28 & 24.41 \\
Si K & 0.40 & 0.60 \\
Cr K & 25.05 & 20.27 \\
Co K & 54.54 & 38.95 \\
MoL & 5.79 & 2.54 \\
Ag L & 1.31 & 0.51 \\
& & \\
Totals & 100.00 & \\
\hline
\end{tabular}

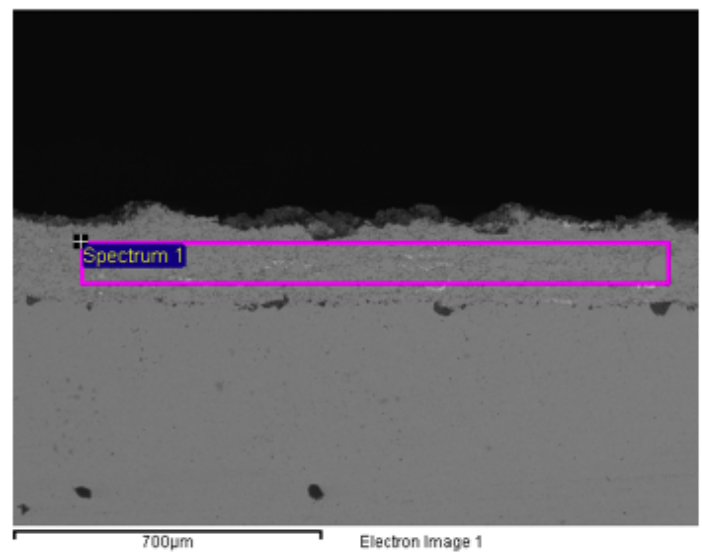

Comment: $2 \%$ - coating

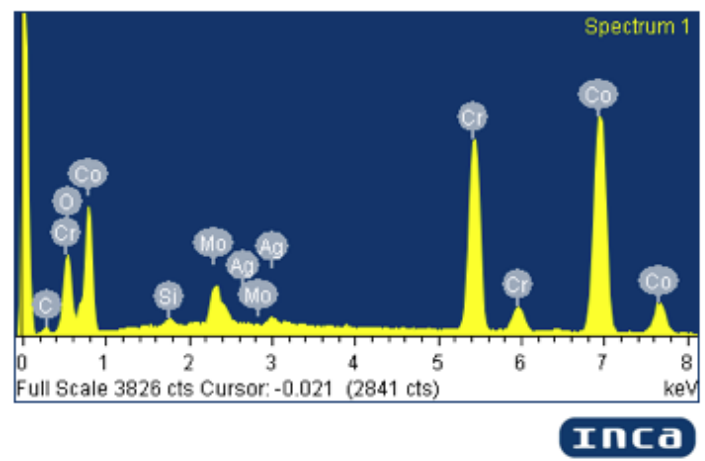

Figure 26: Elemental makeup of a 2\% silver coating cross-section 


\begin{tabular}{l|ll}
\hline Element & Weight\% & Atomic\% \\
& & \\
CK & 5.23 & 20.33 \\
Si K & 0.42 & 0.70 \\
Cr K & 17.22 & 15.47 \\
Ma K & 1.15 & 0.98 \\
Fe K & 64.96 & 54.34 \\
Ni K & 9.14 & 7.27 \\
MoL & 1.88 & 0.91 \\
& & \\
Totals & 100.00 & \\
\hline
\end{tabular}

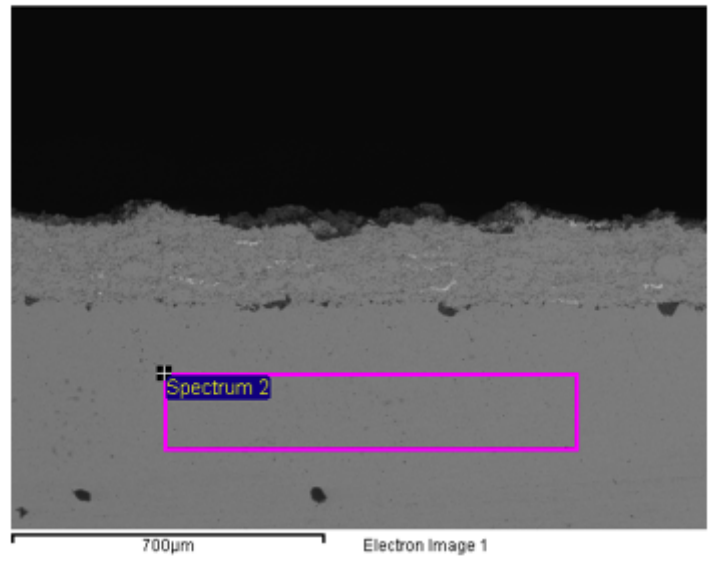

Comment: $2 \%$ steel

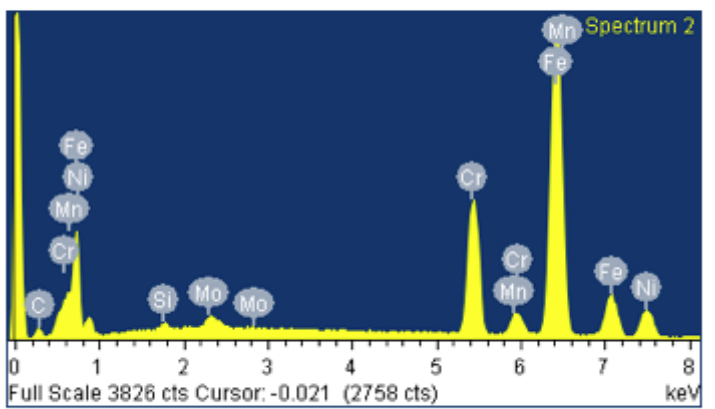

Inca

Figure 27: Elemental makeup of substrate under 2\% silver coating

Elemental mapping was also done, and various elements are shown in Figure 28.

The maps of cobalt and iron especially show where the boundary is, as cobalt is not found in $316 \mathrm{~L} \mathrm{stee}^{101}$ and F75 is only at most $0.75 \%$ iron (Table 1 ). Some silver is also present near the boundary in the elemental map area (Figure 28D). 

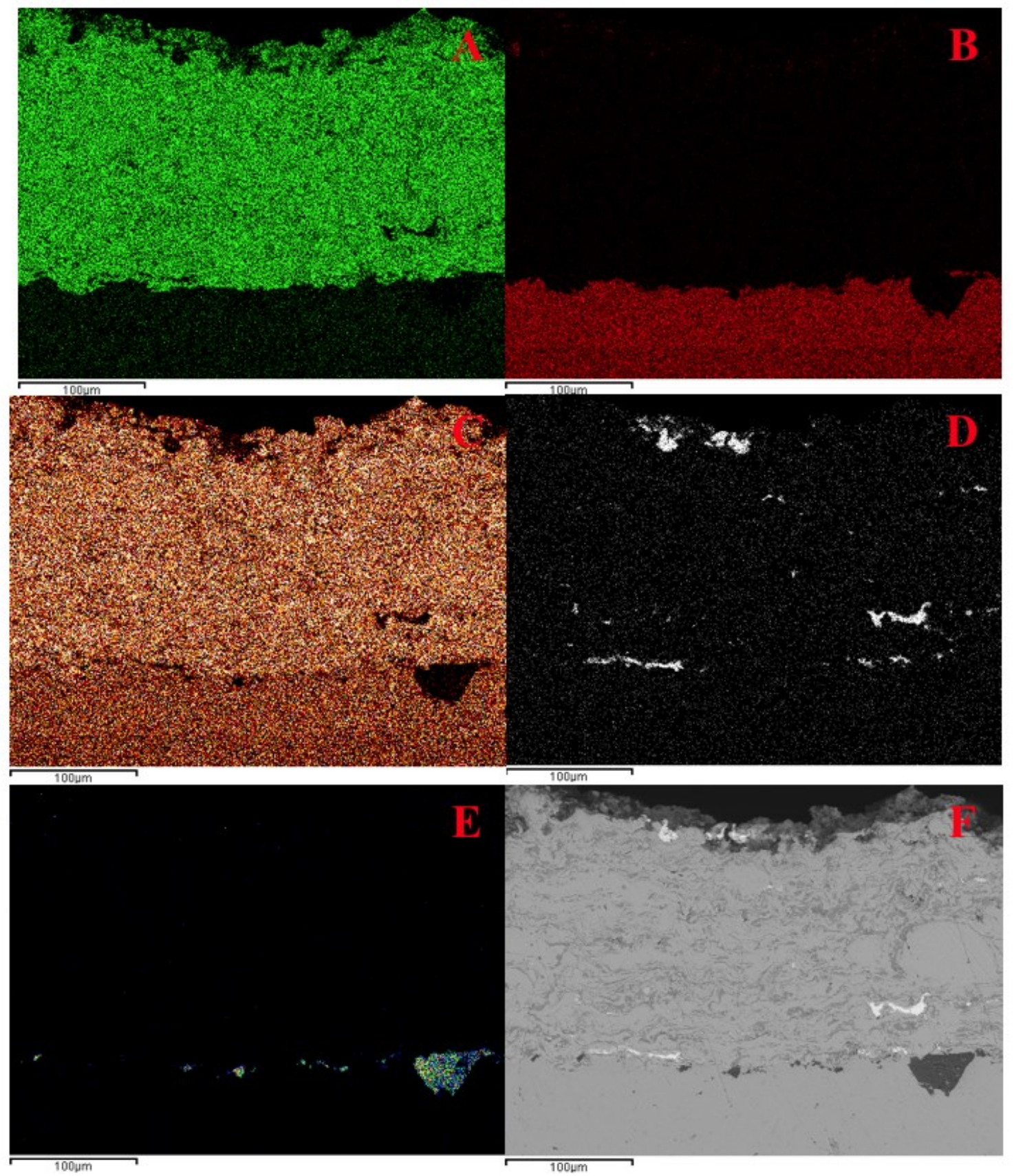

Figure 28: Elemental map of 2\% silver coating cross-section. A: Cobalt, B: Iron, C: Chromium, D: Silver, E: Aluminum, F: Mapped area 

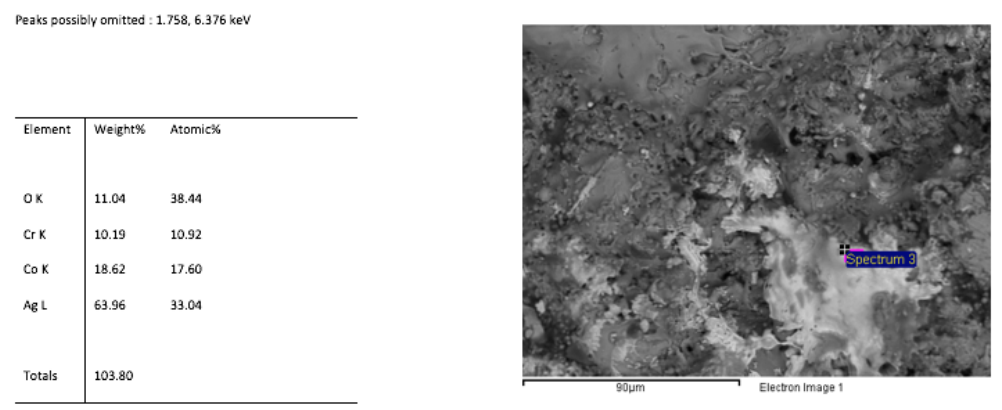

Comment: coated 5\% Ag plasma sprayed coating

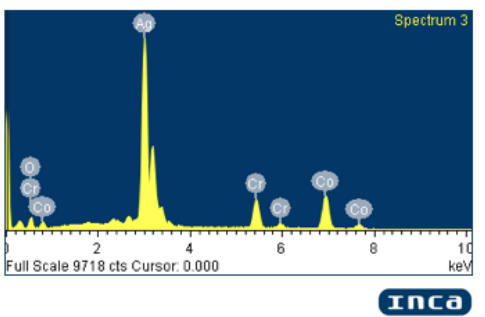

Figure 29: Elemental composition of a bright region on 5\% silver plasma-sprayed coating, indicating that it is silver

These tests were repeated with the 5\% silver plasma-sprayed coating and similar results were found (Figure 29 Figure 30 ). The 5\% silver coating had over $10 \%$ of each area comprised of oxygen, much like the region in the $2 \%$ coating not containing silver. The exact cause for this is unknown, it is possible that the presence of silver in the plasmaspraying process somehow facilitates oxidation of surrounding material. These results could also be coincidence or result from noise in the detection process.
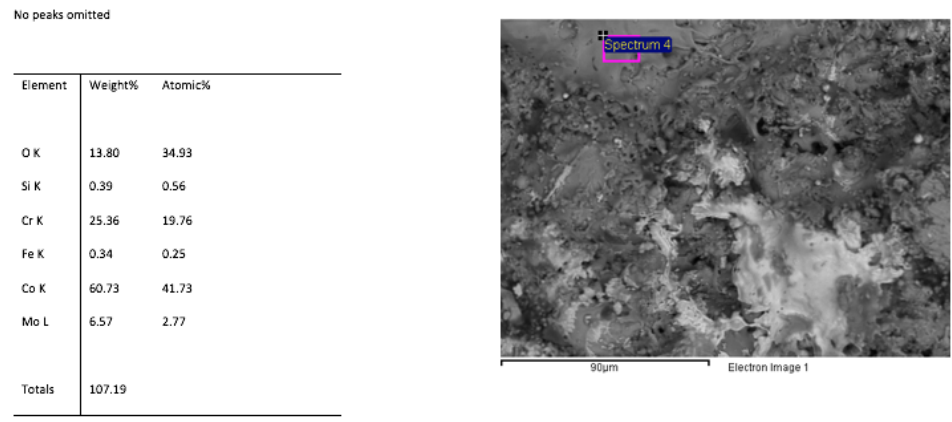

Comment: coated 5\% Ag plasma sprayed coating

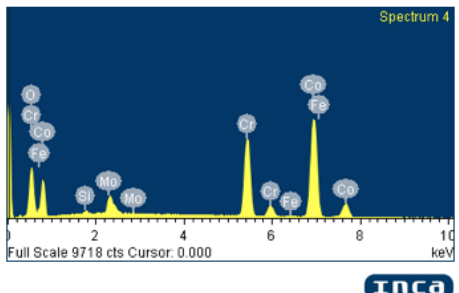

Figure 30: Elemental composition of a dark region on 5\% silver plasma-sprayed coating, showing that it is consistent with the Stellite used 


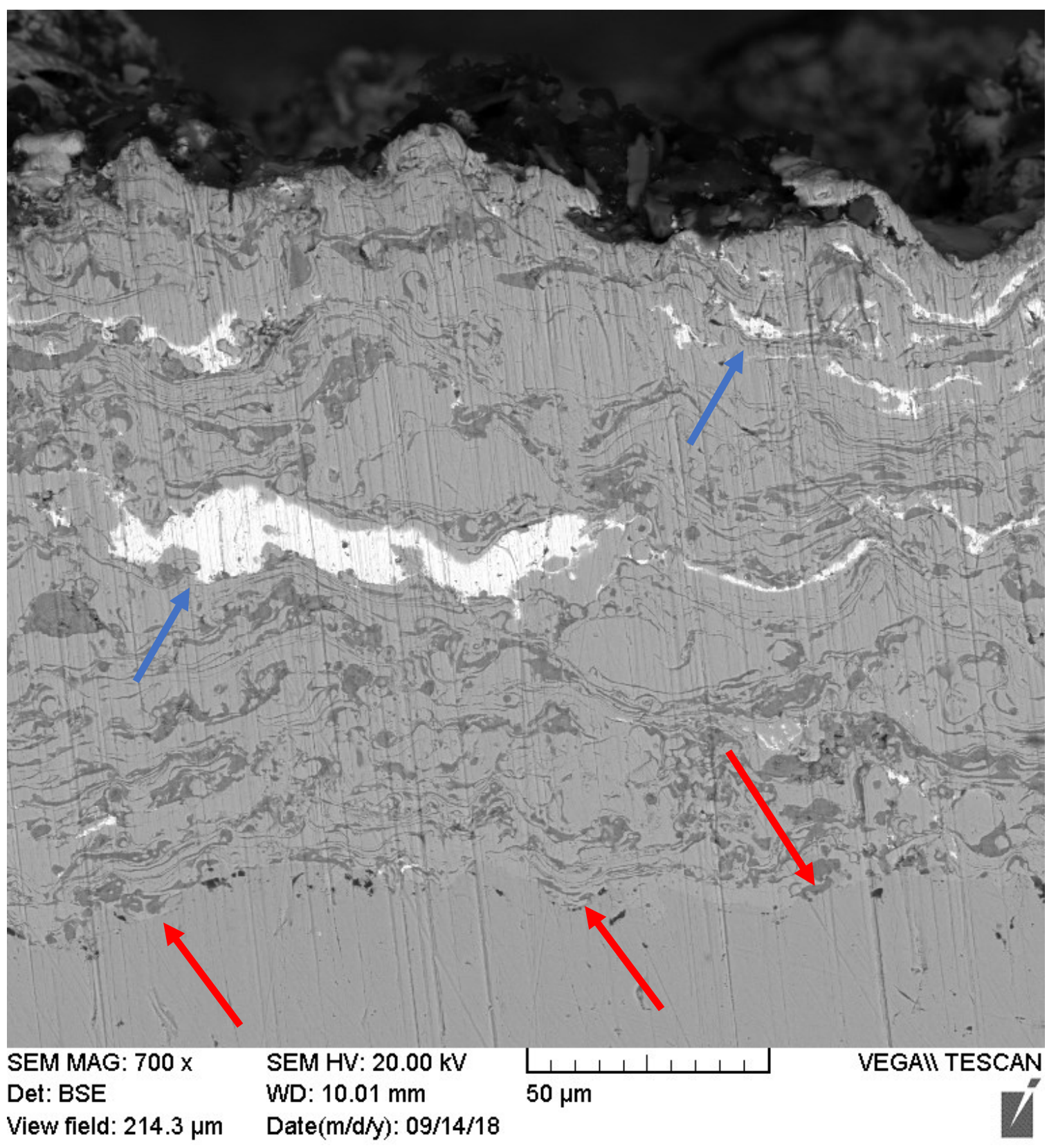

Figure 31: Cross-section of 5\% coating with the interface marked with red arrows and some silver regions marked with blue arrows

The cross-section testing was repeated with the 5\% coating and found similar results to the $2 \%$ coating. Silver is present throughout the cross-section, and the coating appears to be solid throughout (Figure 31), however more cross-sections need to be examined to fully characterize the coating. The elemental makeups found in Figures 32 and 33 are also consistent with the expected alloys. The only observable differences 
between these cross sections are the amount of silver present and the aluminum at the boundary. The $5 \%$ coating has less aluminum near the interface, which can be seen in Figure 31 and in the elemental map of Figure 34. There is also silver near the interface, though the amount seen there is small.

No peaks omitted

\begin{tabular}{l|ll}
\hline Element & Weight\% & Atomic\% \\
& & \\
CK & 5.30 & 17.39 \\
OK & 10.64 & 26.22 \\
Si K & 0.40 & 0.56 \\
Cr K & 23.60 & 17.90 \\
Fe K & 0.59 & 0.42 \\
Co K & 51.08 & 34.19 \\
MoL & 5.46 & 2.25 \\
Ag L & 2.94 & 1.07 \\
& & \\
Totals & 100.00 & \\
\hline
\end{tabular}

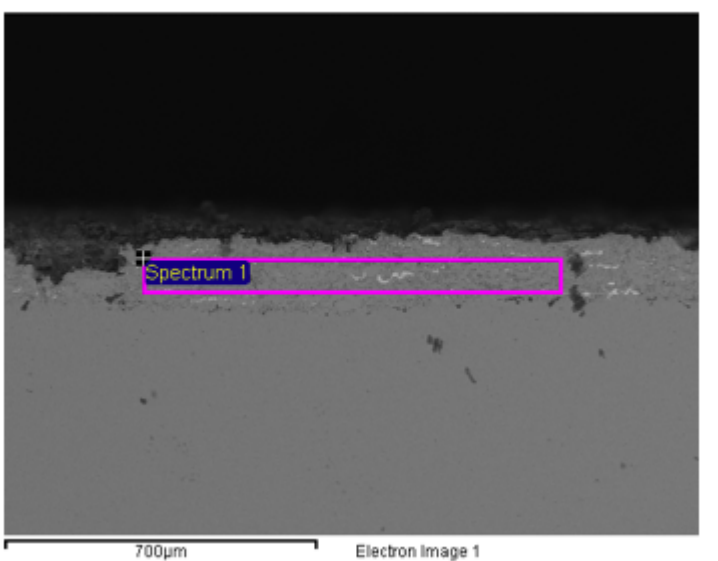

Comment: 5 percent - coating

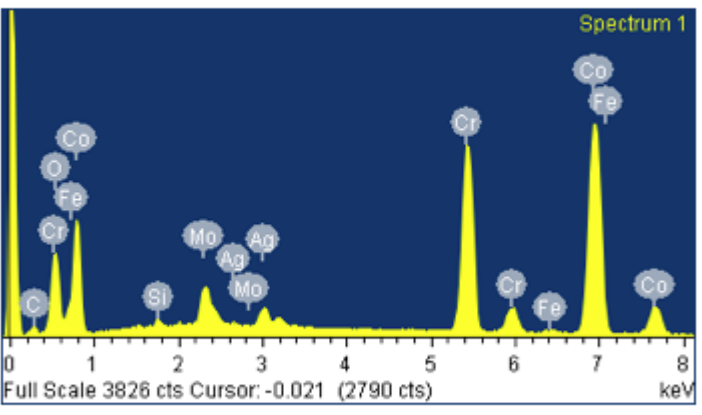

Inca

Figure 32: Elemental makeup of 5\% coating cross-section 
No peaks omitted

\begin{tabular}{l|ll}
\hline Element & Weight\% & Atomic\% \\
& & \\
CK & 3.03 & 12.29 \\
OK & 1.24 & 3.79 \\
Si K & 0.38 & 0.67 \\
Cr K & 17.31 & 16.24 \\
Mn K & 1.29 & 1.15 \\
Fe K & 65.62 & 57.32 \\
Ni K & 8.94 & 7.43 \\
Mo L & 2.19 & 1.11 \\
& & \\
Totals & 100.00 & \\
\hline
\end{tabular}

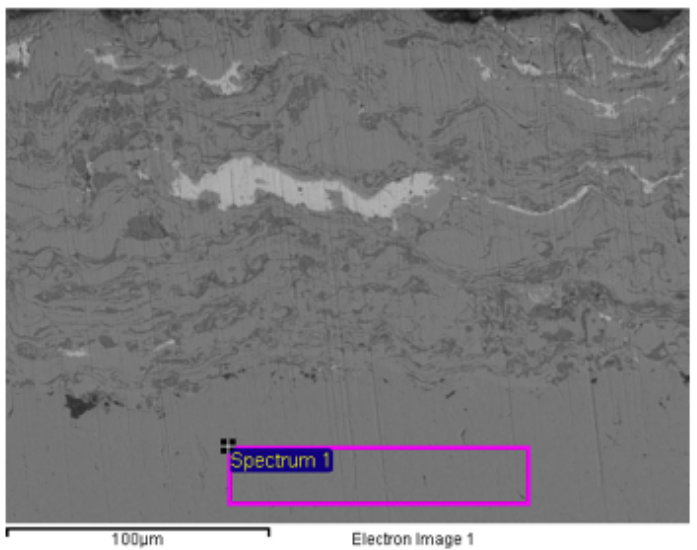

Comment: 5 percent - steel

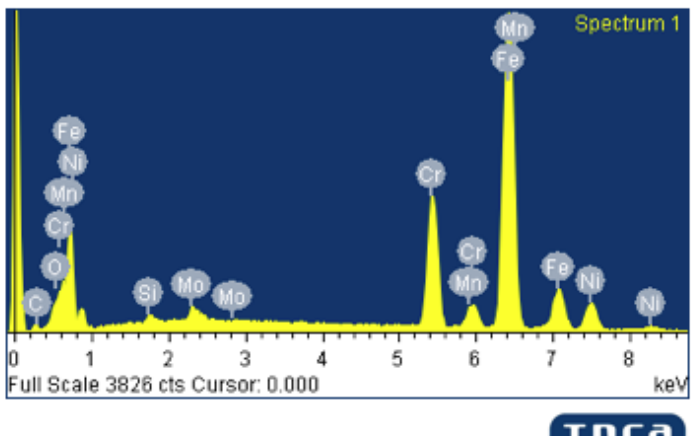

Inca

Figure 33: Elemental makeup of substrate under 5\% coating 


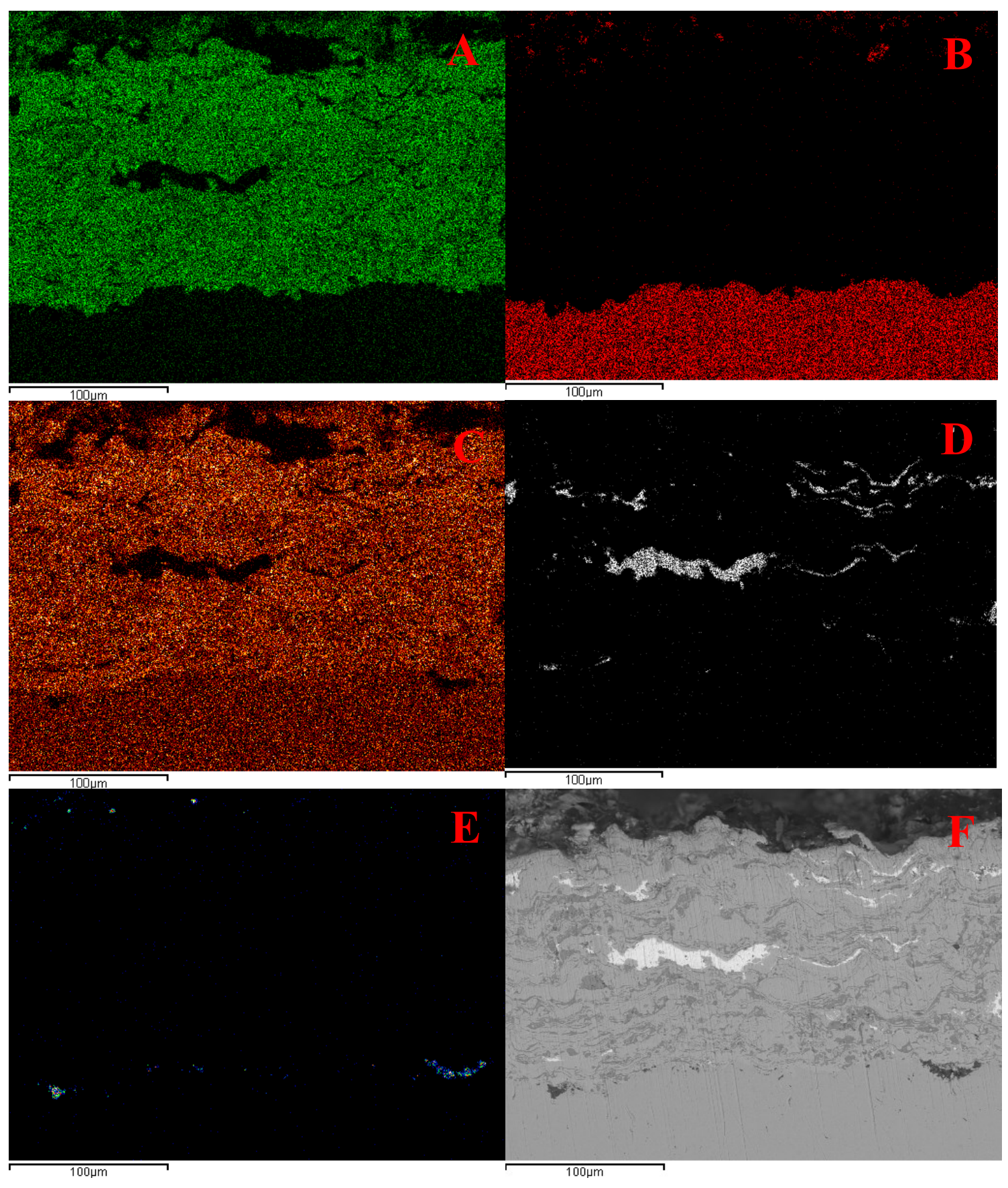

Figure 34: Elemental mapping of 5\% silver coating cross-section. A: Cobalt, B: Iron, C: Chromium, D: Silver, E: Aluminum, F: Mapped area

Most materials inspected via SEM saw significant levels of oxygen present. The uncoated stainless-steel had the least oxygen present, at 4.85 atomic $\%$. The values for most elemental makeups were not normalized to $100 \%$ to keep the context of the quality of the scan. A total less than 100 percent indicated fewer electrons detected than what would be 
expected with a flat surface, and a total over 100 percent would have more electrons detected. This is influenced by the surface topography and the surface angle relative to the detector.

The uncoated Stellite saw significantly greater amounts of oxygen, at 19.8 atomic $\%$ when normalized to $100 \%$. The exact reasoning for this is unknown, though it would not be unlikely to have some surface oxidation, as it is unpolished. The $0 \%$ coating had $10.71 \%$ atomic $\%$ oxygen. The coatings containing silver saw elevated levels of oxygen compared to the $0 \%$, with 47.9 atomic $\%$ and 32.6 atomic $\%$ in the cobalt chromium regions of the $2 \%$ and $5 \%$ silver coatings, respectively. The $2 \%$ coating saw 18.1 atomic $\%$ oxygen around the silver pockets, and the $5 \%$ coating saw 37.0 atomic $\%$ in the silver.

\subsubsection{Revisit after Bacteria Testing}

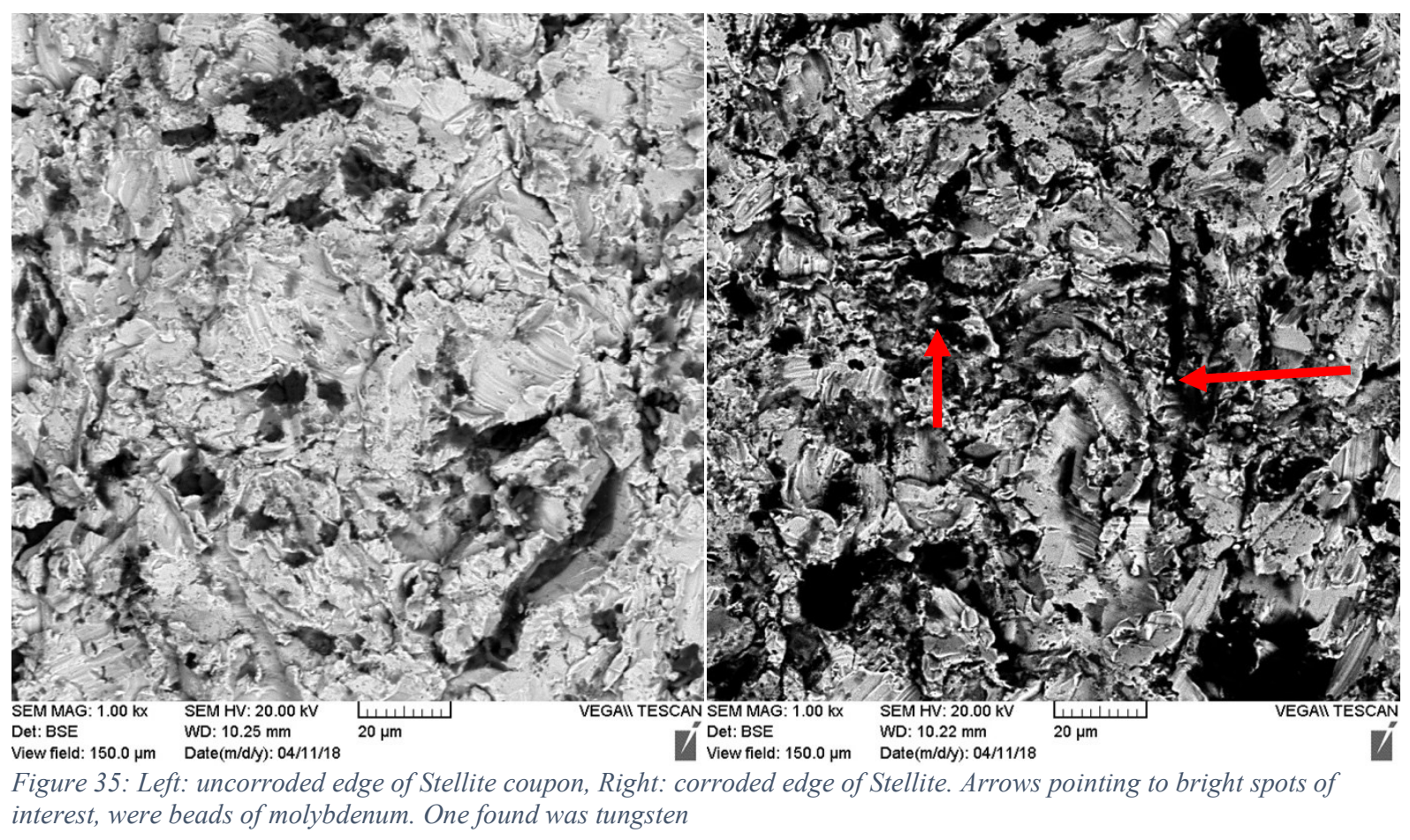


Figure 35 is a comparison of two scans done on the same coupon composed of Stellite that had previously been autoclaved. The side without any visible oxidative layer was scanned first. Figure 36 shows the makeup of a small, relatively uniform area. This breakdown reflects the known composition of Stellite, with the exception of significant amounts of carbon and oxygen.

Spectrum processing :
No peaks omitted
\begin{tabular}{l|ll}
\hline Element & Weight\% & Atomic\% \\
CK & 10.21 & 29.46 \\
OK & 7.52 & 16.30 \\
Al K & 1.76 & 2.26 \\
Si K & 1.52 & 1.88 \\
Ti K & 0.63 & 0.46 \\
Cr K & 25.24 & 16.83 \\
Fe K & 0.70 & 0.43 \\
Co K & 52.98 & 31.16 \\
Mo L & 3.39 & 1.23 \\
& & \\
Totals & 103.96 & \\
\hline
\end{tabular}

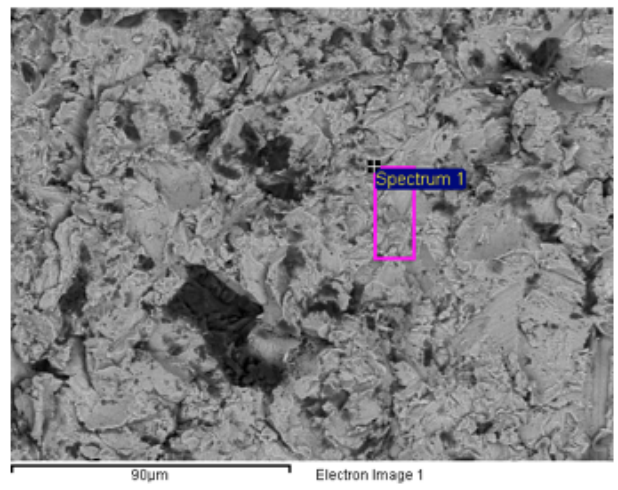

Comment: Stellite ${ }^{*}$ without corrosion

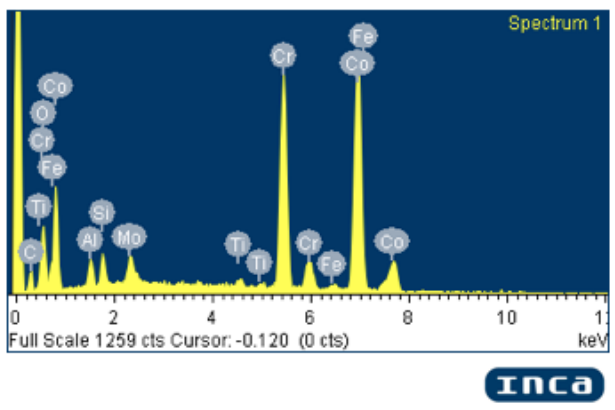

Figure 36: Elemental composition of brighter region of uncorroded Stellite 


Spectrum processing :
No peaks omitted
\begin{tabular}{l|ll}
\hline Element & Weight\% & Atomic\% \\
CK & 5.67 & 12.59 \\
OK & 31.98 & 53.25 \\
AI K & 33.07 & 32.65 \\
Si K & 0.31 & 0.29 \\
Ti K & 0.46 & 0.26 \\
Cr K & 0.76 & 0.39 \\
Co K & 1.27 & 0.57 \\
& & \\
Totals & 73.53 & \\
\hline & & \\
\hline
\end{tabular}
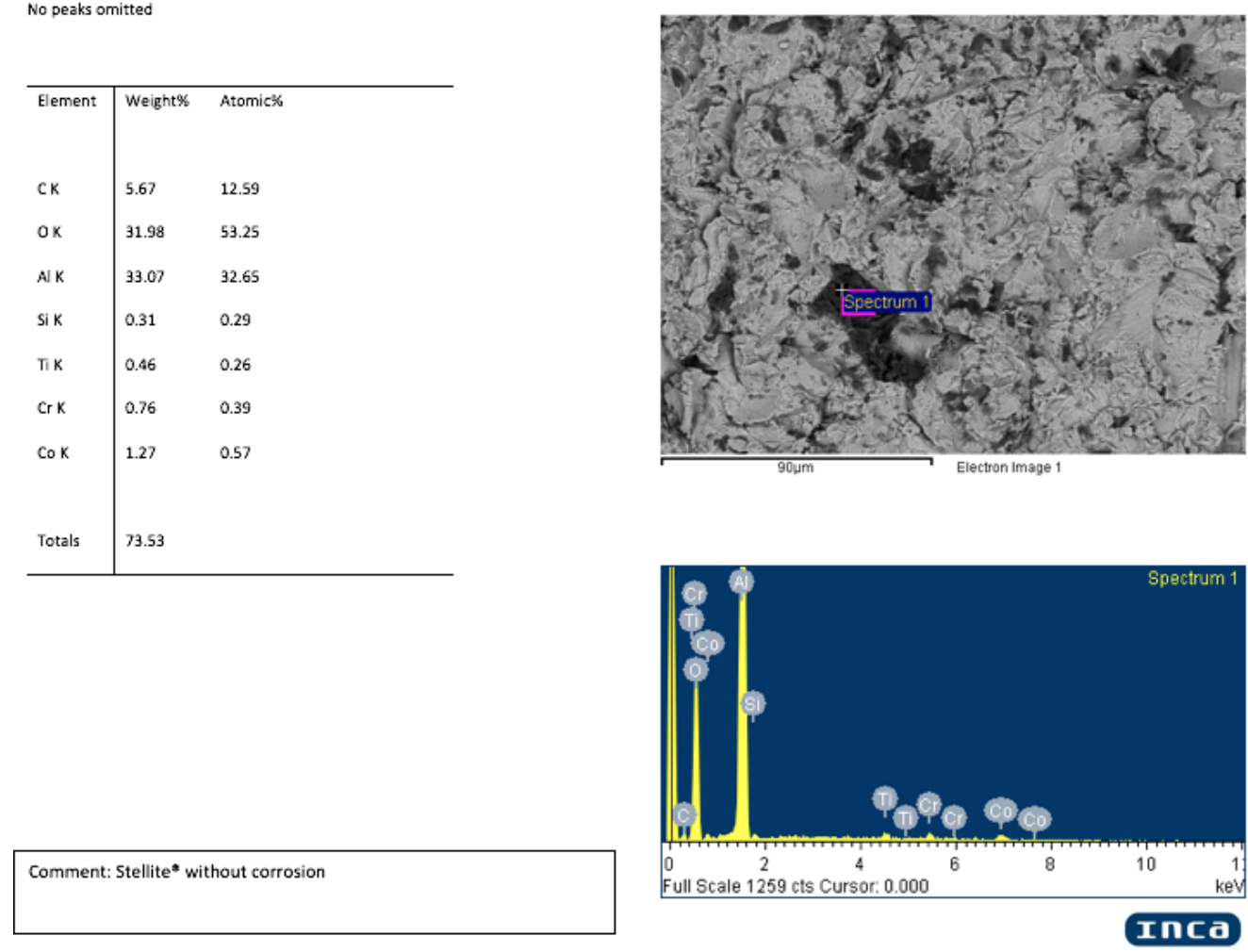

Figure 37: Elemental composition of dark region in uncorroded Stellite, indicating that it is aluminum oxide

There was also a noticeably darker region, which was scanned in Figure 37. The breakdown shows that it is primarily aluminum and oxygen, with an atomic percentage suggesting that it is aluminum oxide $\left(\mathrm{Al}_{2} \mathrm{O}_{3}\right)$. Aluminum is not a listed part of the alloy, though it does appear in other alloys of Stellite ${ }^{102}$. Small pockets of aluminum oxide are visible throughout the surface of the Stellite coupon. Figure 38 shows a darker region on the corroded side of the coupon, and this is also found to be aluminum oxide. The corroded side appears to have a comparable number of these areas to the previously imaged side, suggesting that it is independent from the corrosion issue. 
Spectrum processing :

Peak possibly omitted : $4.530 \mathrm{keV}$

\begin{tabular}{l|ll}
\hline Element & Weight\% & Atomic\% \\
OK & 38.77 & 57.13 \\
AIK & 37.08 & 32.40 \\
Si K & 0.65 & 0.54 \\
SK & 0.46 & 0.34 \\
CrK & 8.42 & 3.82 \\
Fe K & 1.89 & 0.80 \\
Co K & 12.43 & 4.97 \\
& & \\
Totals & 99.70 & \\
\hline
\end{tabular}

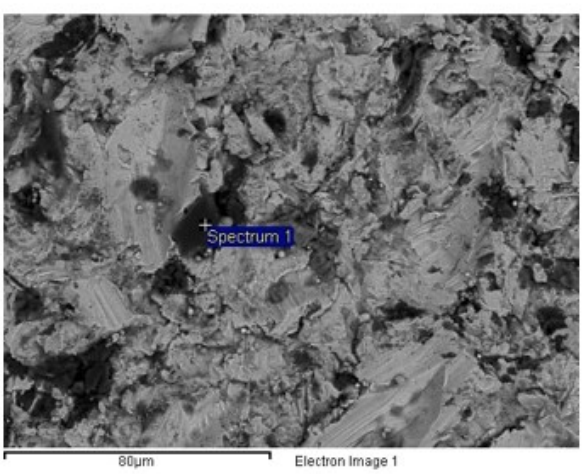

Comment: Stellite ${ }^{*}$ with corrosion

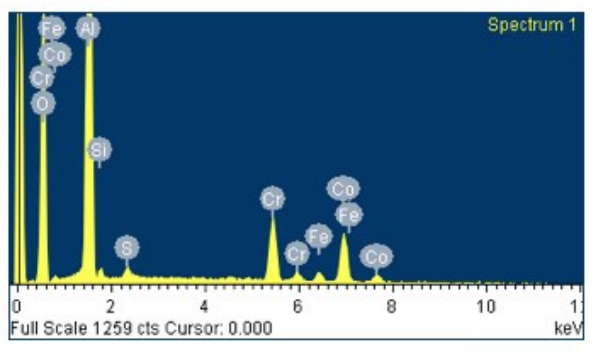

Inca

Figure 38: Elemental composition of a darker region on the corroded Stellite, which is also aluminum oxide Spectrum processing :

No peaks omitted

\begin{tabular}{l|ll}
\hline Element & Weight\% & Atomic\% \\
CK & 11.11 & 28.79 \\
OK & 10.01 & 19.48 \\
A K & 5.12 & 5.91 \\
Si K & 2.26 & 2.50 \\
Cr K & 21.93 & 13.13 \\
Fe K & 3.93 & 2.19 \\
Co K & 50.70 & 26.78 \\
Mo L & 3.76 & 1.22 \\
Totals & 108.81 & \\
\hline
\end{tabular}

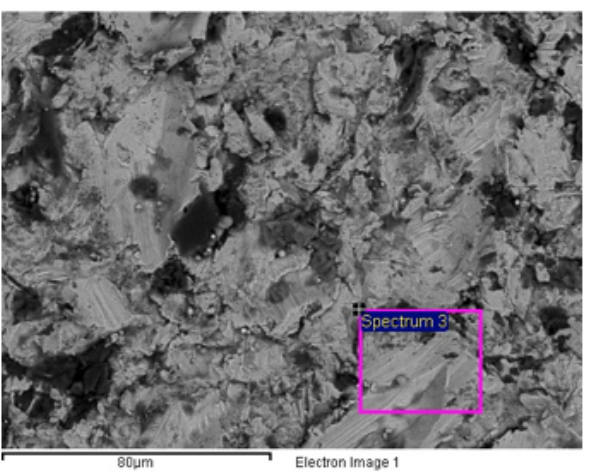

Comment: Stellite ${ }^{*}$ with corrosion

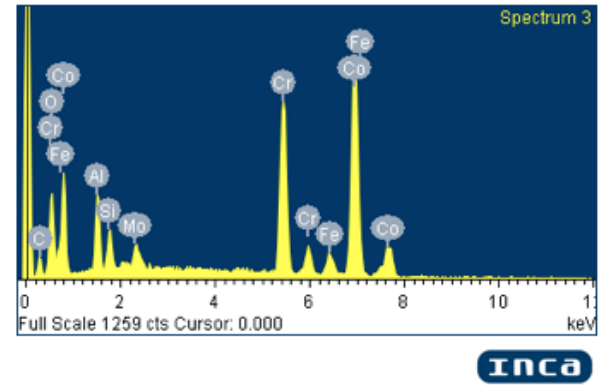

Figure 39: Elemental composition of a brighter region on the corroded Stellite 
Figure 39 shows a scan of an area comparable to Figure 36.
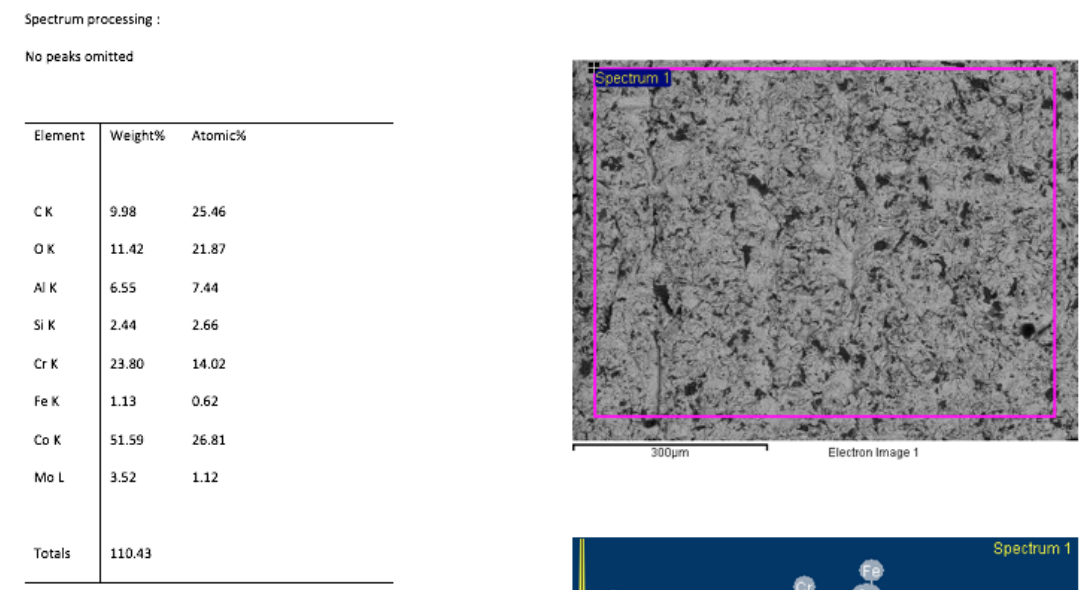

Comment: Stellite ${ }^{\boldsymbol{*}}$ without corrosion

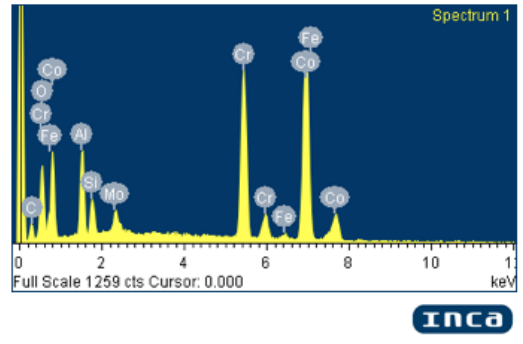

Figure 40: Overall scan of uncorroded Stellite

Figure 40 Figure 41 show the differences in the overall backscatter scans between the uncorroded and corroded coupons.

Spectrum processing

Peak possibly omitted : $4.535 \mathrm{keV}$

\begin{tabular}{l|ll}
\hline Element & Weight\% & Atomic\% \\
& & \\
$\mathrm{CK}$ & 19.81 & 36.63 \\
$\mathrm{OK}$ & 19.97 & 27.72 \\
$\mathrm{~A} K \mathrm{~K}$ & 2.99 & 2.46 \\
$\mathrm{SiK}$ & 4.92 & 3.89 \\
$\mathrm{CrK}$ & 20.25 & 8.65 \\
$\mathrm{FeK}$ & 6.23 & 2.48 \\
$\mathrm{COK}$ & 45.73 & 17.23 \\
$\mathrm{MoL}$ & 4.05 & 0.94 \\
& & \\
Totals & 123.96 & \\
\hline
\end{tabular}

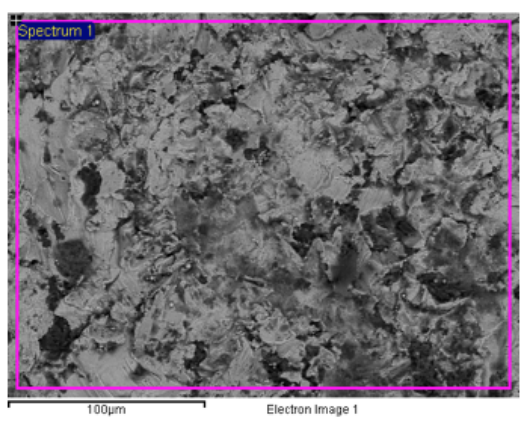

Comment: Stellites with corrosion 들

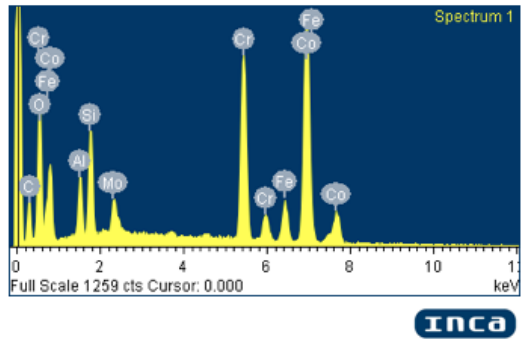

Figure 41: Overall scan of corroded Stellite 

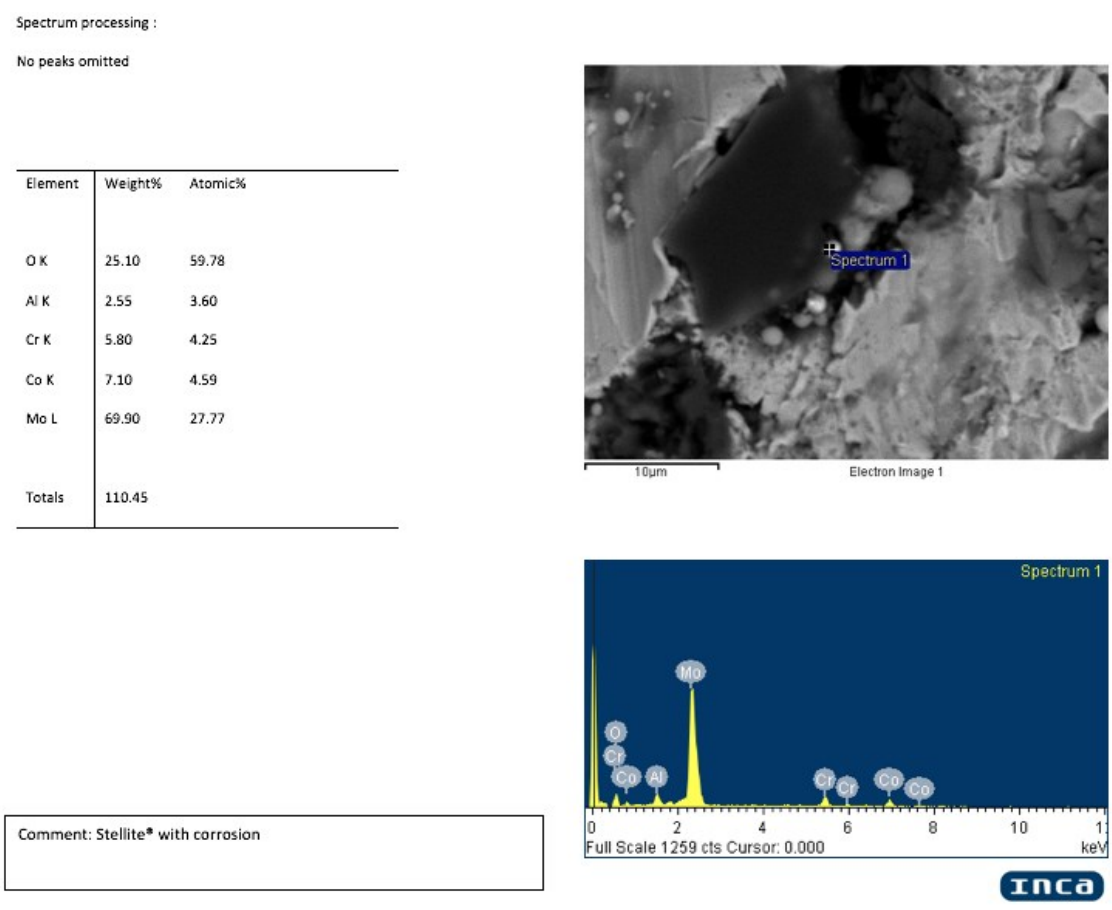

Figure 42: Elemental composition of bright structure on corroded Stellite, which is largely comprised of molybdenum

Figure 42 Figure 43 are scans of bright structures found on the corroded surfaces, and both of them are composed of molybdenum. These precipitates are not found on the side of the coupon that did not oxidize. Molybdenum oxides are used in the process of producing pure molybdenum for alloys, and it is possible that this is a leftover particle that did not react into molybdenum ${ }^{103}$. This is supported by the relatively large amount of oxygen present at $31.85 \%$ of atoms present, though this does not explain the larger count of carbon. 


Spectrum processing :
No peaks omitted
Processing option : All elements analyzed
Number of iterations = 4
\begin{tabular}{l|ll} 
Element & Weight\% & Atomic\% \\
CK & 23.64 & 43.69 \\
OK & 22.96 & 31.85 \\
Si K & 0.80 & 0.63 \\
Cr K & 4.00 & 1.71 \\
Co K & 6.90 & 2.60 \\
Cu K & 2.09 & 0.73 \\
Mo L & 81.23 & 18.79 \\
& & \\
Totals & 141.62 & \\
\hline
\end{tabular}

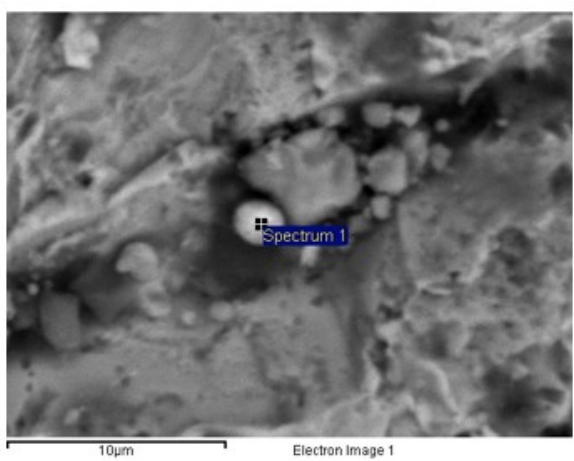

Comment: Stellite ${ }^{\mathbf{s}}$ with corrosion

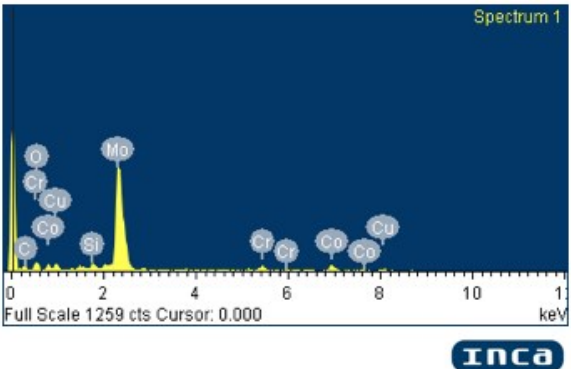

Figure 43: Elemental composition of another bright structure on corroded Stellite, which is also molybdenum

Spectrum processing :

Peak possibly omitted : $3.030 \mathrm{keV}$

\begin{tabular}{l|ll}
\hline Element & Weight\% & Atomic\% \\
& & \\
$\mathrm{CK}$ & 8.34 & 35.49 \\
$\mathrm{Si} \mathrm{K}$ & 2.83 & 5.14 \\
$\mathrm{Cr} \mathrm{K}$ & 20.39 & 20.04 \\
$\mathrm{CoK}$ & 26.49 & 22.97 \\
WM & 58.86 & 16.36 \\
& & \\
Totals & 116.91 & \\
\hline
\end{tabular}
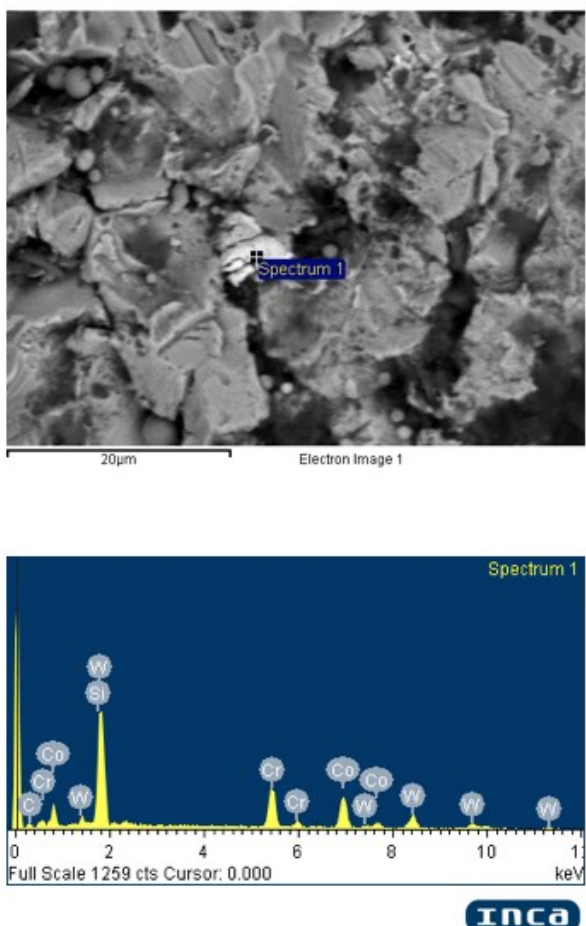

Figure 44: Elemental composition of an amorphous bright structure on corroded Stellite determined to be tungsten 
One other small, bright area was also noticed and scanned, as seen in Figure 44. The area is approximately $8 \mu \mathrm{m}$ in diameter and is irregular, unlike the molybdenum structures. The spectrum analysis determined this to be tungsten, which was not intentionally added to the alloy. Tungsten is also used in several other alloys of Stellite ${ }^{102}$ and could have resulted from cross-contamination. This was the only tungsten found on the coupon and is considered an anomaly.

\subsubsection{Adhesion Strength}

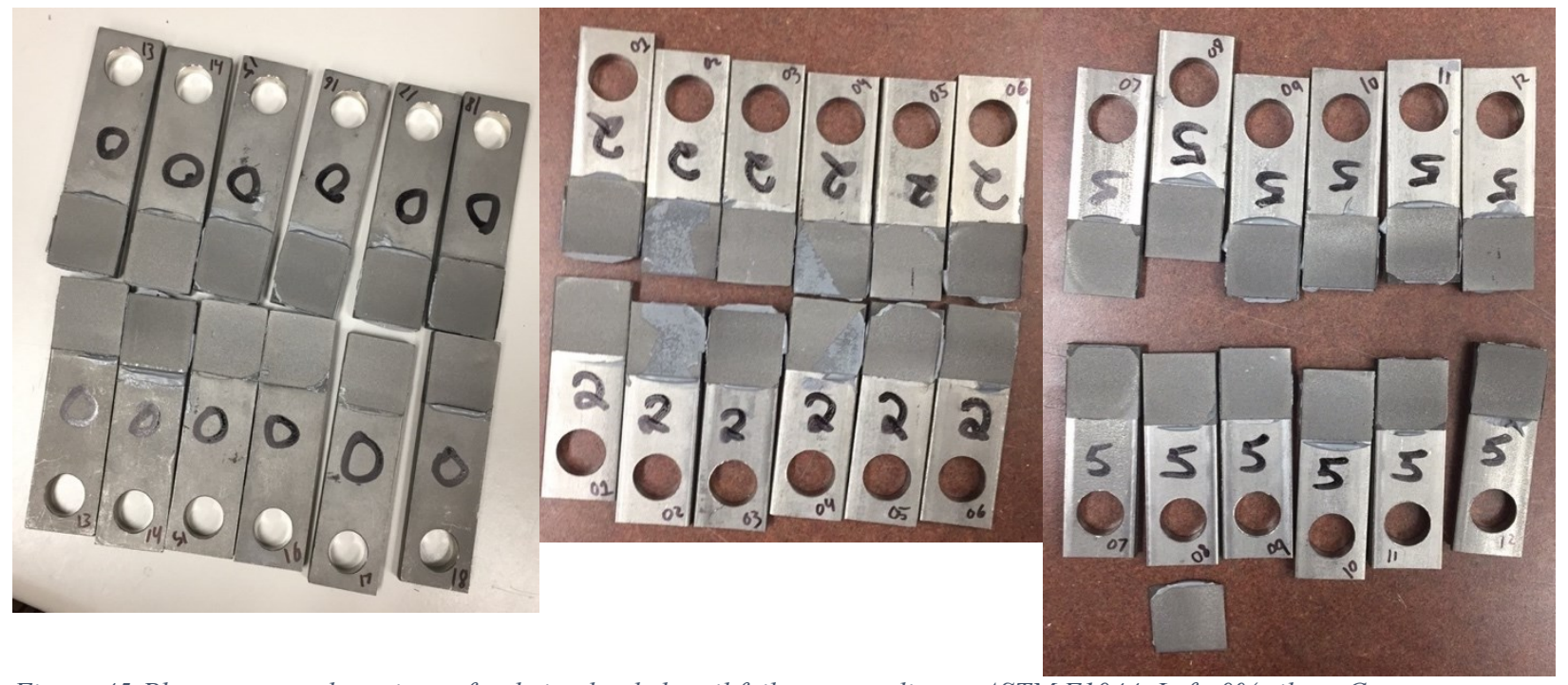

Figure 45:Plasma-sprayed coatings after being loaded until failure according to ASTM F1044. Left: 0\% silver, Center: $2 \%$ silver, Right: $5 \%$ silver. Each column was a pair adhered together

Figure 45 shows the pairs of coupons after the loading cycle. Each specimen is vertically adjacent to the specimen it was paired with. Each pair was numbered in the order that they were loaded. The coatings failed evenly on most test cycles. Only pairs 2 and 4 in Figure 45 seem to have failed in the epoxy layer, thus the strength of these may be underestimated (27.8 and 26.9 MPa, respectively). Therefore, the vast majority of cases saw the failure load on the coatings themselves, negating concerns for variance in the 
amount of epoxy used. The average ultimate stress of the $0 \%$ silver coating was $22.3 \pm 1.7$ MPa, 2\% silver was $24.7 \pm 3.2 \mathrm{MPa}$, and $5 \%$ silver was $17.7 \pm 4.7 \mathrm{MPa}$. These values are plotted in Figure 46.

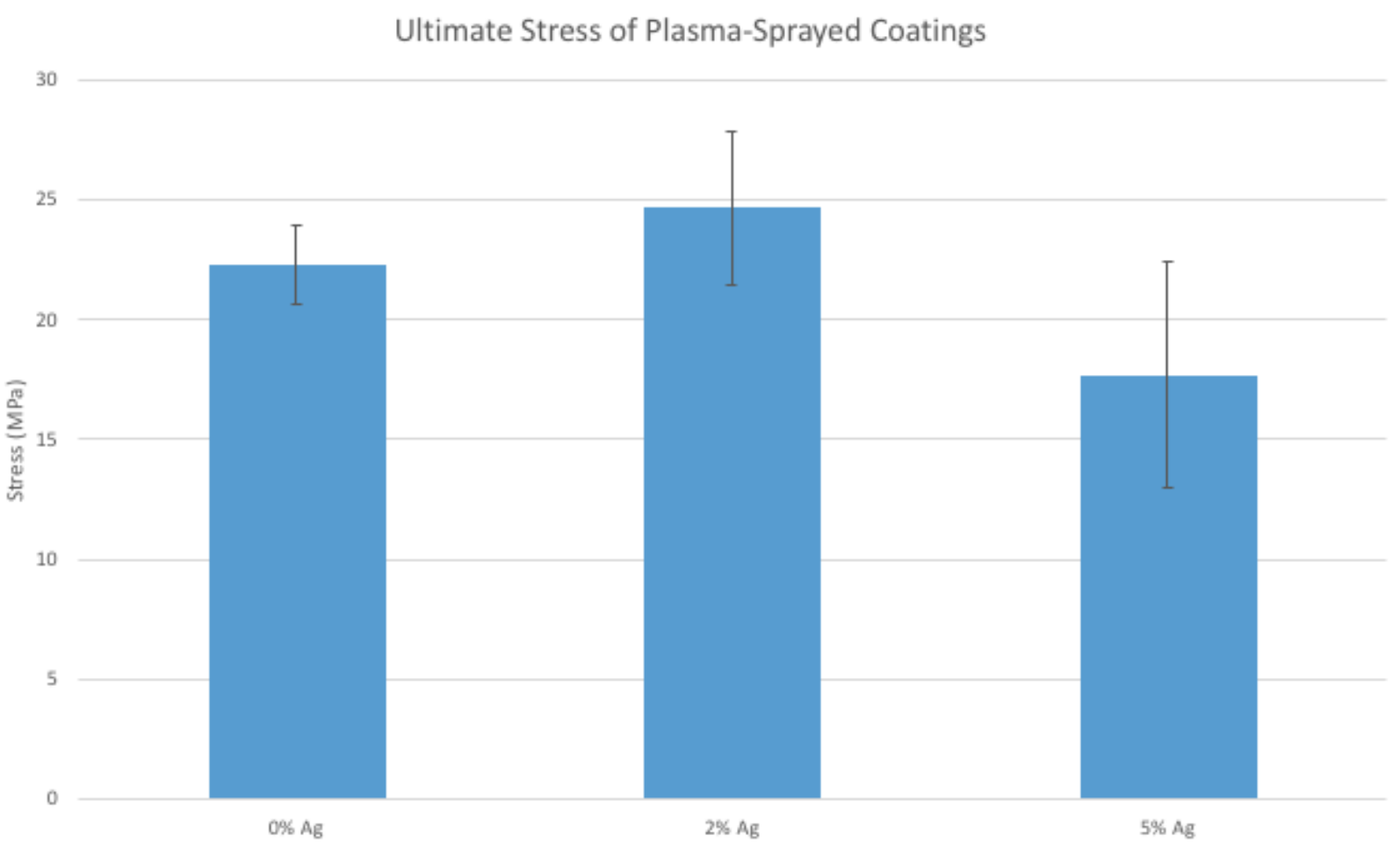

Figure 46: The average ultimate stresses of each plasma-sprayed coating, plotted with standard deviation

\subsubsection{Silver Elution}

Using mass spectrometry, no detectable levels of silver were found in the tested solutions for any of the coating compositions. 


\subsubsection{Bacteria}

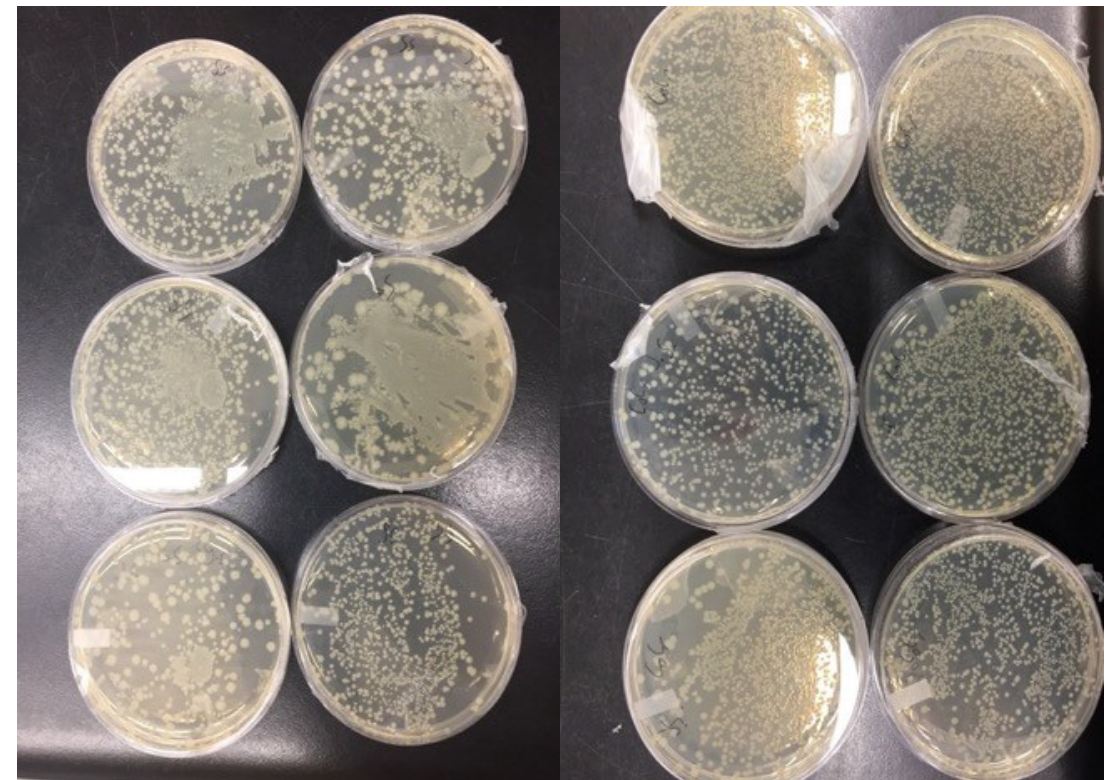

Figure 47: Bacteria plates from: Left: uncoated 316L steel, Right: uncoated Stellite. These were used as the controls

Figure 47 Figure 48 are the bacteria plates after 24 hours of incubation. The plates are in no particular order in each group. The colonies in each group were counted and compiled into a table (Table 3).

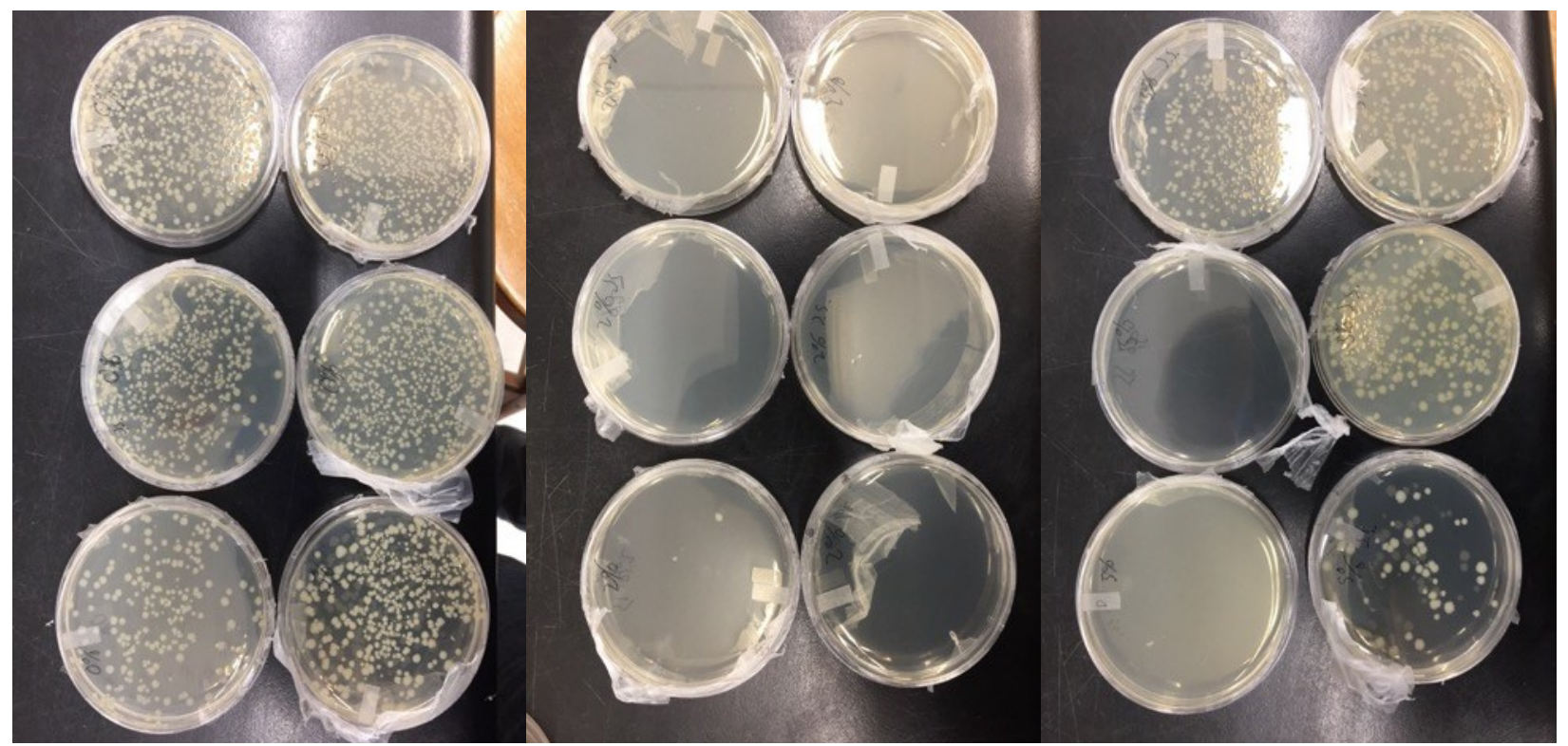

Figure 48: Bacteria plates from: Left: $0 \%$ silver plasma sprayed coatings, Center: $2 \%$ silver, Right: 5\% silver 


\begin{tabular}{|l|l|l|l|l|}
\hline & $\mathrm{CoCr}$ & $0 \%$ & $2 \%$ & $5 \%$ \\
\hline & 1152 & 612 & 0 & 316 \\
\hline & 1317 & 698 & 0 & 286 \\
\hline & 642 & 533 & 0 & 0 \\
\hline & 1286 & 651 & 0 & 309 \\
\hline & 833 & 211 & 0 & 0 (dry) \\
\hline & 1293 & 433 & 2 & 50 \\
\hline Average & 1087 & 525 & 0.33 & 192.2 \\
\hline $\begin{array}{l}\text { Standard } \\
\text { dev }\end{array}$ & 258.75 & 163.54 & 0.75 & 137.79 \\
\hline
\end{tabular}

\subsection{Discussion}

\subsubsection{Scanning Electron Microscopy}

The images taken of the plasma-sprayed coatings show that the general surface characteristics were what was expected. The surface morphology is similar to what was produced by Luckey et al. ${ }^{83}$, and the silver was found on the surface of the coating. This is critical for the coating to exhibit antimicrobial properties. The presence of silver at the surface does not guarantee antimicrobial activity. The silver needs to interact with bacteria, requiring bacteria to either come into direct contact with the silver regions or free silver ions. The plasma-sprayed coating that contained a higher percentage of silver had more silver regions (Figure 19), which was also expected. The composition tests reflected this.

The oxygen content in the coatings was extremely high, nearly half of the atomic makeup of some regions. The SEM was expected to have higher oxygen counts than what were actually there; noise in the system can manifest as a reading of lighter elements. Furthermore, the space inside the SEM is not a perfect vacuum, and some free-floating oxygen is expected. The readings of oxygen are extremely high, especially in the plasmasprayed coatings containing silver. Low pressure or vacuum plasma-spraying could be performed to reduce oxidation, and would be of interest in future work. 
The microstructure seen in the cross-section examinations shows a very solid, well bonded coating. This would indicate that the coating would be strong in adhesion, which was seen during the adhesion testing. The silver is distributed throughout the coating, however any silver not directly on the surface would not have the opportunity to come into contact with bacteria. The structure is not porous, so having silver under the surface of the coating would have no practical purpose in preventing bacteria colonization. The silver was mechanically mixed into the Stellite powder before being plasma-sprayed, however a graded plasma-spraying process may yield more favorable results. Gradually increasing the silver content of the material sprayed would ensure that most of the silver used would be at the surface, reducing waste.

\subsubsection{Revisit after Bacteria Testing}

The images and scans taken of the specimens show some slight differences between the corroded and uncorroded areas. The findings back the idea that there is some inherent difference in the side of the specimen that was not significantly oxidized during the autoclaving process. The makeups of the two sides are similar, with the exception of the iron content. The corroded side has $3.93 \%$ iron by weight, versus $0.70 \%$ by weight on the clean side. The total percentage counts are slightly different between the two, but there is a significant difference in iron content. The corroded side also has a slightly larger amount of silicon (2.26\% versus $1.52 \%)$. This difference is more apparent when larger areas are viewed in Figures 40 and 41, with $3.97 \%$ and $2.21 \%$ respectively when normalized to $100 \%$. The iron contents are also significantly different, with the corroded side at $5.03 \%$ and the clean side at $1.02 \%$. F75 cobalt chromium can contain up to $0.75 \%$ iron by mass ${ }^{94}$, 
but the manufacturer claims no iron is used in their alloy ${ }^{102}$. This means that iron was not intended to be in the coupons. It is unclear how the iron came into contact with the coupons but seeing that the oxidation pattern was consistent on all Stellite coupons used, it suggests that this resulted from the manufacturing process. The coupon imaged in the SEM was taken directly from the box it was shipped in and autoclaved.

The pockets of aluminum oxide are more difficult to spot in the corroded images, as the overall image appears darker. This is likely due to the fact that there are a number of small, bright globular structures in the frame. The gradient of the image is best fit to show contrast, so having pockets of denser materials would shift the overall image to be darker.

\subsubsection{Adhesion Strength}

The adhesive strengths of the coatings were greater than expected. The strongest coatings developed by Fielding et al. had an average strength of $18.21 \pm 4.8 \mathrm{MPa}^{71}$, which was only stronger than the 5\% silver plasma-sprayed coating. There was a significant decline in strength from the $2 \%$ silver to the $5 \%$ silver coating. This suggests that increasing the silver content of the plasma-sprayed coating decreases the adhesive strength. The 5\% silver coating was strong enough to be considered a success when compared to the coatings produced by Fielding et al.

For the shear test, custom yokes were made. The original design was provided by David Raude to be sure that they would fit in the MTS frame. Due to a communication error, the yokes that were machined were missing a suitable area for the actuators to grab onto. To circumvent this, small divots were machined into the base of the yokes, and plates were soldered in to make an area for the yoke to be mounted. This process made the yokes 
slightly different, as these plates were made of scrap metal found in the Machine Shop. The final assembly can be seen in Figure 8. The assembly was pulled entirely in tension, so the geometry of the plates within the grips would have no effect on the results as long as there was no slippage. The yokes were found to remain firmly in place throughout testing and were inspected between load cycles.

As previously mentioned, loading on Stellite coupons was performed with bolts with a 9/16" diameter in lieu of dowels. The coupons were inspected after each round and no deformation was found around the machined hole, so the bolts were considered a valid substitution for dowels. During the Stellite testing, it was observed that the bolt had a greater clearance which allowed it to move freely when not under load. Once the MTS put a load on the system, the bolt would straighten and remain normal to the coupon for the rest of the testing. The stainless-steel coupons were loaded with $5 / 8$ " dowels and no visible deformation was observed in the test coupons.

During the process of curing the epoxy, some slight variance was observed. The plasma-sprayed coatings were bonded such that the coatings were the only areas of the coupons with epoxy on them. Any excess was wiped away as best as possible, but some flowed from the sides after being placed in the vice. This could have reinforced the two coupons together, though the effects would be minimal, as most of the excess epoxy was removed. The amount of epoxy varied between each pair of coupons, as the amount used was not measured. Enough epoxy was used to fully cover both surfaces without creating a significant difference in epoxy thickness between each pair.

The curvature of the coupons seen in Figure 2 was only observed in the stainless-steel coupons. This could have led to some differences in measured adhesion strength between 
the Stellite substrate and steel substrate. Coatings on the outside of the curve were paired with those on the inside to maintain flush contact, and a square inch of the coatings was bonded together. The loading was also performed in a direction orthogonal to the curved axis, suggesting that the curvature would not have had a significant effect on the results.

During the testing, the coupons gave little indication that they were about to fail. The plasma-sprayed coatings would not make any noise before sudden failure. The coatings appear to have primarily failed within the coating, near the interface with the substrate. This is suggested by the appearances in Figure 45, where both coupons from each pair retain the appearance of the coating. One coating from each pair was also noticably thicker than the other, containing all of the epoxy and most of the coating from the other coupon. Pairs 2 and 4 appear to have failed in the epoxy layer, also tearing the coatings in the process. The shear strength of the epoxy when applied to these materials is not known, though it typically has a shear strength of 27.6-41.4 MPa when applied to steel. The epoxy is known to have a shear strength as low as $13.8 \mathrm{MPa}$ when applied to zinc ${ }^{104}$, so it is possible that the epoxy may have started to fail under some of the loads. Testing in the future with a stronger epoxy may yield more accurate results.

The $2 \%$ silver plasma-sprayed coating is the strongest of the plasma-sprayed coatings, having an ultimate stress of $24.66 \mathrm{MPa}$. The $5 \%$ silver coating was slightly weaker than the $2 \%$, with an average ultimate stress $28 \%$ less than that of the $2 \%$ coating. The $0 \%$ silver coating failed under similar stresses as the $2 \%$ (22.30 MPa versus 24.66 $\mathrm{MPa}$ ), however it is important to note that these coatings were on different substrates. The $0 \%$ were on cobalt chromium, whereas the $2 \%$ and $5 \%$ were on stainless-steel. There is a trend seen where increasing silver content in the plasma sprayed coatings decreased shear 
strength ( $2 \%$ silver versus $5 \%$ silver), but this cannot be confirmed with the $0 \%$ silver coating failing before the $2 \%$ silver coating. It is possible that the plasma-sprayed coating better adhered to the steel than to the Stellite, but this is unconfirmed by the results. That being said, all of the test groups had shear strengths that would be considered successful. Human femoral trabecular bone has a yield shear strength of approximately 5-10 $\mathrm{MPa}^{105}$, meaning that the bone surrounding an orthopedic implant would fail before these coatings. The coatings are therefore strong enough for use in biomedical application.

\subsubsection{Silver Elution}

The results of the elution test were not expected. In previous work, silver would gradually leach from the material to create a concentration of silver ions in the surrounding fluid $^{71}$. This would allow for the silver to interact with bacteria more easily.

One thing to note when performing the leaching testing was that not all of the solution that the coupons were immersed in was collected for testing. Each coupon was set in a container with $100 \mathrm{ml}$ of distilled water, but the containers provided by Paracel Laboratories could only store approximately $60 \mathrm{ml}$. An effort was made to mix the solution before bottling it, and there was no visible settling in the solution.

When the period of immersion was complete, it was noted that the sides of the coatings turned a bright blue-green color. This was observable after one week, and the twoweek group had an even more distinct color change, as seen in Figure 49. The coloring has a similar appearance to cobalt chromite blue-green ${ }^{106}$, a pigment. 


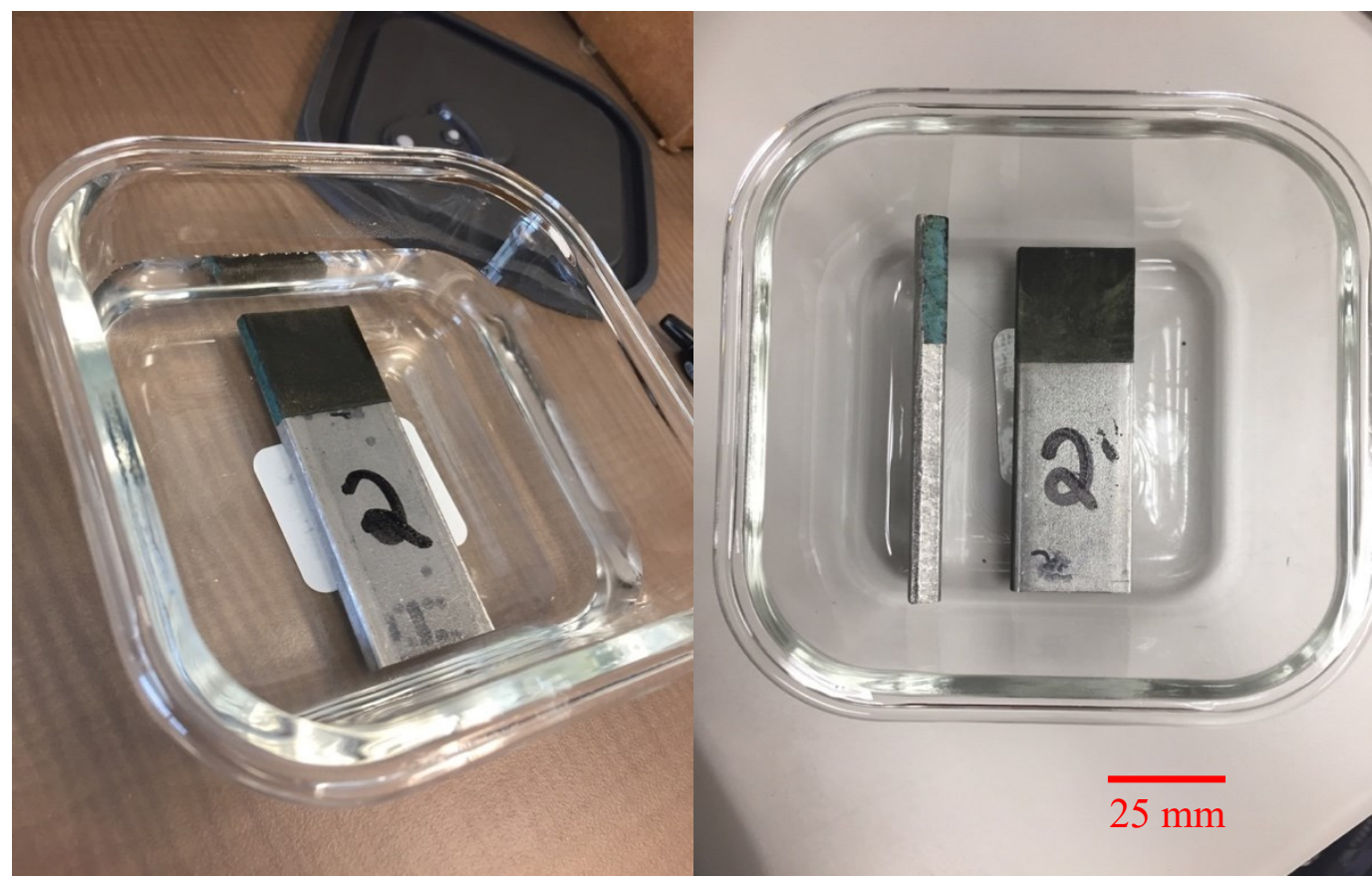

Figure 49: Left: 2\% silver coating after one week of submersion in distilled water, shortly before the solution was collected. Right: Two $2 \%$ silver coatings after two weeks of submersion.

It appears likely that this color change is the result of oxidation of the cobalt and chromium in the coating. It is unclear why the main surface of the coating did not undergo significant color changes, when all surfaces were fully exposed to water. These colors changes were observed on every coupon submerged in the water.

One of the possible explanations for these results was the choice in solution. Fielding et al. used phosphate-buffered saline to immerse their coatings. Furthermore, they mechanically stimulated the system by shaking it continuously ${ }^{71}$. This could potentially have allowed for silver to more readily dissociate into the solution. Sterile water was used in this thesis to better replicate what would be used in water processing facilities, and to make the test easier to repeat. Testing flowing water over the coating was beyond the scope of this study and testing with this could have resulted in different findings. The study was limited in terms of immersive solutions used, and further testing with other chemicals used in industry should be tested to get a better understanding of the coating properties. 


\subsubsection{Bacteria}

The bacteria test found that the $2 \%$ silver plasma-sprayed coatings were effective in preventing E. coli proliferation. The 5\% silver coatings were also able to reduce E. coli growth, though this was not as successful as the $2 \%$ silver coating. This was not an expected result; silver is the antimicrobial agent and increasing its concentration was expected to increase potency.

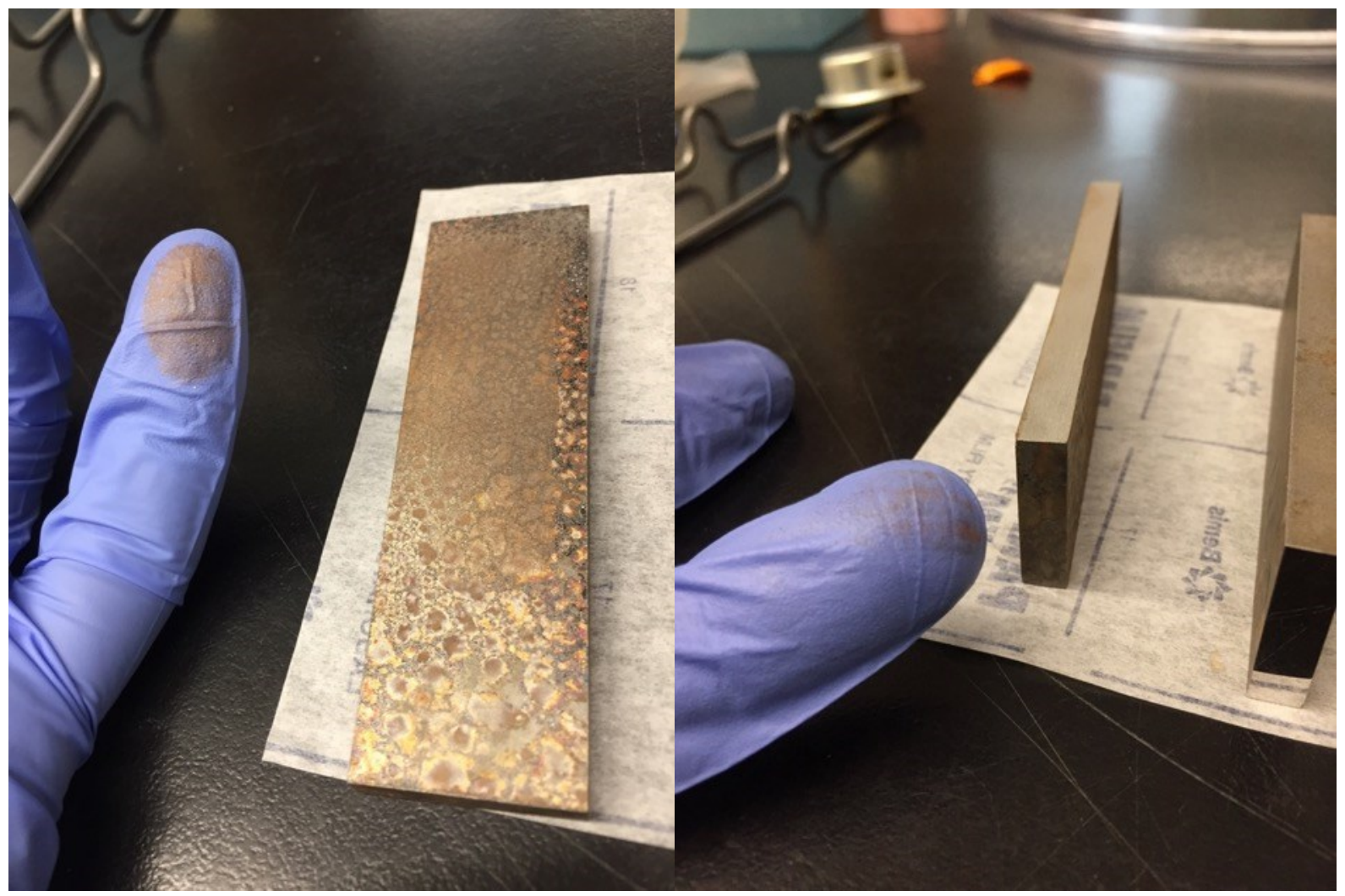

Figure 50: Left: Corrosion on Stellite coupon that formed from autoclaving wiped off on glove, Right: comparison of uncorroded edge (left) and corroded edge (right). Oxidation from the "uncorroded" edge can be seen on the glove

When the cobalt chromium coupons were first autoclaved, a significant amount of corrosion was observed. An oxidative layer was found to form on all of the sides except for one. This was consistent across all tested Stellite pieces, where one of the long edges had minimal oxidation on it. This edge discrepancy was explored with the SEM, as previously mentioned. The lack of oxidation appeared to be independent of orientation in 
the box, as the "clean side" was found evenly distributed between sides facing the container and sides facing other coupons. The side of the coupon facing down was observed to have less oxidation than other sides, so it was decided to flip all test coupons upside down for the autoclaving process. The oxidation was found to be a red-brown color and could mostly be wiped away from the metal (Figure 50), leaving behind a faint stain. It was speculated to be iron oxide, judging from the color, but as seen in the SEM results, this was inconclusive. Subsequent autoclaving yielded less oxidation than the initial process but was not prevented from repetitive autoclaving.

The high levels of oxidation were speculated to be a result of the roughness of the surface of the Stellite coupons, and that polishing would reduce this. A previously autoclaved Stellite coupon was polished along two edges, one with 600 grit sandpaper and the other up to 1200 grit sandpaper. This coupon was then autoclaved in a pipette tip box with a Stellite coupon that was not previously autoclaved. This was done to compare the edges of the coupons, since the polished coupon had newly exposed material on the surface. As seen in Figure 51, there is no observable corrosion on either polished surface. Both surfaces were thoroughly wiped, and no oxidized material was found, unlike the untreated coupon. 


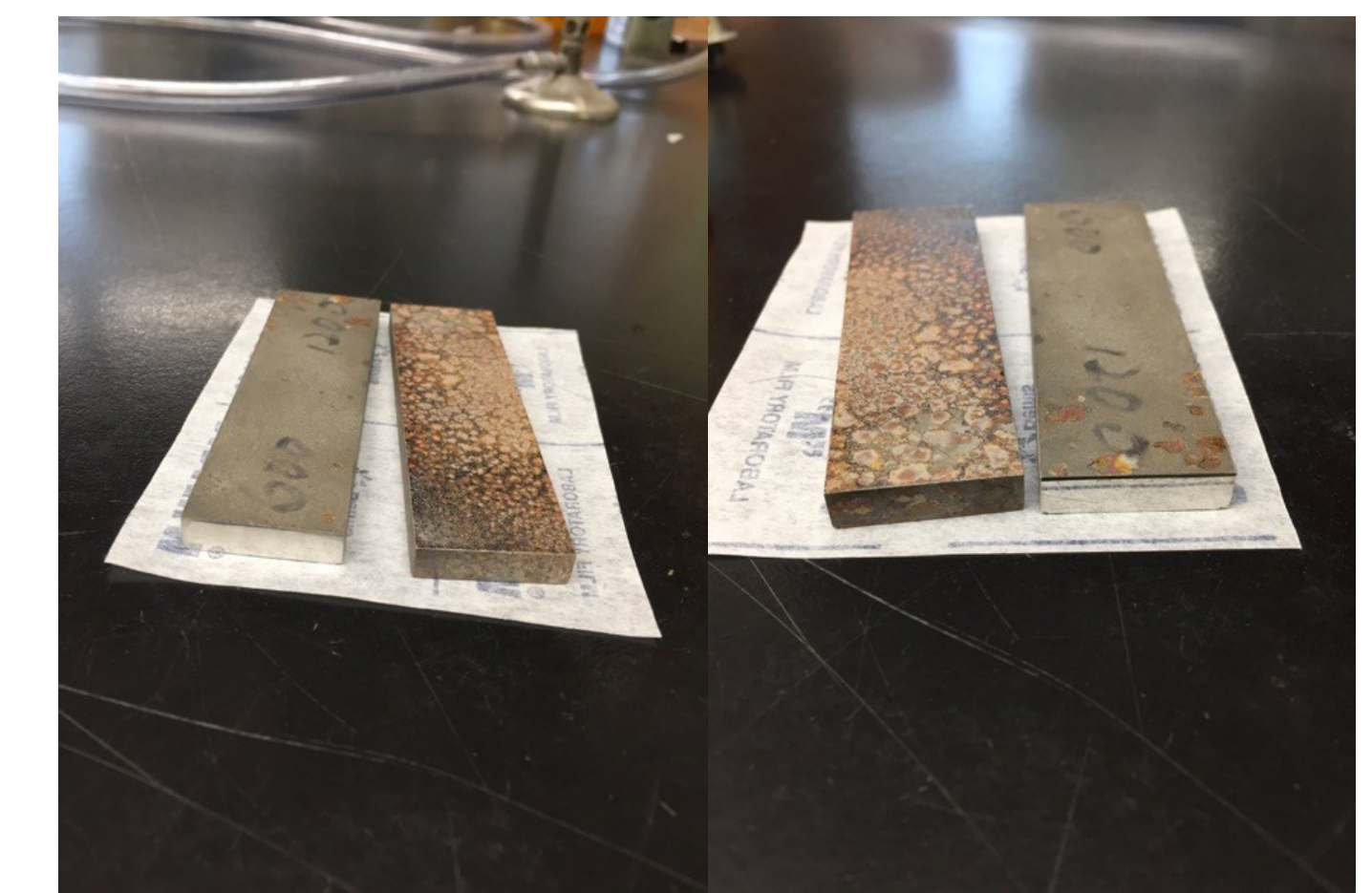

Figure 51: Left: Stellite polished to 600 grit compared to untreated Stellite, Right: untreated Stellite compared with Stellite polished to 1200 grit

The corrosion of these materials could hold potential merit in preventing bacterial colonization. Some metal oxides are known to disrupt cellular functions in bacteria, including cobalt oxide ${ }^{107}$, chromium oxide ${ }^{108}$, and silver oxide. Silver oxide is dependent on releasing silver ions into the surroundings and is not the active agent. Iron oxide and titanium oxide are not effective in preventing bacterial proliferation ${ }^{107,109}$. E. coli grew on corroded uncoated Stellite coupons at comparable amounts to the uncoated stainless-steel coupons, further suggesting that iron oxide would not hinder bacteria growth. Intentionally allowing the coatings to corrode could create a stronger antimicrobial surface. The corrosion of the Stellite could be reduced in the future by autoclaving the test area facedown on a smooth surface. Experimenting with other autoclaving settings may further reduce the corrosion, though this was not achieved with this study. Polishing the coatings 
was not attempted, though this could possibly be used to prevent corrosion. This would need to be done in such a way that the antibiotic properties are not disturbed.

The plasma-sprayed coatings were found to be surprisingly hydrophobic during the bacterial testing. This was not initially observed during the leaching tests, likely because they were fully immersed in water in that experiment. When the bacterial culture was pipetted onto the coating, a bead would form on most plasma-sprayed coatings, as seen in Figure 52. If the culture was dropped from a height of approximately $2 \mathrm{~cm}$, the bead would bounce on the surface. This was especially noticeable during the pilot studies when smaller volumes of culture were tested $(20 \mu \mathrm{l}$ versus $50 \mu \mathrm{l}$ used in the final design).

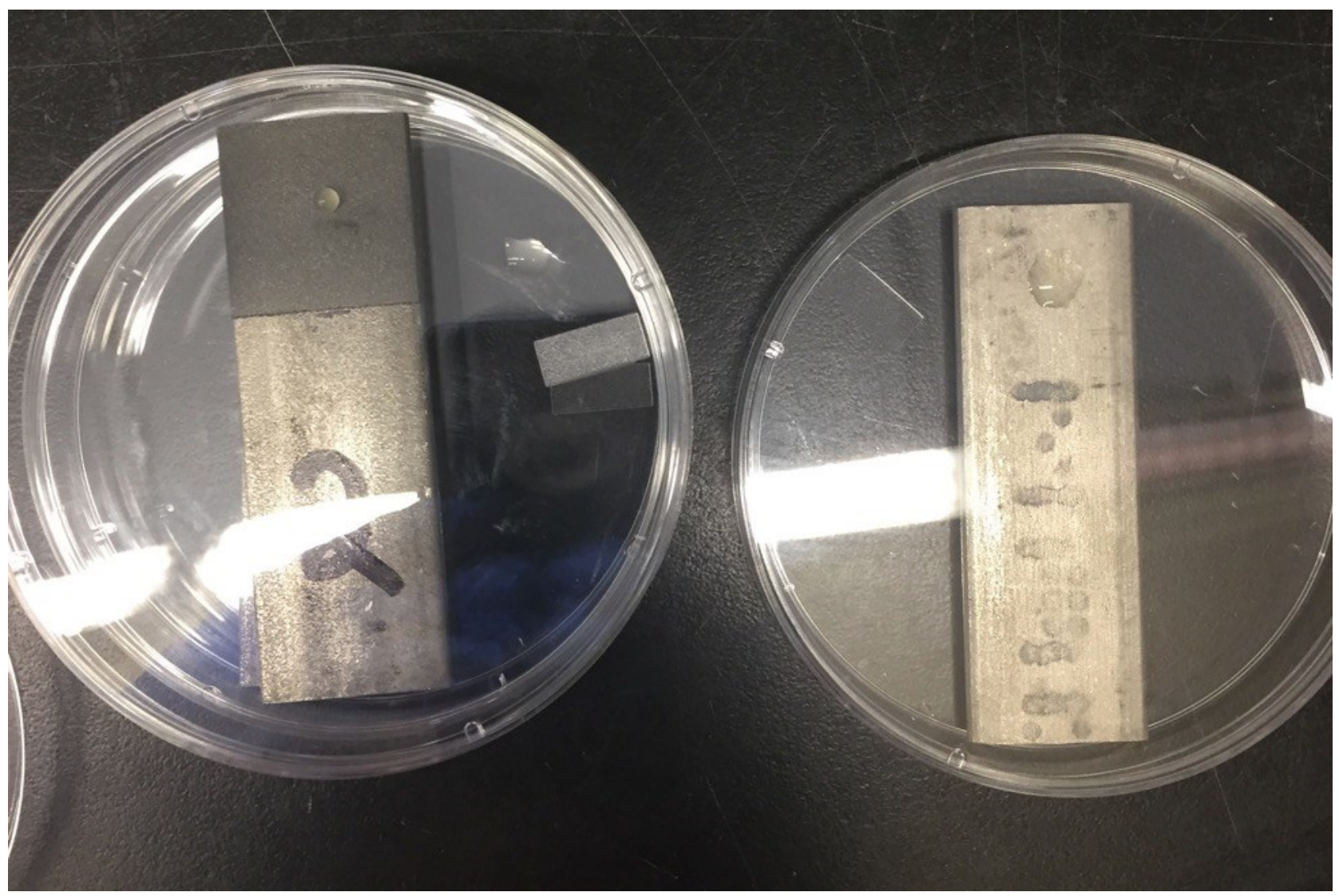

Figure 52: $20 \mu$ l of bacteria culture on a 2\% silver coating (left) versus an uncoated 316L steel coupon (right). This demonstrates the hydrophobic properties of the coating 
When initially testing the bacterial growth, the culture was allowed to first dry on the surface of the coupon and then left in the incubator for a period of 72 hours, and no water was originally added to the container. This was done at the recommendation of Dr. Wong, as this strain of bacteria was expected to be able to survive on the surface. The initial runs of the test failed to yield any successful colony formations, even on the control surfaces known to allow for bacterial growth ${ }^{100}$. The procedure was repeated with shorter incubation periods of 48 and 24 hours without success. The process was repeated without allowing the culture to dry on the surface and also including $1 \mathrm{ml}$ of sterile water in the container to keep the inside of the container moist. This was done with both the uncoated stainless-steel and Stellite coupons and the bacteria proliferated. This method was justified by the generally aquatic conditions seen in food processing plants and inside the human body. The bacteria were found to grow if the culture was still in a liquid phase after incubation. On occasion, some cultures would dry out despite having sterile water added to the container. This appeared to happen most frequently in petri dishes where some of the water would become trapped under the coupon. When moving the dishes, great care was taken to keep the water from adhering to the coupons. During the rinsing phase, one of the $5 \%$ samples was observed to have dried out, and a "D" was marked on the agar plate to denote this. This was one of the $5 \%$ plates that showed no bacterial growth.

Despite repeated attempts, bacteria would not initially grow on the surface of the $0 \%$ silver plasma-sprayed coating. Since this coating was Stellite on Stellite, there was an expectation for bacterial growth to occur. The uncoated Stellite coupon was found to allow for bacterial growth at levels comparable to the stainless-steel coupons. There was reason to believe that there was some sort of contaminant in the coating left from the 
manufacturing process that was killing the bacteria. This was unconfirmed by the SEM, but following a cycle in an ultrasonic cleaner, the $0 \%$ silver coatings yielded bacterial colonies in quantities similar to the uncoated Stellite coupons, so this cleaning method was used in the final iteration of the experiment.

One other observation made was that the culture would sometimes change color over the course of the first incubation period, especially on samples that dried out. The culture would change from a slightly opaque yellow-brown to a darker red-brown. It is unclear what the cause of this color shift is, but it was found only on plasma-sprayed coatings that did not experience bacterial growth. Figure 53 is an example of this. The color could potentially come from the oxidative layer formed in the Stellite, but this would not explain why it was not found on the uncoated Stellite coupons. The oxidative layer did not appear to hinder bacterial growth, as evident by the proliferation of bacteria in this group relative to the uncoated stainless-steel group.

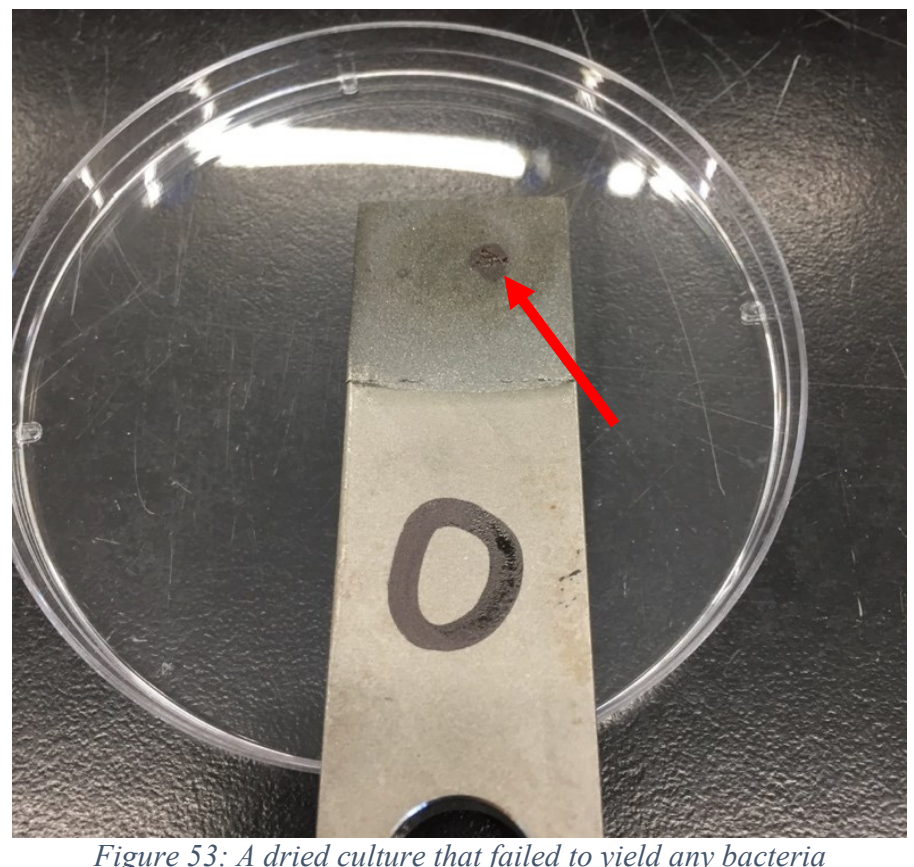

Figure 53: A dried culture that failed to yield any bacteria 
During the rinsing process, not all of the solution was removed from the coupon. The coupons were gently shaken to loosen as much solution as possible, but approximately 50-100 $\mu 1$ would remain (Figure 12) on each coating. This amount remained relatively consistent and is not considered to be a cause for variance.

When quantifying the results, some estimations needed to be used. Bacterial colonies were defined as circular structures with defined edges. In many cases, these colonies would grow into each other, blurring the boundaries between them. A best effort was made to distinguish how many colonies were part of a cluster, looking for boundary lines between previously separate colonies. Some of these were not possible to determine, so an estimate was made depending on the size of the cluster relative to the size of nearby colonies. The uncoated stainless-steel group, saw large clusters covering significant portions of the plate. This made quantifying the growth on these plates extremely difficult, as the area of these large clusters likely stems from how the solution was spread over the plate. A best effort was made to evenly spread the diluted solution with sterile beads, but there was likely some variance stemming from this. Quantifying the total area of these clusters would therefore produce results not reflective of the quantity of bacteria present after incubation.

\subsubsection{Uncoated Stellite vs 0\%}

The uncoated Stellite was found to harbor a significant quantity of bacteria, averaging 1087 colonies per plate. This is significantly greater than what was found during the dilutions testing. A dilution of $10^{-4}$ of solution taken from an uncoated Stellite coupon grew 317 colonies, which were rather small and scattered (Figure 13). The reason for this overall increase in colony count is not fully understood. A different vial of culture was used 
for the dilution test than the main trial, otherwise both procedures was identical. The increase in bacteria count was found in the stainless-steel group as well.

The uncoated Stellite was found to grow significantly more bacteria than the $0 \%$ silver plasma-sprayed coating. This is surprising, as the two have identical compositions, previously confirmed via SEM backscatter spectroscopy. The surface characteristics between the two are drastically different, and it is speculated that some of the bacteria could have been trapped in the crevices of the plasma-sprayed coating. During the incubation phase, the bacteria could have settled on the surface of the coating and were not fully removed during the rinsing process. The relatively smooth surface of the uncoated coupons would likely not trap bacteria. This test confirmed that bacteria can survive on the surface of plasma-sprayed Stellite.

\subsubsection{2. $0 \%$ vs $5 \%$}

The 5\% silver plasma-sprayed coating has a significantly smaller amount of bacterial growth than the $0 \%$ silver plasma-sprayed coating. On average the $5 \%$ group saw $60 \%$ fewer bacterial colonies than the $0 \%$ group. When calculating the average of the $5 \%$ group, the dry specimen was not considered but the plate with no growth was. This can be considered an outlier, and when it is removed the average is 240.25 colonies per plate, which is still less than half of the $0 \%$ silver group ( 525 colonies per plate). The three major differences between these groups were the incubation method, substrate material, and silver present in the coating. The uncoated stainless-steel was incubated in petri dishes, whereas the uncoated Stellite was incubated in tip boxes. The two groups saw comparable bacteria growth, with the stainless-steel plates showing fewer countable colonies but five out of six saw large amalgamations of colonies. The incubation containers are unlikely to have 
influenced bacteria proliferation, as both uncoated materials are known to harbor bacteria growth and a positive yield was found ${ }^{100}$. The similar levels of bacteria growth also indicate that the substrate material did not significantly influence the results between these two groups. Furthermore, when analyzed by the SEM elevated levels of iron were not found on the surface of any of the plasma-sprayed coatings, showing that the substrate materials did not find a way to the surface during the manufacturing process. The only significant difference between these coatings was the silver added to the $5 \%$ coating.

As seen in the SEM images of the 5\% silver coating, the regions of silver are largely scattered across the surface randomly (Figure 19D). Comparing the results of the $0 \%$ silver coating to the 5\% silver coating, it is likely that if the silver present is responsible for inhibiting the bacteria, then only bacteria that came into direct contact with the silver was killed. This is further backed by the results of the leaching test, where no detectable levels of silver particles were found in the water around the coating. The only way for the silver to interfere with the cellular functions of the bacteria would be for the bacteria to grow directly on the silver surface. If a bacteria colony started on the Stellite surface and proliferated outward, it is currently unclear what would happen if it came into contact with silver. It is possible that only those particular bacteria cells would be killed, or the entire colony would be killed off. This could be investigated using fluorescent labelling of viable bacteria but was not performed in this study. Looking at the drastic reduction in colony counts between the $0 \%$ silver and $5 \%$ silver groups, along with the relatively small area covered by silver, it can be speculated that any bacteria colony that comes into contact with a silver region will not survive. This would explain why some bacteria still survived, as there are a number of spaces devoid of silver where colonies could form. Further 
optimization of the plasma-spray process could be performed to achieve a wider distribution of silver on the surface.

\subsubsection{3. $0 \%$ vs $2 \%$}

The $2 \%$ silver plasma-sprayed coatings had a significantly different result from both the $0 \%$ and $5 \%$ silver coatings. Only one of the six plates had any colonies on it, and there were only two present. This would suggest that the $2 \%$ coating was effective in killing almost all bacteria on the surface, but this is contradicted by the results of the $5 \%$ coating. The only difference between the $2 \%$ and $5 \%$ coatings was the amount of silver in the

coating material, which was the only non-bioinert compound used. The possibility of human error always exists, but this is an improbable cause for this discrepancy. Testing was done on the $2 \%$ and $5 \%$ groups on the same day, and great care was taken to process all samples identically. A human error could have resulted in one of the plates being off, but errors occurring on every $2 \%$ plate and not the others are unlikely. There was concern that some unobserved contaminant from the manufacturing process or the environment was causing cell death on the plasma-sprayed coatings, since bacteria was not initially proliferating on the $0 \%$ silver coating, and it could be possible that the ultrasonic cleaning did not fully loosen this from the $2 \%$ silver coating. This would not explain why the other plasma-sprayed coatings harbored bacteria growth, but it was a suspected issue. The $0 \%$ silver coating was able to grow bacteria on the surface only after being ultrasonically cleaned, suggesting that something was loosened from the coating. The $2 \%$ silver coatings were cleaned in the same batch as some of the $5 \%$ silver coatings and the uncoated 
stainless-steel coupons. There were no observed issues with the ultrasonic cleaner, running three consecutive cycles as expected.

A possible explanation for the $2 \%$ coating being more effective than the $5 \%$ coating is that the bacteria initially proliferated faster on the $2 \%$ coating, rarely coming into contact with a silver region. The colonies present would have amalgamated, forming a few large colonies. When this inevitably came into contact with silver, the cells on the silver were killed off. As these cells fell apart, silver was scattered to other cells in the colony. This would eventually lead to the death of the entire colony. By increasing the silver count in the $5 \%$ coating, colonies would be more likely to be killed off by the silver in the earlier stages, preventing mass conglomeration that could have occurred on the $2 \%$ coating. Though this would have killed off more bacteria at first, small colonies between silver regions could have survived until the plating process. This could explain the stark contrast between the $2 \%$ and $5 \%$ plate counts.

The effects of the silver could have also been influenced by the formation of silver oxide. Previous works done with silver as an active agent depended on silver ions to interfere with cell functions ${ }^{83,86}$, and silver oxide may alter the effectiveness. The SEM results do not specifically suggest the presence of silver oxide, however it does leave room for silver oxide. Testing for silver oxide and other silver-based molecules may yield a better understanding of the mechanism of these coatings.

The plating process used was not the most accurate method of testing, as it primarily depended on colony-forming units to be transferred to the plate. The dilutions were intentionally mixed to distribute these units as evenly as possible. That being said, some variance was expected. The effectiveness of the coatings would have been better assessed 
using a live/dead kit, where fluorescent-labeled proteins are added to discern between living and dead bacteria. This would have also been useful in mapping out how the bacteria are distributed in relation to the silver regions. This was beyond the scope of this study but could be useful in future characterization of these coatings. Alternatively, fluorescentlabeled bacteria could be tracked in real time to better understand their interactions with the coating materials.

When compared to previously documented coatings, only the $2 \%$ silver coating can be considered a success. The silver-containing coatings produced by Fielding et al. were able to kill almost all bacteria present ${ }^{71}$. The group tested with P. aeruginosa, whereas this thesis used E. coli. The use of only one bacteria strain limits the conclusions drawn from the study and testing with numerous pathogens should be done to prove efficacy. Furthermore, this thesis did not test the coatings on human cells. 


\section{Chapter 4: Sintered Coatings}

\subsection{Introduction}

Sintering is another potentially valuable method of producing coatings on alloys. Sintering is primarily performed to produce alloys ${ }^{87}$, however it can also be used to produce surfaces. Unlike plasma-spraying, the surface characteristics in a sintered material can be significantly altered depending on production methods ${ }^{61}$. One of the major drawbacks with sintering is that it is highly dependent on the melting point of the sintered material ${ }^{59}$. Plasma-spraying is largely unaffected by the melting points of the powdered materials ${ }^{58}$, allowing for silver to be mixed with cobalt and chromium. To circumvent this issue, multistage sintering was used. Silver was sintered onto a previous prepared sintered titanium coating. By altering the sintering conditions, materials can be made that are porous $^{61}$, increasing the effective surface area and allowing for potential drug delivery. Kennametal Stellite was more interested in plasma-sprayed coatings, so developing a sintered antibacterial coating would be focused on biomedical application. Titanium was used as a base material for the sintered coating instead of cobalt chromium. This was done to utilize the increased bone tissue integration associated with titanium oxide ${ }^{56}$.

Much like the plasma-sprayed coatings, the sintered coatings needed to show efficacy in antibacterial properties while maintaining structural integrity. The sintered coatings underwent largely identical testing as the plasma-sprayed coatings, with the exception of silver elution. In focusing on biomedical application, the primary target of this coating would be to prevent bacteria colonization on the surface of an implant rather than bacteria surviving in the surrounding fluid. 


\section{$\underline{4.2 \text { Methods and Materials }}$}

\subsubsection{Production}

For the production of the sintered coatings, only Stellite F75 test coupons were used. The sintering was performed in two stages, first with titanium powder, followed by an addition of atomized silver. This was done due to the significant difference in melting points between the two metals (approximately $960^{\circ}$ Celsius and $1670^{\circ}$ Celsius for pure silver and pure titanium, respectively). Ti-104 -325 mesh (99.7\% pure) titanium powder was used in the first stage, purchased from Atlantic Equipment Engineers. At -325 mesh, the titanium particles are no larger than $44 \mu \mathrm{m}$ in diameter. The titanium was formed into a compaction directly on the surface of Stellite coupons. A compaction was used as opposed to other methods, such as slurrying, to produce a porous structure. The silver was later added as a slurry with the intent to fill the spaces in the titanium. This was done to improve integration of silver into the titanium. Porous titanium on an orthopedic implant would have the added benefit of improved osseointegration due to an increase in surface $\operatorname{area}^{56}$. To perform the initial compaction step on the powder, a custom die (Figure 54) was machined from 4140 alloy steel at the Carleton University Mechanical and Aerospace Engineering Machine Shop. The punch used had a contact area of 1"x1.25" with rounded corners with a radius of 0.125 ". This was larger than the desired 1 "x 1 " area to ensure that there was a viable test area. The die was lubricated with Rexco Formula Five ${ }^{\circledR}$ Mold Release Wax to prevent the compaction from sticking to the die. This wax was reapplied after every third compaction produced. 


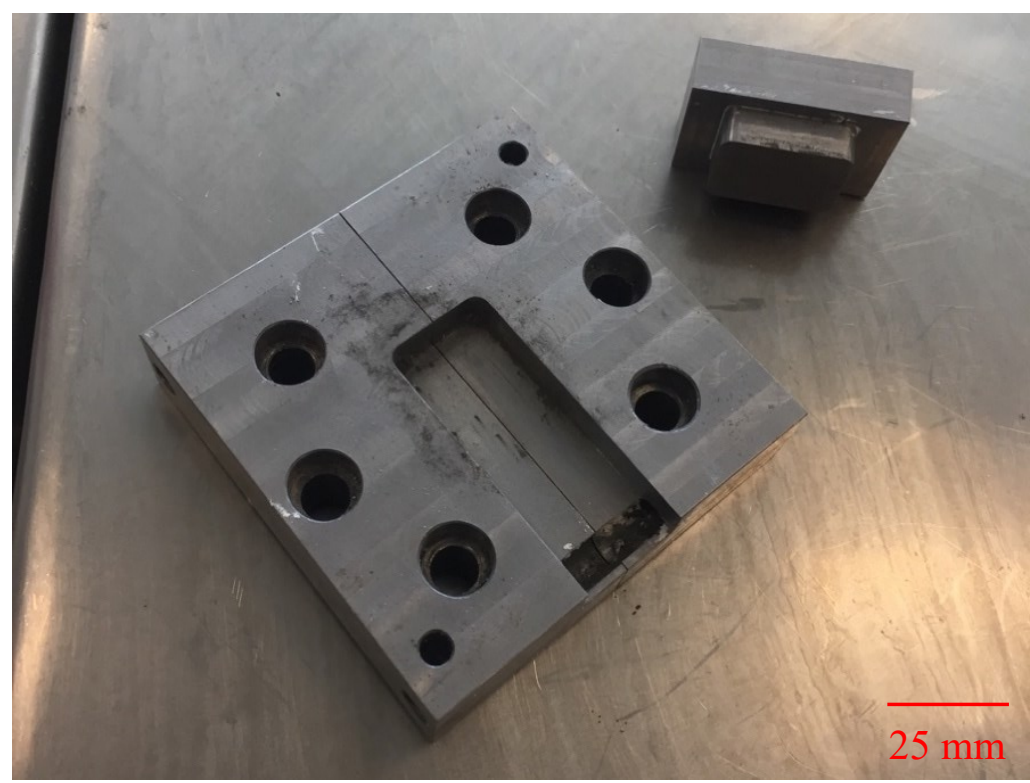

Figure 54: Custom die used for sintering compaction. A Stellite coupon was loaded into the die and had titanium compacted on top with a punch (top right)

The titanium was mixed with polyvinyl alcohol to keep the compaction together until it could be sintered. The alcohol would later burn off in the sintering oven. The mixture was placed inside of a plastic bag to reduce the amount of polyvinyl alcohol from evaporating when not in use. A layer of the mixture approximately 0.25 " thick was then applied to the coupon over the coating region, which rested in the die (Figure 55).

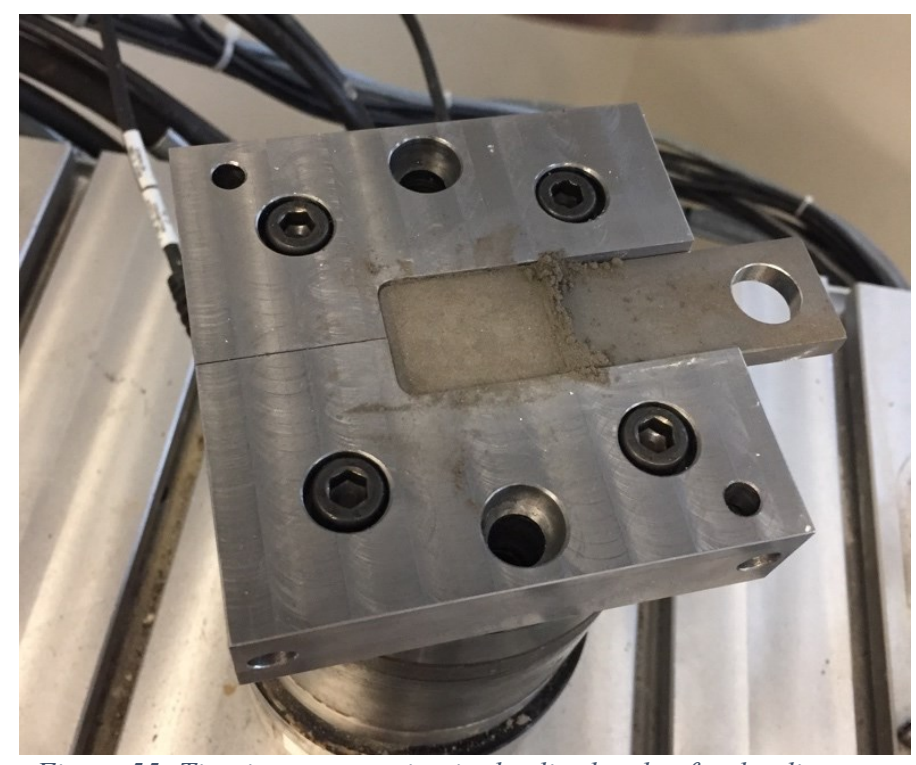

Figure 55: Titanium compaction in the die shortly after loading 
The punch was set in place to ensure there was enough mixture to cover the entire area. The mixture was only held in place on three of the four sides, so that lateral expansion of the powder on the free side would allow more complete compaction under load.

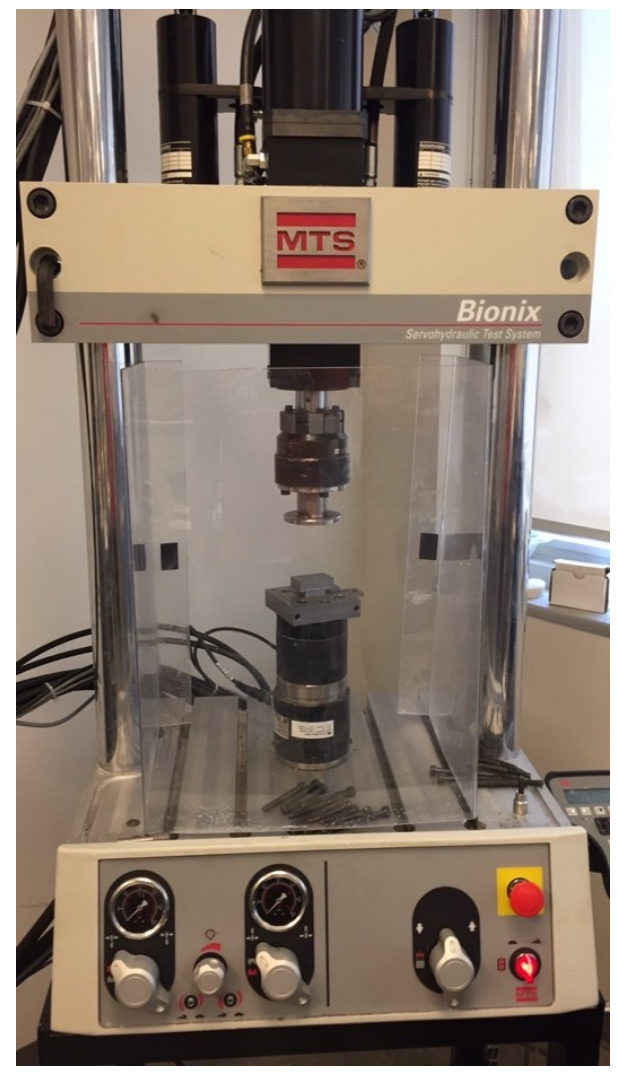

Figure 56: The MTS frame used for titanium compaction with the die and punch setup

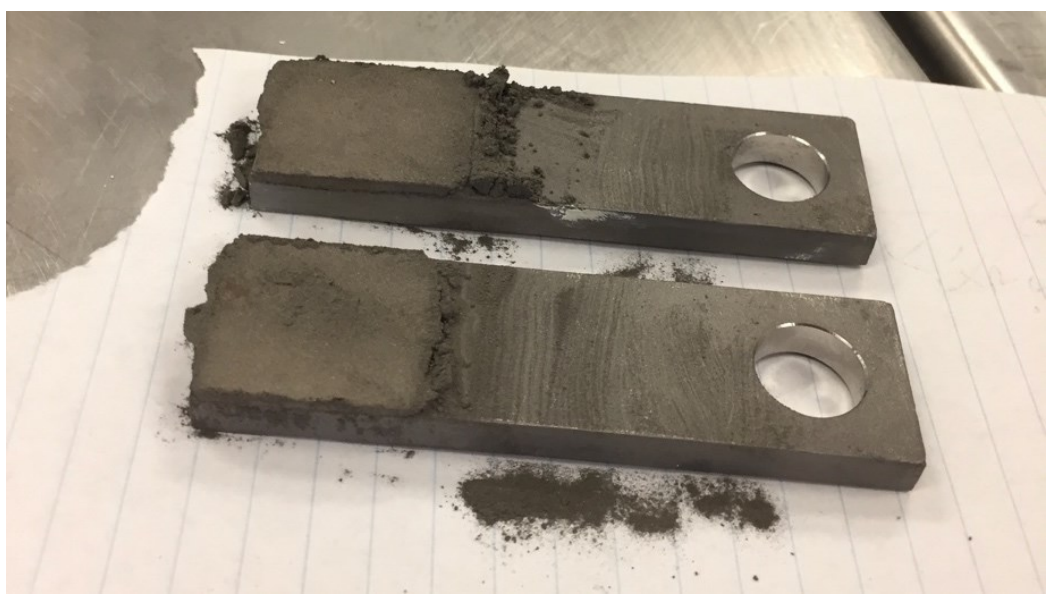

Figure 57: Titanium compactions after being removed from the die. Some loose powder would leak from one side of the compactions, and a best effort was made to brush it away without disturbing the compaction. 
The compaction was performed on an MTS 370.02 Axial / Torsional Load Frame (Figure 56). The die was secured in place, and the actuator was brought down manually. Once contact was established, the die was visually inspected to ensure proper alignment. The actuator was then brought down in $10 \mu \mathrm{m}$ intervals. The force applied was gradually increased up to $10 \mathrm{kN}$, visually inspecting the die after each $1 \mathrm{kN}$ increment. Once $10 \mathrm{kN}$ was reached, it was left for two minutes. The measured force gradually decreased as stress relaxation occurred, and the actuator was brought down another $10 \mu \mathrm{m}$ when the measured force dropped below $9.950 \mathrm{kN}$ to maintain a force close to $10 \mathrm{kN}$.

Once the time elapsed, the actuator was raised, and the die was removed. The coupon was then carefully removed from the die and placed to the side. Figure 57 shows coupons with compactions on them. The loose powder to the right of the compaction was removed as best as possible. Some remained after this process to keep from disturbing the compaction.

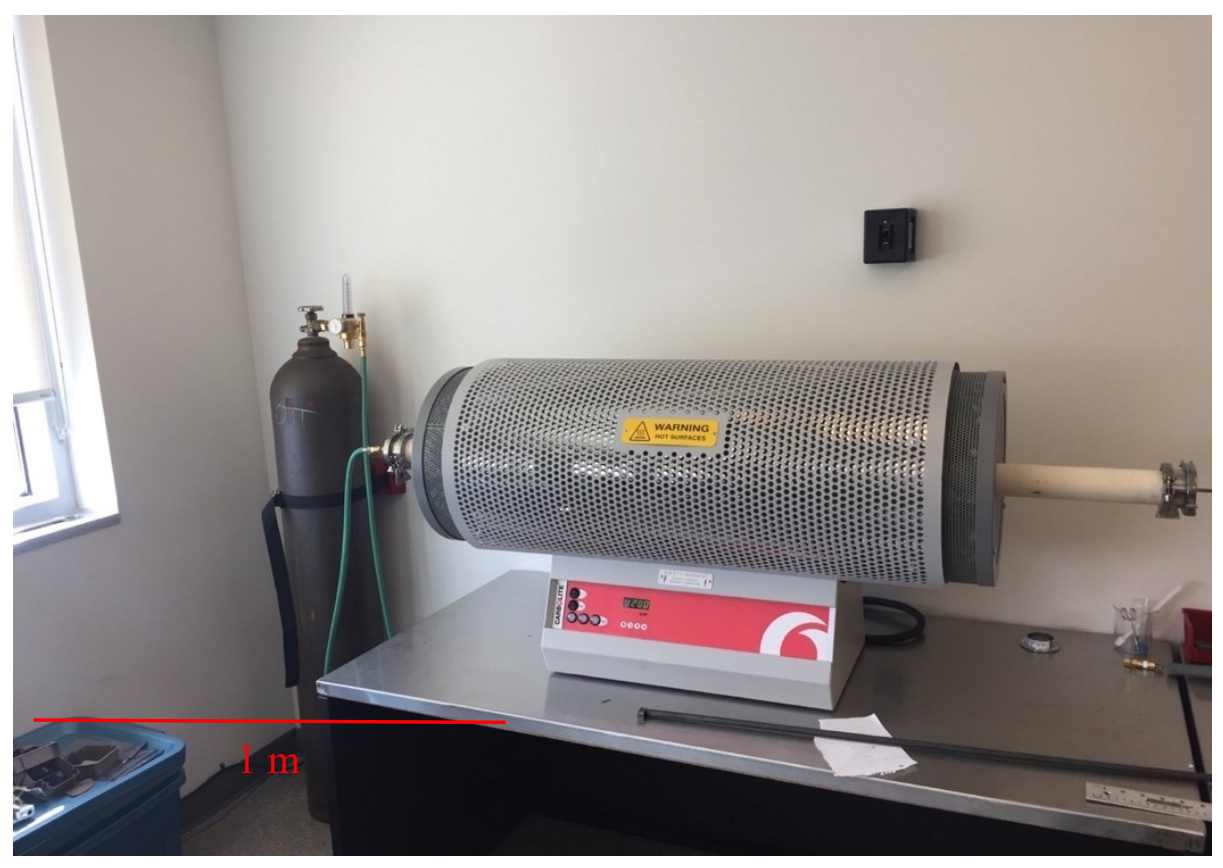

Figure 58: The tube furnace during a first stage sintering cycle 
The coupons were then loaded into a sintering oven in groups of up to seven at a time. A Carbolite STF $15 / 610$ tube furnace was used (Figure 58). The oven was set to $1200^{\circ} \mathrm{C}$ for a duration of 3 hours, not including the ramp up and ramp down. The oven took approximately one hour to reach the set temperature and 90 minutes to return to temperatures below $400^{\circ} \mathrm{C}$. To prevent oxidation of the titanium, argon gas was used as an oxygen displacer inside the oven. Once the coupons were loaded and the oven was setup, argon was allowed to flow at 10 liters/minute for two minutes to push all of the oxygen from the tube. This was then lowered to approximately 1 liter/minute to prevent oxygen from reentering the tube. The argon flow was cut off once the temperature in the tube went below $400^{\circ}$ Celsius, and the tube was allowed to return to room temperature overnight. The coupons were then removed the following day. Approximately half of the titanium coated coupons were left without any silver, and the other half were sintered again with silver. Some sintered titanium samples failed to compact properly, resulting in a coating that easily crumbled. These samples were not used in further testing, though one was later imaged with the SEM.

The same silver was used in the sintered coatings as in the plasma sprayed samples. The atomized silver powder was mixed with polyvinyl alcohol to form a thick paste, which was then applied to the sintered titanium coatings. The area was coated as evenly as possible, and the coupons were loaded into the furnace as soon as this was done. These coupons were sintered at $700^{\circ} \mathrm{C}$ for 2 hours. This was also performed with argon being used as an oxygen displacer, following the same procedure as the previous step. Figure 59 shows the coupons before and after the secondary sintering process. The coupons containing silver were each numbered in the order that they were placed in the oven. 


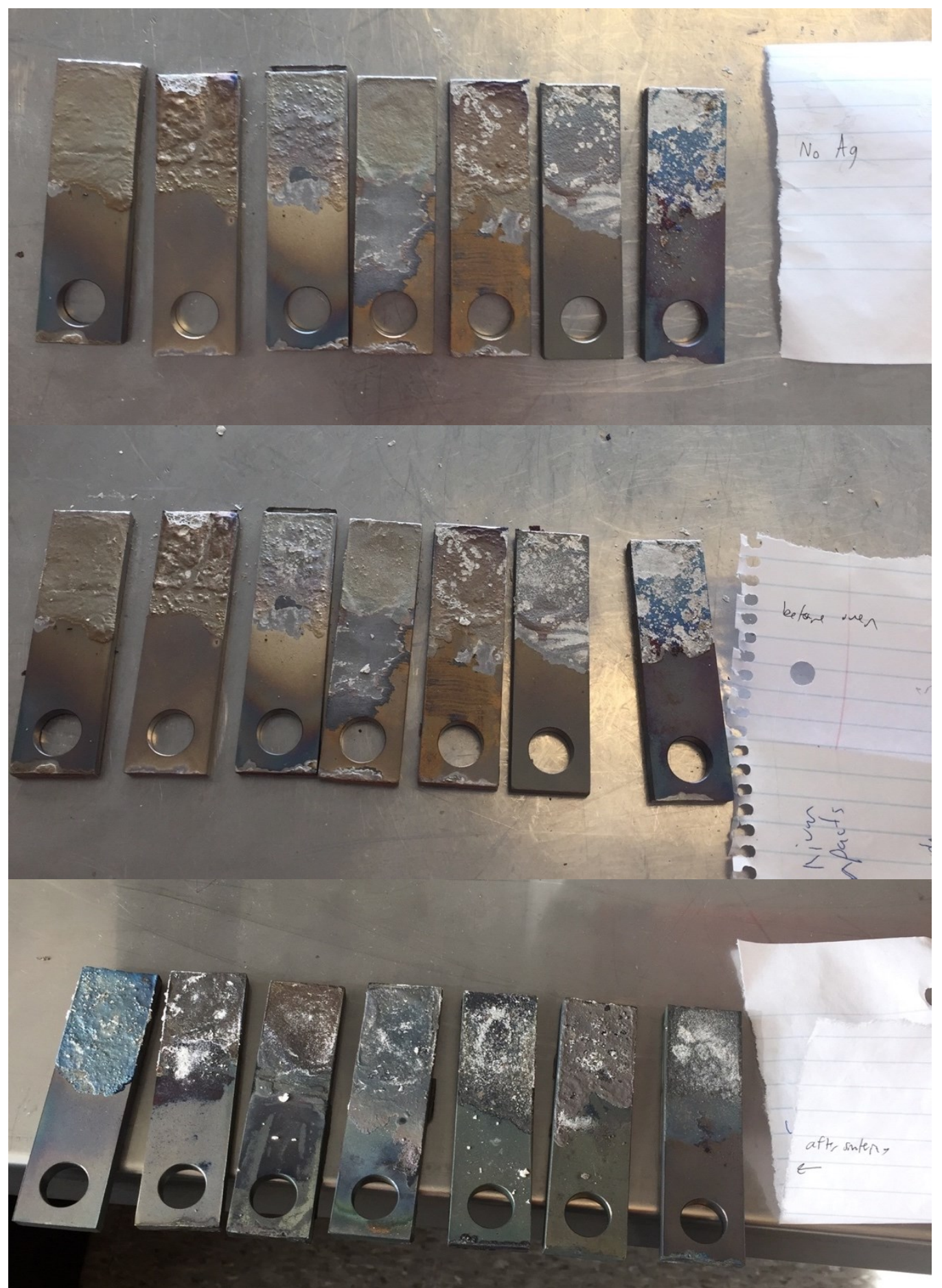

Figure 59: Top: Sintered titanium coatings, Center: the same coupons after adding the silver slurry, Bottom: Sintered titanium and silver coatings 


\subsubsection{Testing}

\subsubsection{Scanning Electron Microscopy}

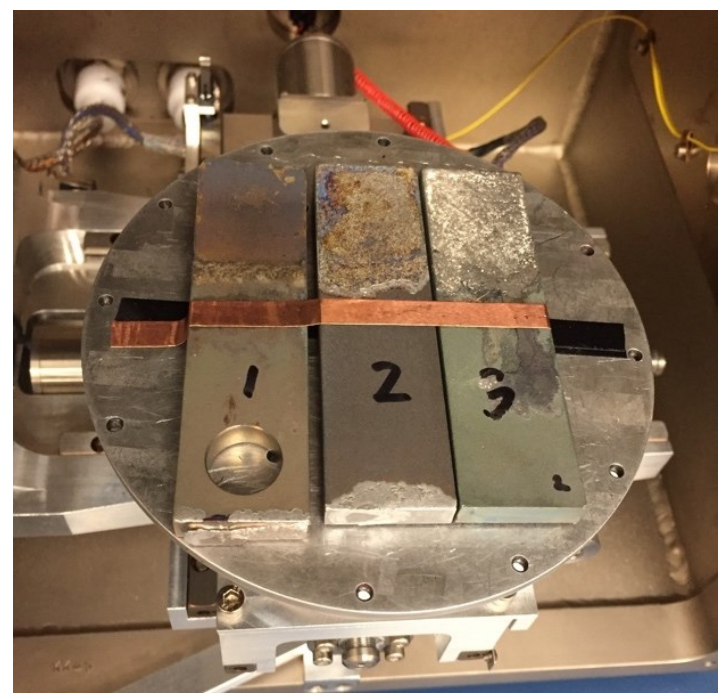

Figure 60: Sintered coatings before being loaded into SEM. An identical setup was used for the plasma-sprayed coatings. Left: failed compaction, Center: sintered titanium, Right: sintered titanium and silver

The method used to initially examine the sintered coatings via SEM was identical to the one used on the plasma-sprayed coatings. The coupons were loaded onto a disk which was set inside the SEM (Figure 60). Following the bacterial testing, the sintered coatings were reexamined to see if there were any changes to the surface from the bacterial testing process. Elemental maps were also produced of several elements of interest to better understand their distributions.

\subsubsection{Adhesion Strength}

Sintered samples were selected based on morphology and general appearance. 12 coatings of similar appearance were selected and paired. Figure 61 shows these coatings, where each column is a pair of coupons that were bonded together with epoxy. The pairs were also labeled numbers 1-6 from left to right. 


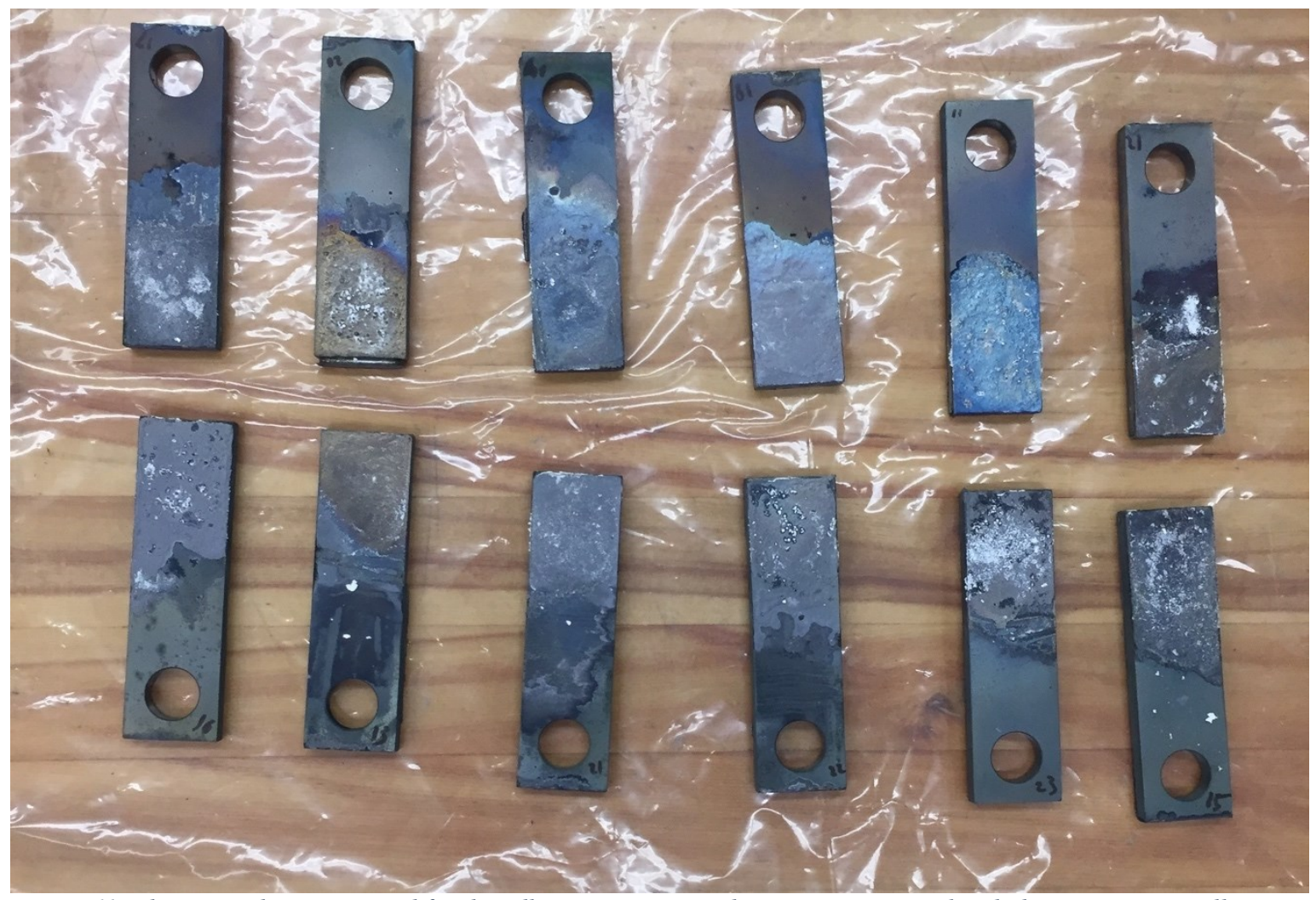

Figure 61: The sintered coatings used for the adhesion testing. Each coating was paired with the coating vertically adjacent

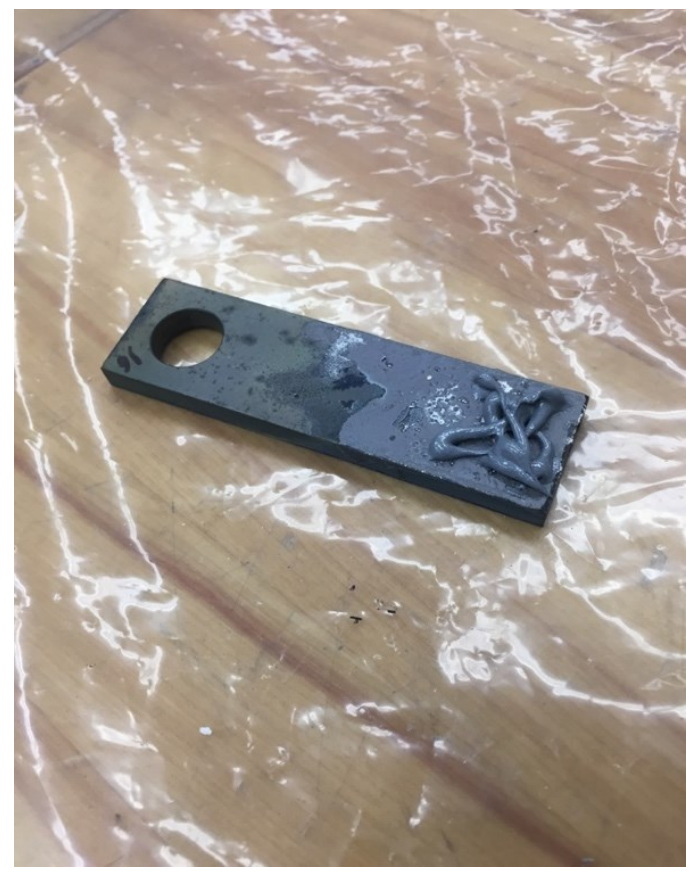

Figure 62: Sintered coating with applied epoxy 
The epoxy was applied to the sintered coatings in a similar manner as the plasmasprayed coatings. Figure 62 shows the epoxy applied to a sintered coating shortly before the second coating was added. The sintered coatings were measured to 1 inch and marked, as seen in Figure 63. The coatings had epoxy applied up to this mark to ensure a 1 square inch contact area. Any excess epoxy was removed before curing. The sintered coatings were bonded on a different day than the plasma-sprayed coating using a metal clamp. After cooling down, the pairs were loaded into the yokes (Figure 64) and then set into the MTS load frame (Figure 65). The same loading conditions were used on the plasma-sprayed coatings and the sintered coatings.

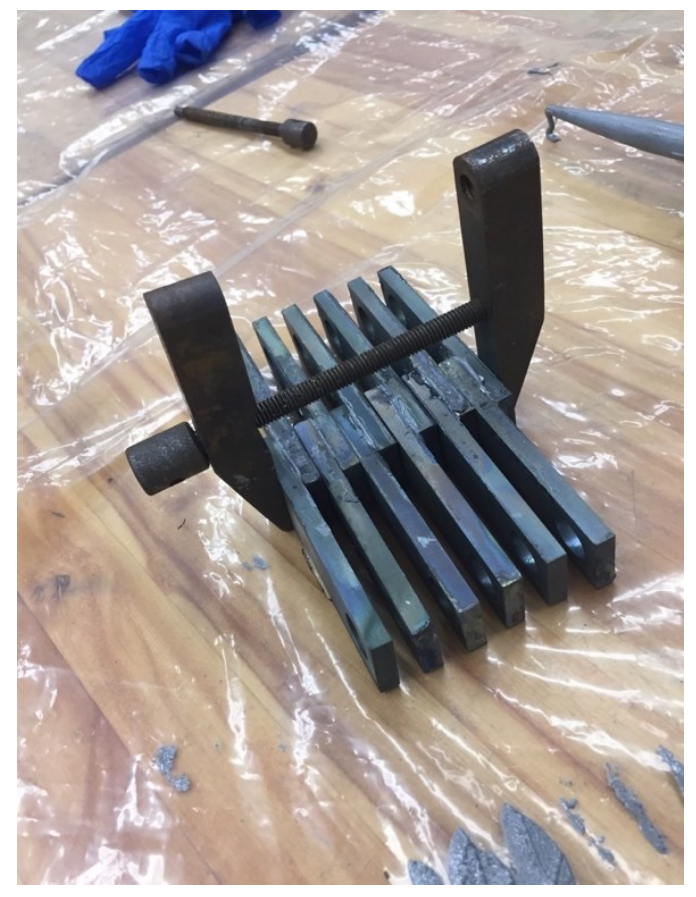

Figure 63: Sintered coupons clamped together before entering the furnace. Markings can be seen on the sides where they were measured to one inch. The epoxy was only applied to a one square inch area 


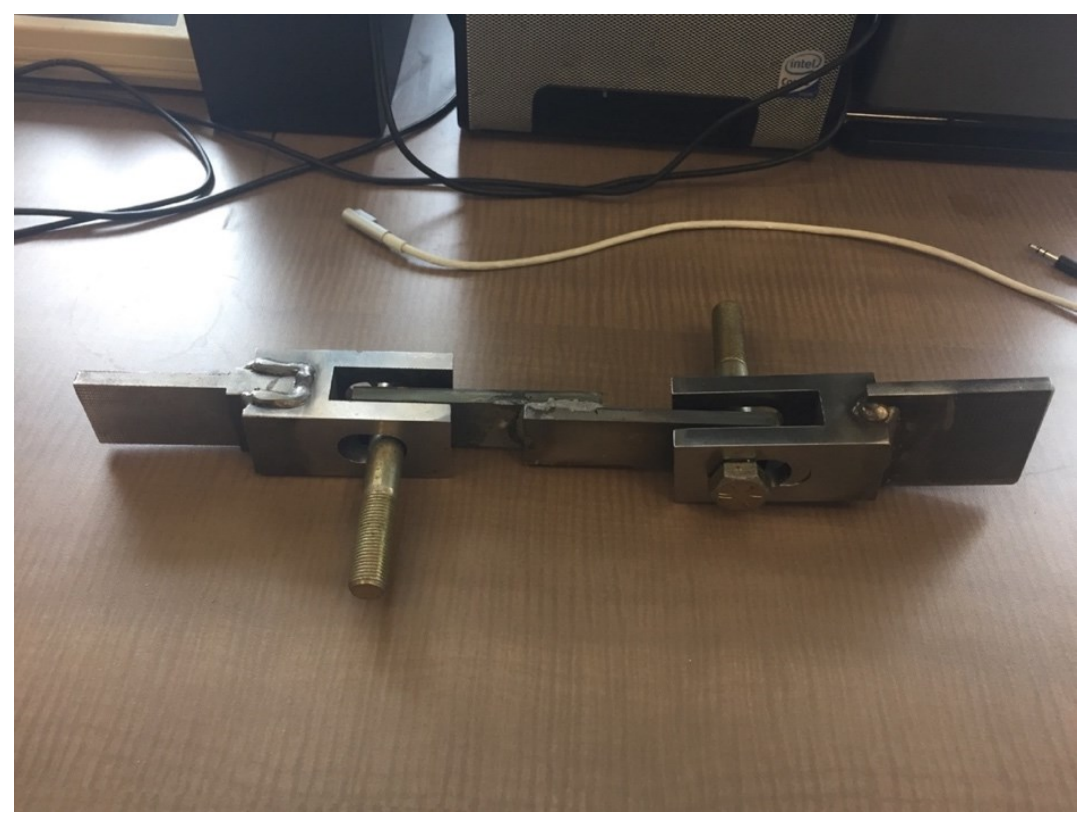

Figure 64: Sintered coupons set in yokes before being setup in the MTS frame. The same setup was used for plasmasprayed coatings except the 316 L coupons used 5/8" dowels instead of bolts

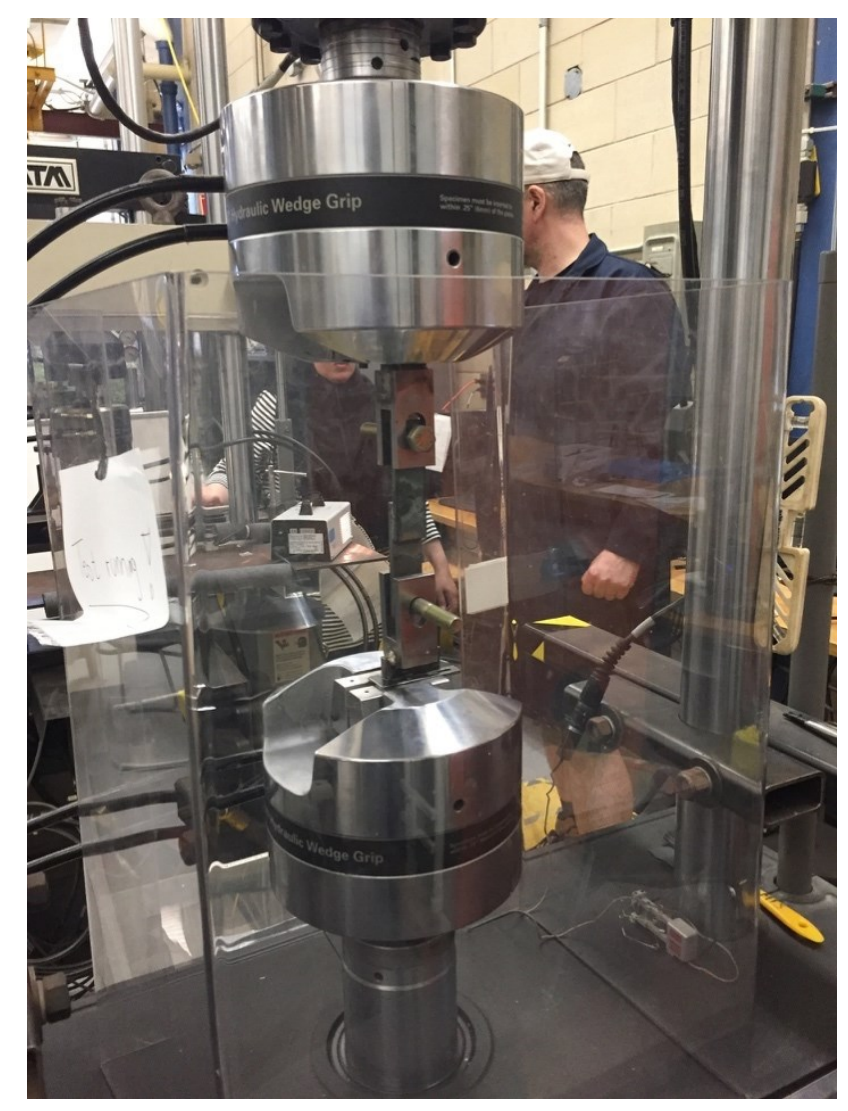

Figure 65: Pair of sintered coatings loaded into the MTS frame 


\subsubsection{Bacteria}

All bacterial testing was performed in an identical manner to the testing done on the plasma-sprayed coatings. All sintered coatings were on the longer Stellite coupons, so they were incubated in sterile pipette tip boxes.

\subsection{Results}

\subsubsection{Scanning Electron Microscopy}

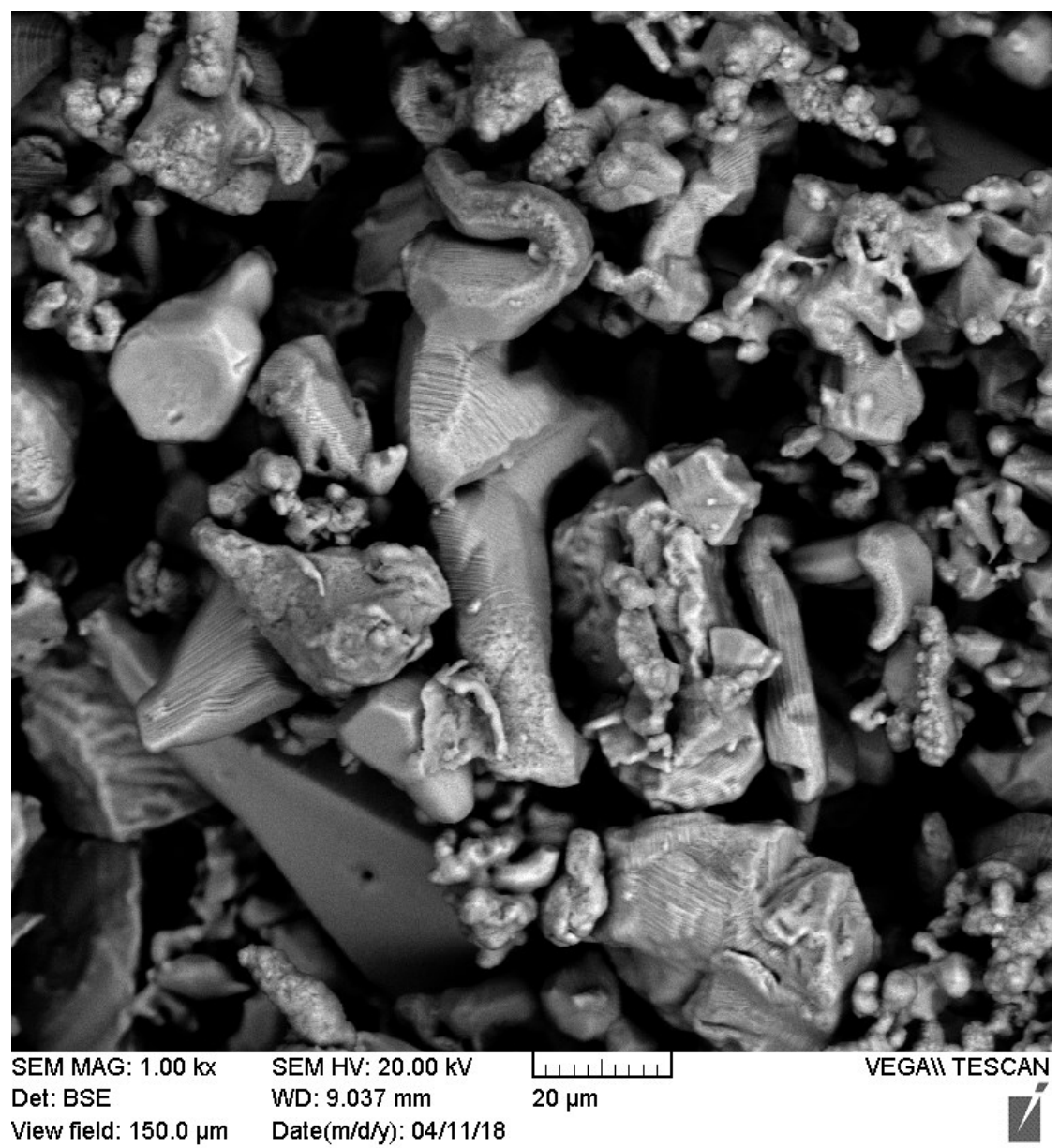

Figure 66: Failed titanium compaction at 1000x magnification, backscatter image

One of the unsuccessful titanium compactions was also imaged, as seen in Figure

66. The structure of this compaction is notably very loose and porous. The exact cause of this result is unknown, but there is a significant volume of void space in the structure. The 
microscopic structures in the compaction are very irregular and do not appear to follow any particular pattern. The structure itself is solid and rigid, though the image shows very small connections between particles. This would explain the fragility of the coating.

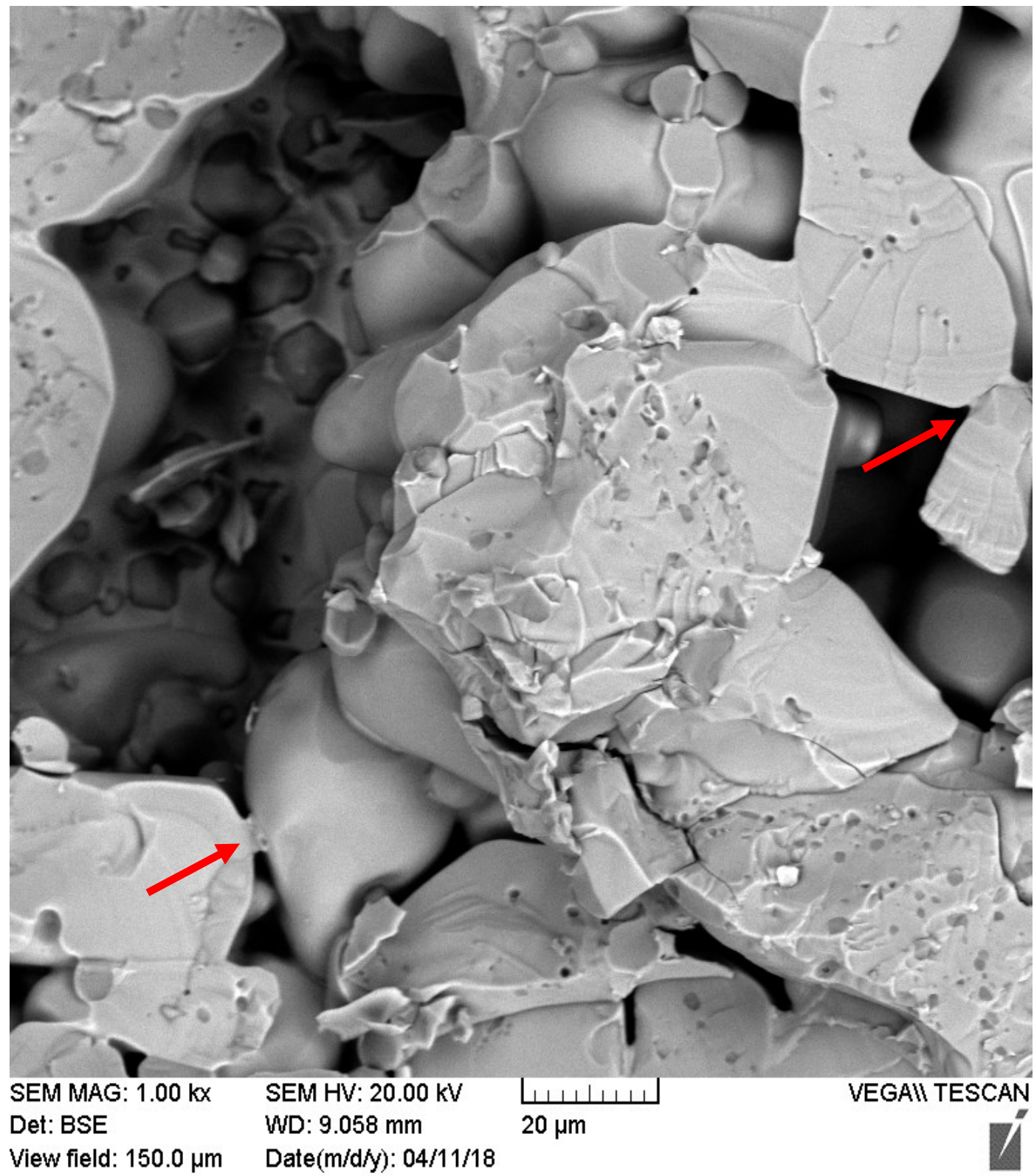

Figure 67: Sintered titanium at 1000x magnification. Some necks between titanium grains are marked with arrows

Figure 67 shows a magnified area of a sintered titanium coating that was considered to be successful. The structure of the coating is noticeably more porous than the plasma-sprayed coatings. The cavernous areas seen on either side of the image appear to be connected, with 
further pockets visible throughout the region. The titanium seen appears to be more crystalline in structure than the plasma-sprayed Stellite. Some areas of necking between particles are also noticeable in Figure 67 and have been noted with arrows.

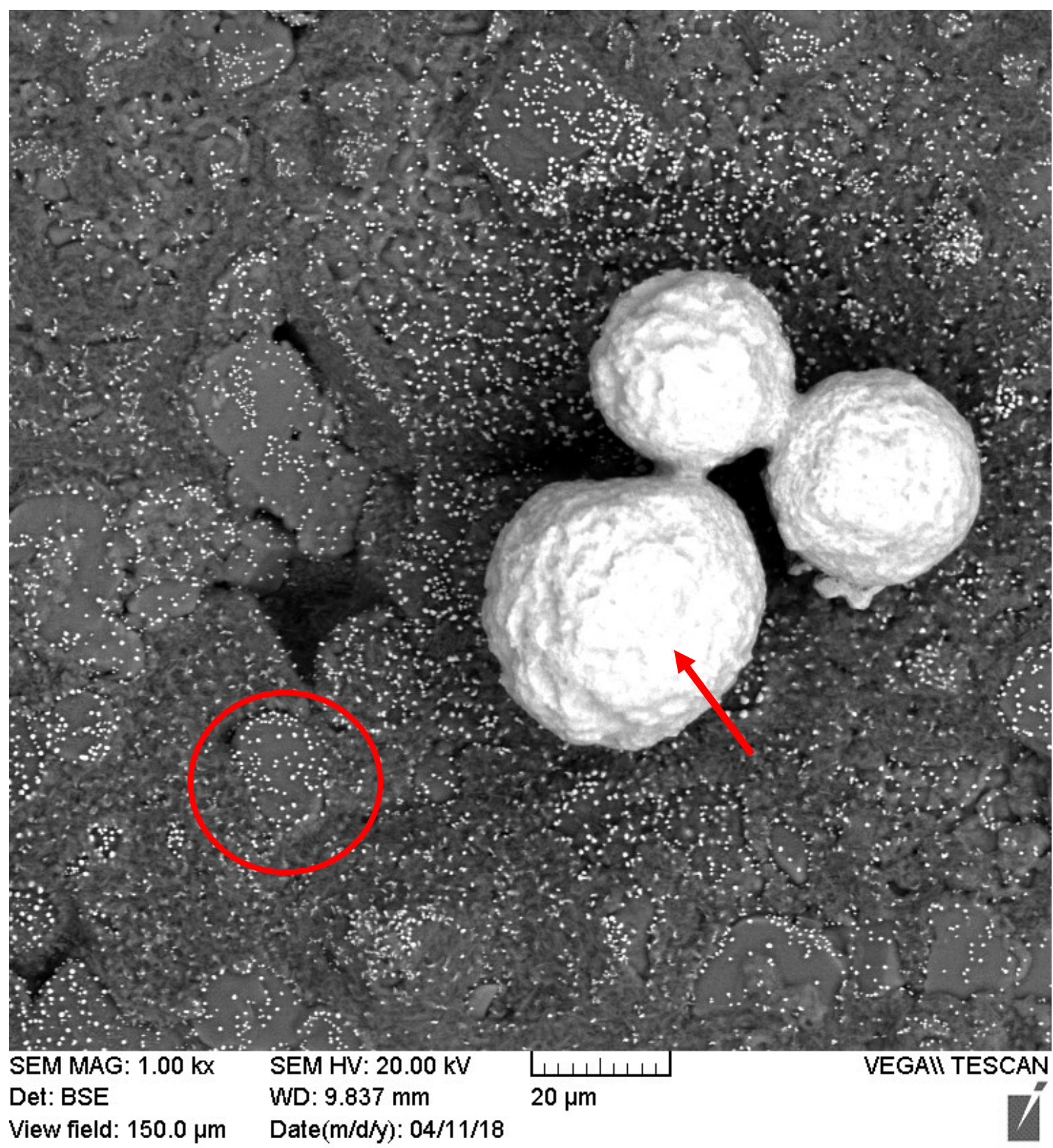

Figure 68: Sintered titanium and silver at 1000x magnification. The large globular structures (marked with an arrow) and small bright spots (circled in red) were identified as silver

Figure 68 is a similar scan to Figure 67 on a sintered coating containing silver. The titanium background appears to be relatively smooth, with small pockets forming with 
diameters of approximately 10-20 $\mu \mathrm{m}$. A number of small globular structures are visible on the surface, three of these can be seen in Figure 68. There are notable necks formed between them, showing that the sintering was effective in joining particles together. There are also a number of very small structures appearing on the titanium surface as well, appearing to be approximately $500 \mathrm{~nm}$ in diameter. These smaller objects are distributed relatively evenly across the surface of the coating. These structures appear significantly brighter than the background in the backscatter images. There is no visible neck formation between these, as most of these objects are too far apart to connect via sintering.

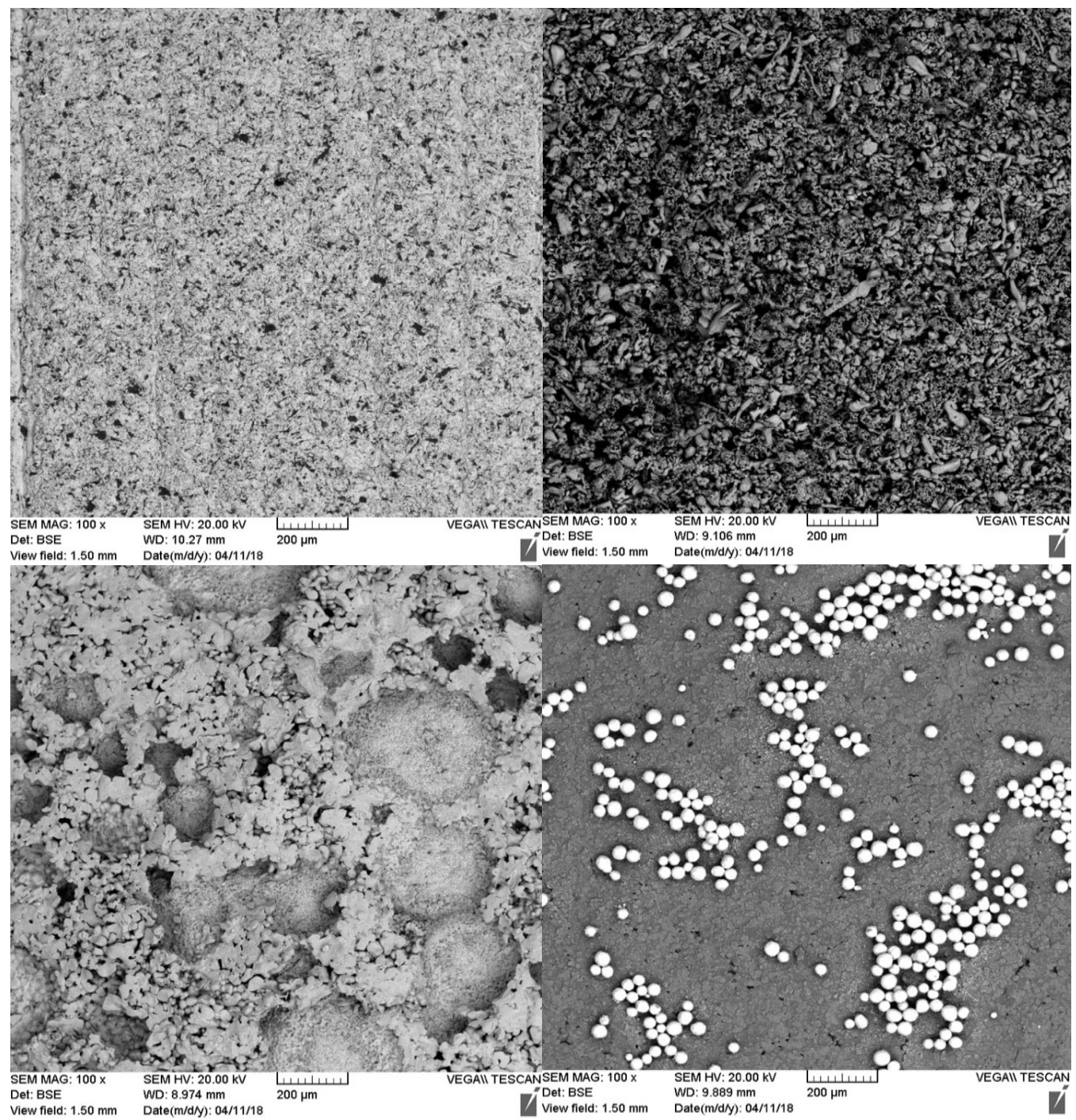

Figure 69: Top left: Base Stellite coupon, Top right: failed titanium compaction, Bottom left: successful titanium compaction, bottom right: successful titanium compaction with silver added. All are to 100x magnification 
Figure 69 is a comparison of the cobalt chromium coupon, unsuccessful titanium compaction, sintered titanium, and sintered titanium and silver coatings. At 100x magnification, and the looseness of the failed titanium compaction becomes apparent. When observed at this magnification, there are some significantly larger pockets in the sintered titanium coating (Figure 69 bottom left). The exact source of these are unknown, though it is possible that these were spaces once occupied by droplets of polyvinyl alcohol that burned off in the furnace. The coatings were sintered without any external pressure, so the titanium powder would not have filled these voids. The structure at the bottom of these pockets is not as porous as the surrounding area, but there appear to be small holes throughout these pockets.

When the sintered titanium and silver coating is viewed at 100x magnification, it is clear that there are a large number of bright structures on the surface, however it appears that they formed on the surface of the titanium in a single layer. These structures also appear to be resting on the surface of the titanium and are not embedded within it. They are approximately $20-40 \mu \mathrm{m}$ in diameter, which would be consistent with the silver powder used $^{110}$. The titanium in this coating is also noticeably less porous than the sintered titanium-only coating. 


Spectrum processing :
No peaks omitted
\begin{tabular}{l|ll}
\hline Element & Weight\% & Atomic\% \\
CK & 6.00 & 17.30 \\
OK & 10.89 & 23.59 \\
TiK & 81.73 & 59.12 \\
& & \\
Totals & 98.62 & \\
\hline
\end{tabular}

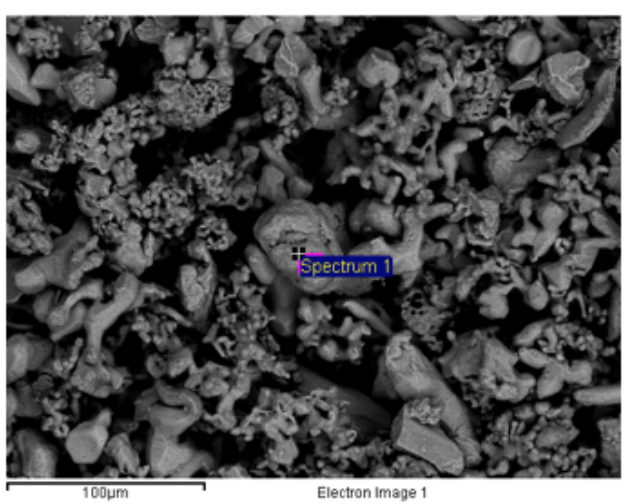

Comment: Unsuccessful titanium compaction

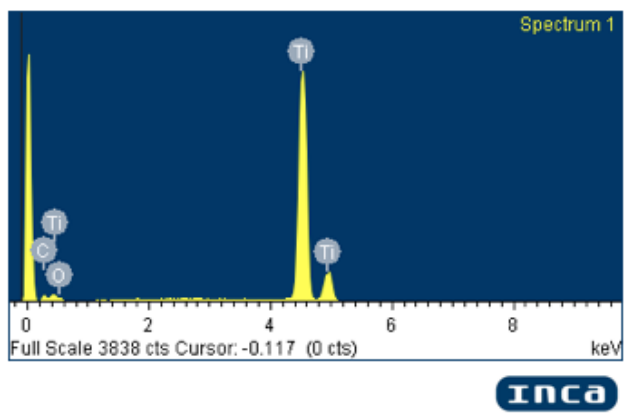

Figure 70: Point scan of unsuccessful titanium compaction

The unsuccessful titanium compaction was found to be comprised almost entirely of titanium (Figure 70 Figure 71). Both scans found large amounts of oxygen, particularly in the overall scan. This suggests that there was oxygen present during the sintering phase, which could have contributed to the overall structure. The larger scan also had a total count of $84.48 \%$, likely due to electrons becoming trapped in the small voids at the surface of the structure. 


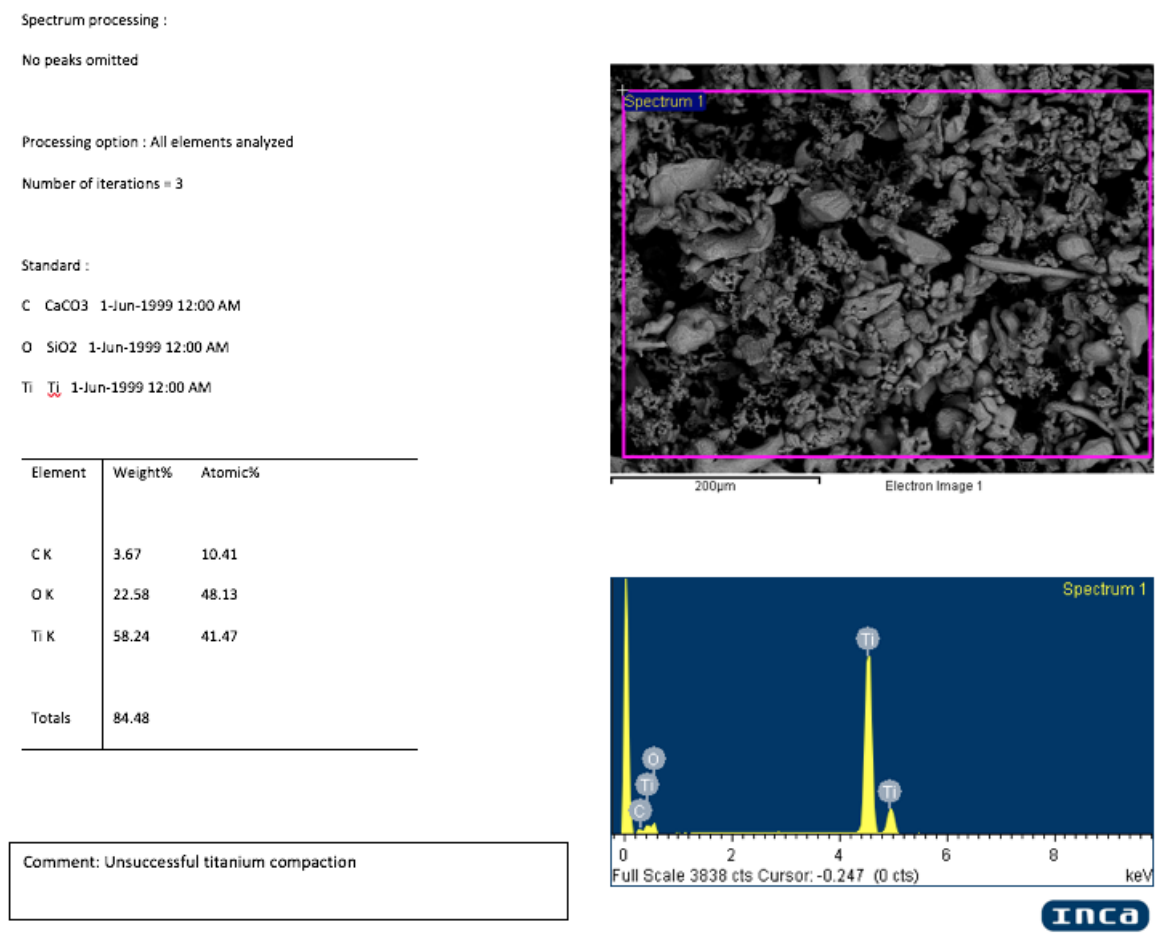

Figure 71: Larger scan of unsuccessful titanium compaction

Spectrum processing :

No peaks omitted

\begin{tabular}{l|ll}
\hline Element & Weight\% & Atomic\% \\
OK & 5.86 & 17.04 \\
TiK & 56.75 & 55.08 \\
CrK & 6.95 & 6.22 \\
Co K & 26.96 & 21.27 \\
Mo L & 0.81 & 0.39 \\
& & \\
Totals & 97.34 & \\
\hline
\end{tabular}
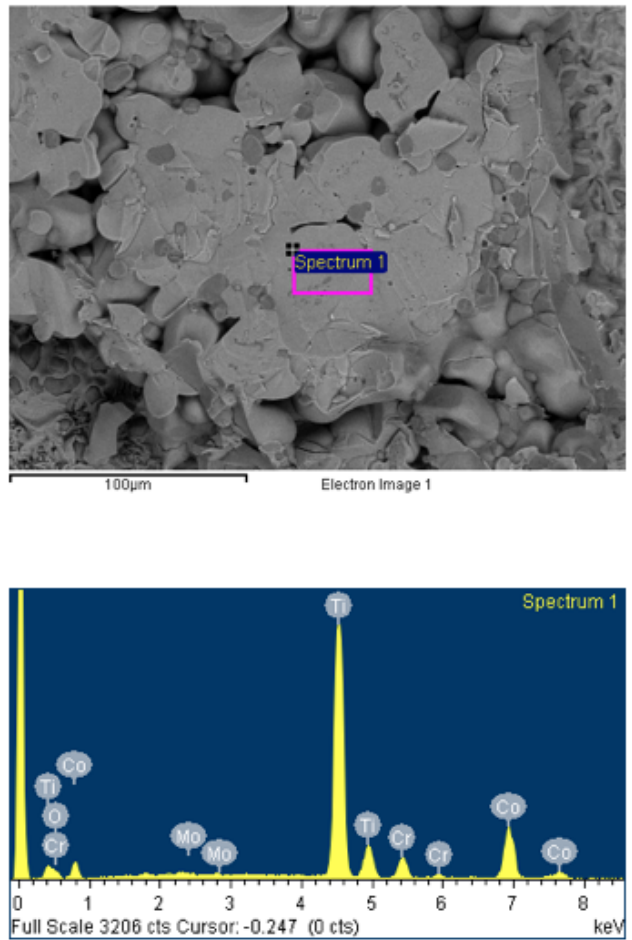

Comment: Sintered Titanium

Figure 72: Sintered titanium elemental makeup showing significant amounts of cobalt and chromium 
Figure 72 is a spectrum scan of a relatively flat region of the sintered titanium coating. The results show that this is predominantly titanium, at $56.75 \%$ by weight. Curiously, there is a large amount of cobalt, but not chromium. This does not appear to be Stellite, as there is little chromium relative to cobalt. During the sintering process, the substrate was observed to glow orange during the titanium sintering, and it is possible that some cobalt mixed with the titanium. This would not explain the relatively low chromium, which is seen throughout the brighter areas of the sintered titanium. A small amount of molybdenum is also present, likely from the substrate.

Spectrum processing :
No peaks omitted
\begin{tabular}{l|ll}
\hline Element & Weight\% & Atomic\% \\
N K & 13.60 & 25.70 \\
OK & 19.80 & 32.75 \\
TiK & 73.70 & 40.71 \\
Cr K & 0.66 & 0.34 \\
Co K & 1.15 & 0.51 \\
Totals & 108.91 & \\
\hline
\end{tabular}
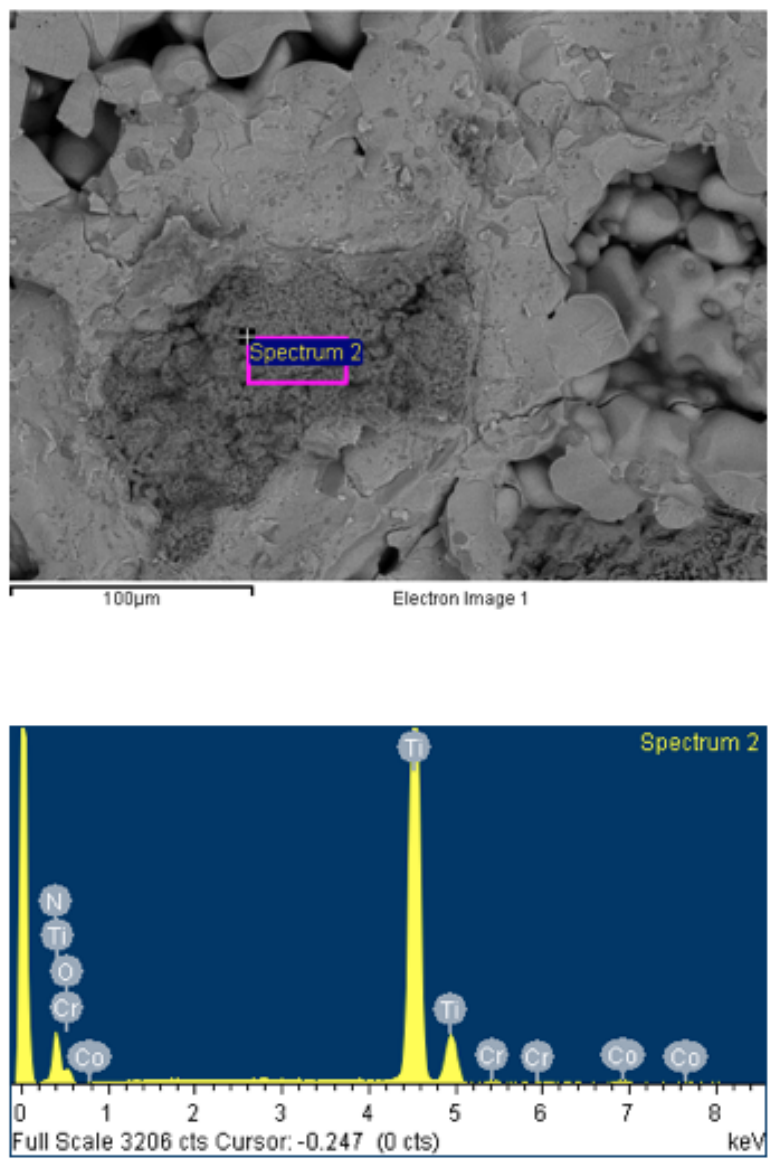
Figure 73 is another scan from the same coating, but from a darker, rougher region. This area contains a greater percentage of titanium than the nearby flat area, and relatively minute quantities of cobalt and chromium. There are also significant quantities of oxygen and nitrogen. There is approximately twice as much oxygen present in the darker region than the lighter one (30.1 atomic\% versus 17.5 atomic\% when normalized to $100 \%$ ). This would explain the difference in image intensity between the regions. The exact source of nitrogen is unknown, as polyvinyl alcohol contains no nitrogen. When the alcohol burned off, it is possible that it oxidized parts of the coating.
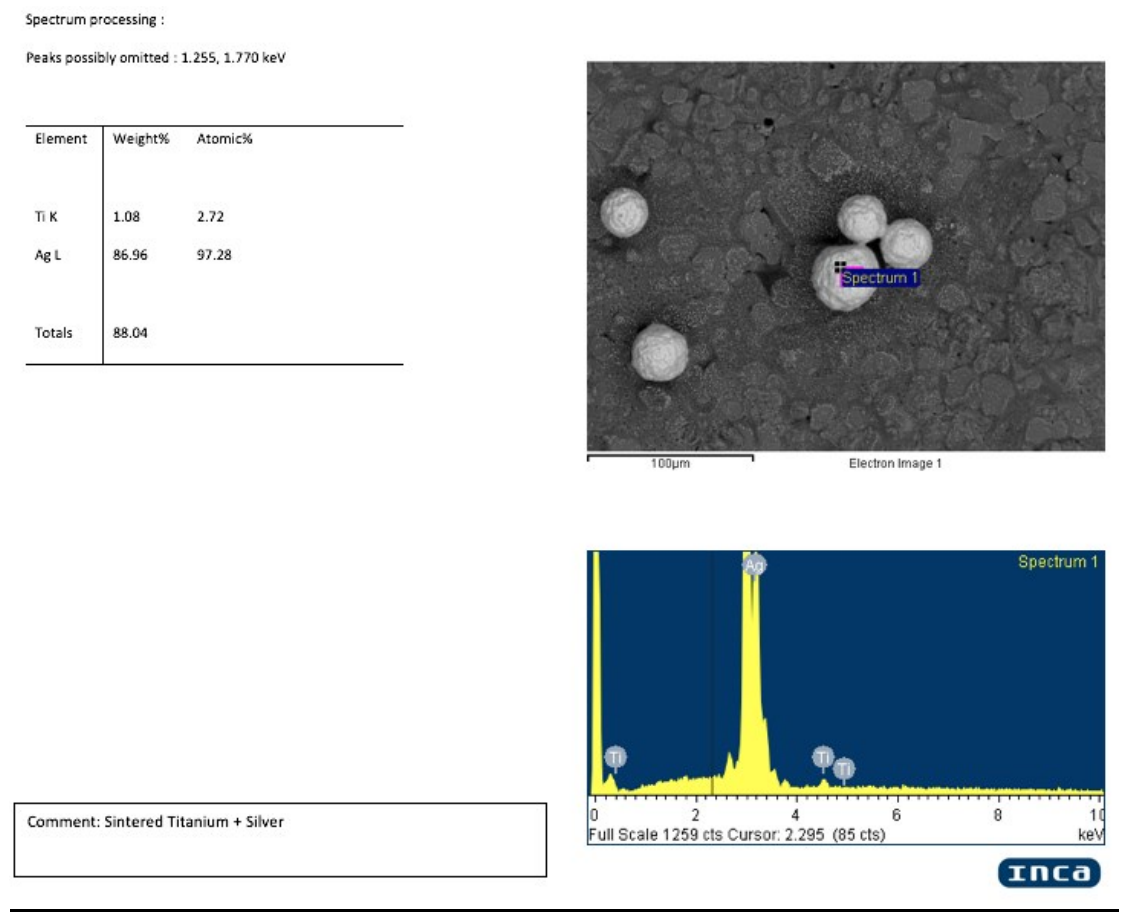

Figure 74: Elemental makeup of bright structures on sintered titanium and silver

In Figure 74, one of the large globular structures in the titanium and silver sintered coating was scanned. The results show that these are silver, containing only a small amount of titanium. 

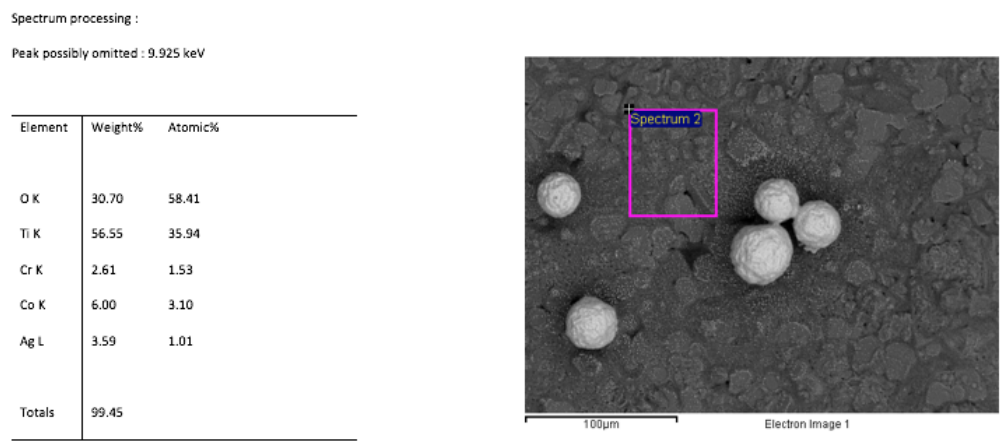

Comment: sample 3-2

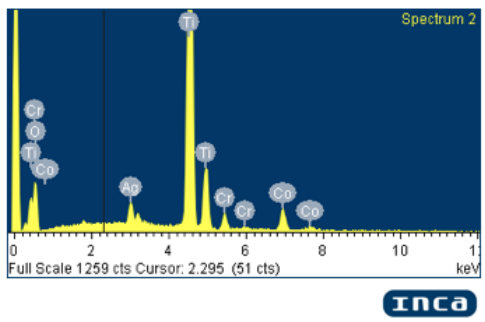

Figure 75: Elemental makeup of background of sintered titanium and silver, showing small amounts of silver

The surface of these coatings (Figure 75 Figure 76) are primarily titanium, with small amounts of chromium, cobalt, and silver. There is also a very large amount of oxygen, suggesting that the titanium oxidized even more during the second round of sintering. The amount of oxygen present on the surface is greater than any other surface tested in this thesis. The silver seen in Figure 67 has no oxygen detected, indicating that there is no silver oxide present on the large silver structures. The oxide presence on the background material cannot be specifically determined, as titanium, chromium, cobalt, and silver are all detected in these regions. The metals on the surface are all close in atomic number with the exception of silver. The brightness in the image is related to the atomic number, therefore titanium, chromium, and cobalt would all appear similar, and silver would be significantly brighter. It was assumed that the $500 \mathrm{~nm}$ bright structures found on the surface are comprised largely of silver but were too small for compositional analysis. 


Spectrum processing :
No peaks omitted
\begin{tabular}{l|ll}
\hline Element & Weight\% & Atomic\% \\
OK & 33.38 & 58.37 \\
$\pi$ K & 64.68 & 37.77 \\
Cr K & 2.17 & 1.17 \\
Co K & 4.29 & 2.04 \\
AgL & 2.56 & 0.66 \\
Totals & 107.07 & \\
\hline
\end{tabular}

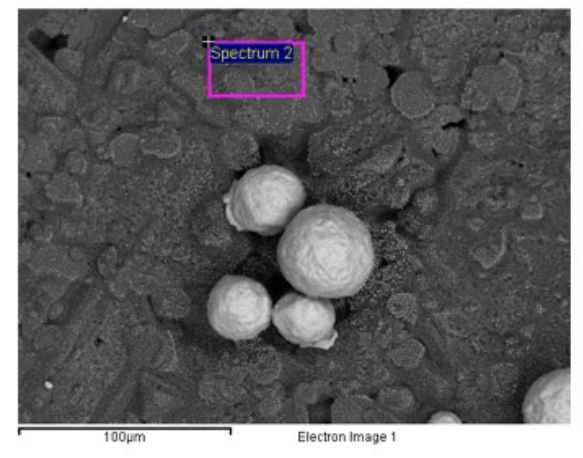

Comment: Sintered Titanium + Silver

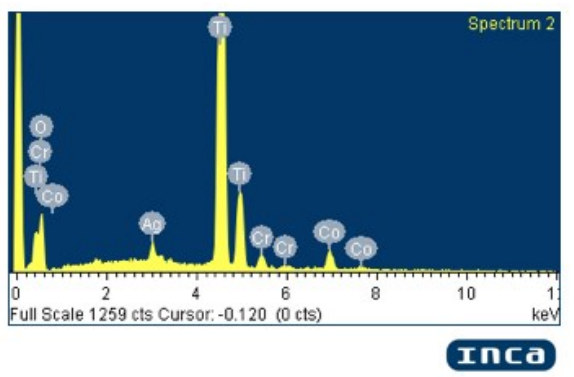

Figure 76: Elemental makeup of another region in the background of sintered titanium and silver, also showing significant amounts of silver

\subsubsection{Revisit After Bacteria Testing}

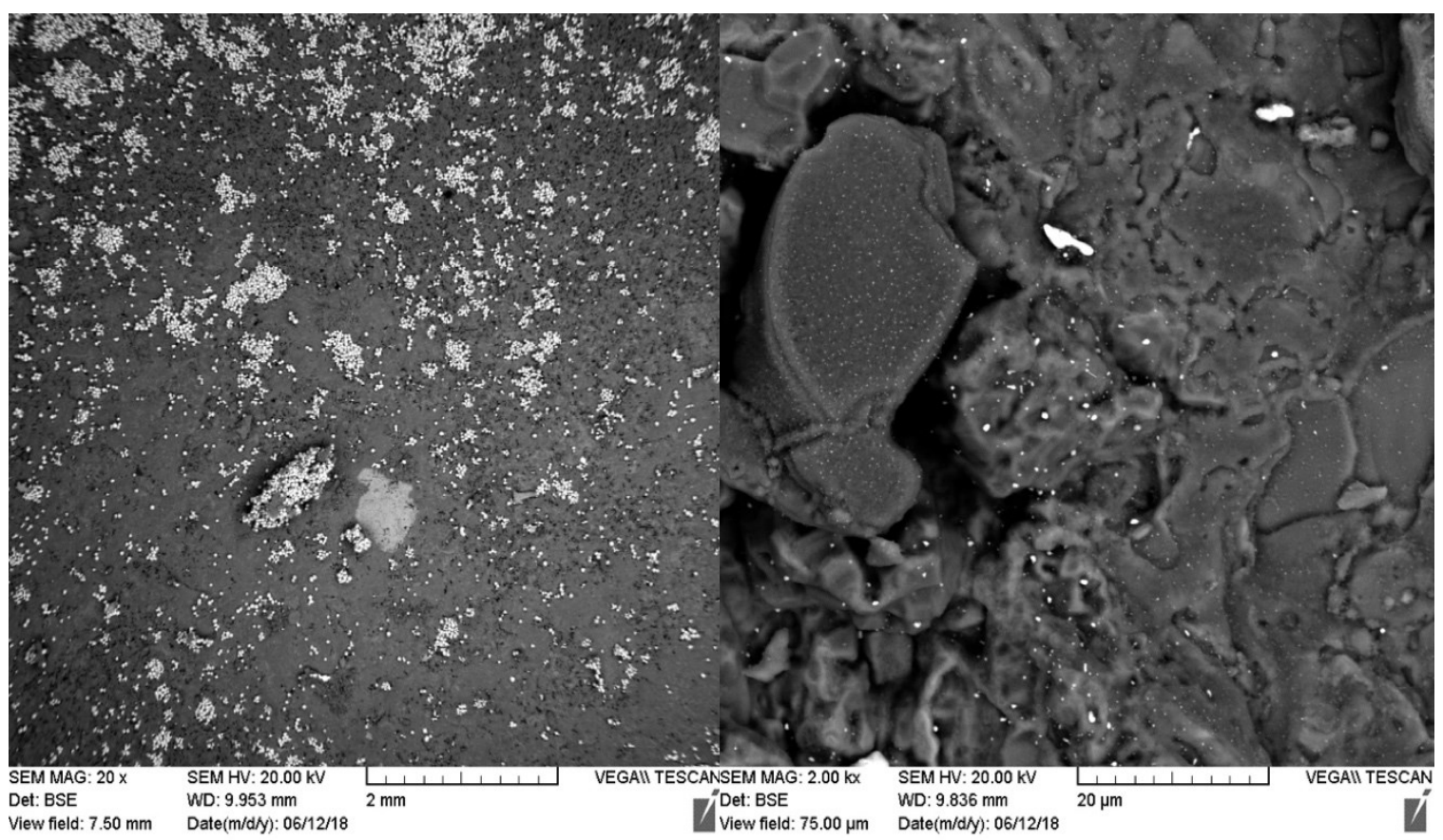

Figure 77: Left: Ttitanium and silver sintered coating at 20x magnification, Right: same coating at 2000x magnification. This coating had not yet undergone ultrasonic cleaning. The bright areas in these images are silver 
As seen in Figure 77 Figure 78, there is a significant difference in the amount of silver present on the surfaces. Silver has a substantially greater atomic mass than the background metals, so the bright spots in Figure 77 Figure 78 are silver. The silver generally took two forms on the surface: globular structures approximately $40 \mu \mathrm{m}$ in diameter and small fragments approximately $1 \mu \mathrm{m}$ in diameter. Both forms are present on both coupons tested here, though their quantities and distributions vary. The larger structures in Figure 78 are primarily concentrated in craters in the titanium, with a few scattered along the surface.

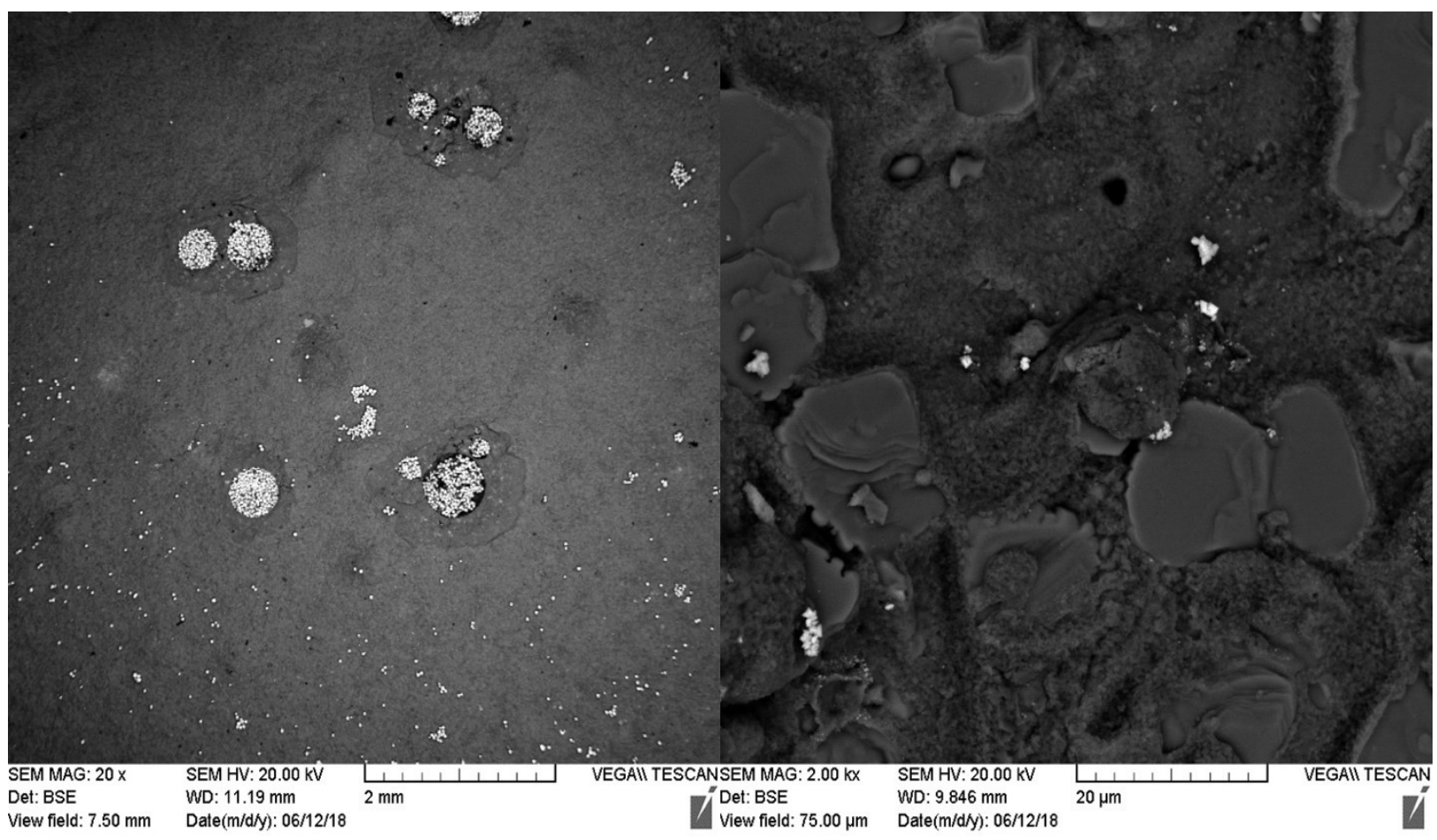

Figure 78: Left: Ultrasonically cleaned titanium and silver sintered coating at 20x magnification, Right: same coating at 2000x magnification. The bright areas in these images are silver 


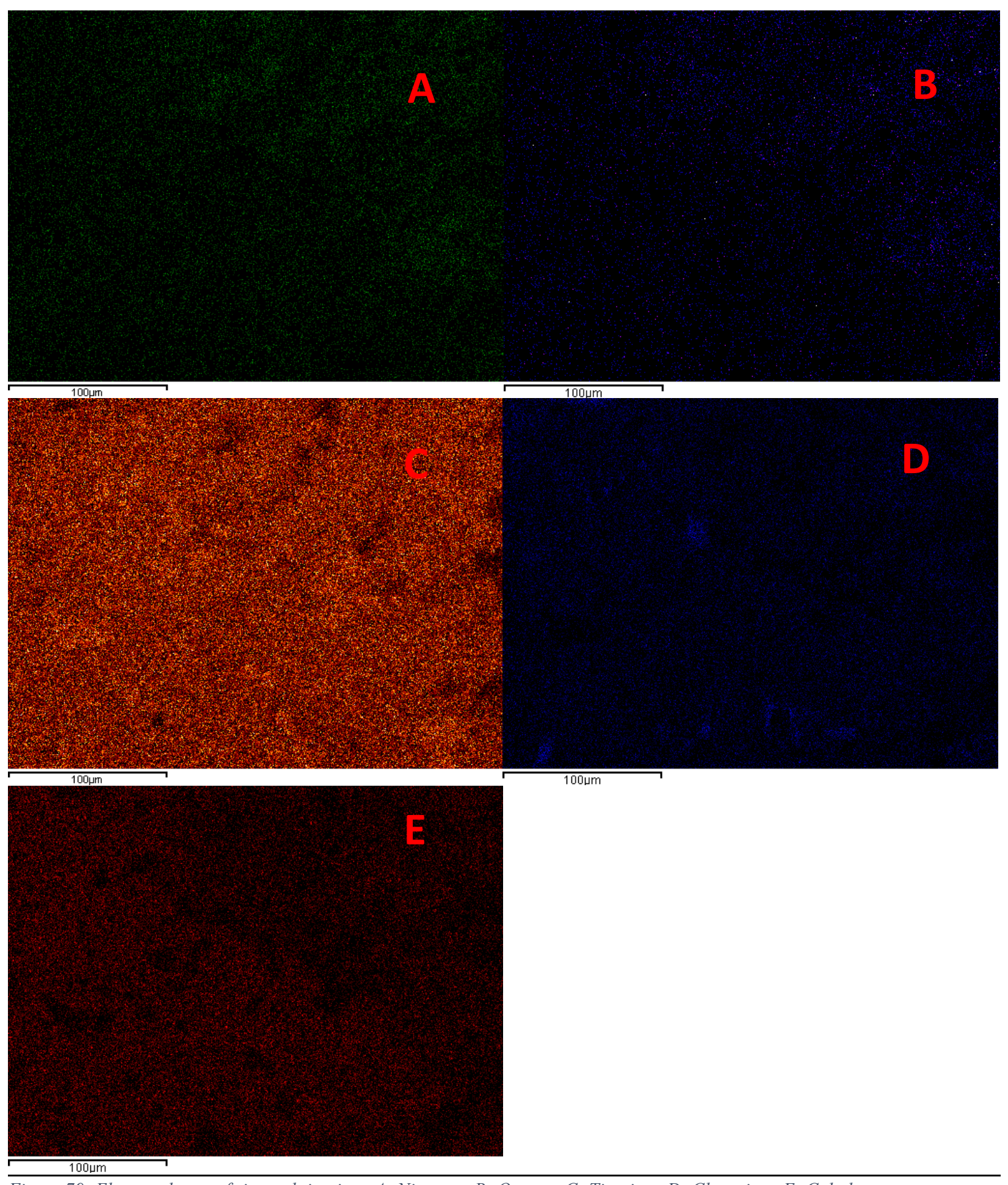

Figure 79: Elemental map of sintered titanium. A: Nitrogen, B: Oxygen, C: Titanium, D: Chromium, E: Cobalt

To test the distribution of elements on each coating, elemental mapping was used.

Each coating was tested for a duration of 10 minutes and was performed at 1000x magnification. Figure 79 shows the various elements tested on a region of sintered titanium. 
The main area of interest was the difference between the lighter region in the bottom left and the darker region in the upper right of Figure 80. Different colors were used for different elements, but the colors chosen were kept consistent between coatings.

Looking at Figure 79, there are some subtle differences in the two regions. The darker region had lower levels of cobalt relative to the lighter region and had higher levels of oxygen and slightly higher levels of nitrogen. This shift would explain the difference in color; lighter elements appear darker in these images, and cobalt was the heaviest element found. The titanium levels appear to be consistent across the two regions. The darker region may contain greater levels of titanium oxide, thus leading to better osseointegration ${ }^{56}$, but the high levels of titanium and oxygen across the coating would suggest that there would be osseointegration throughout. The mapping was done for a region with noticeable contrast (Figure 80).

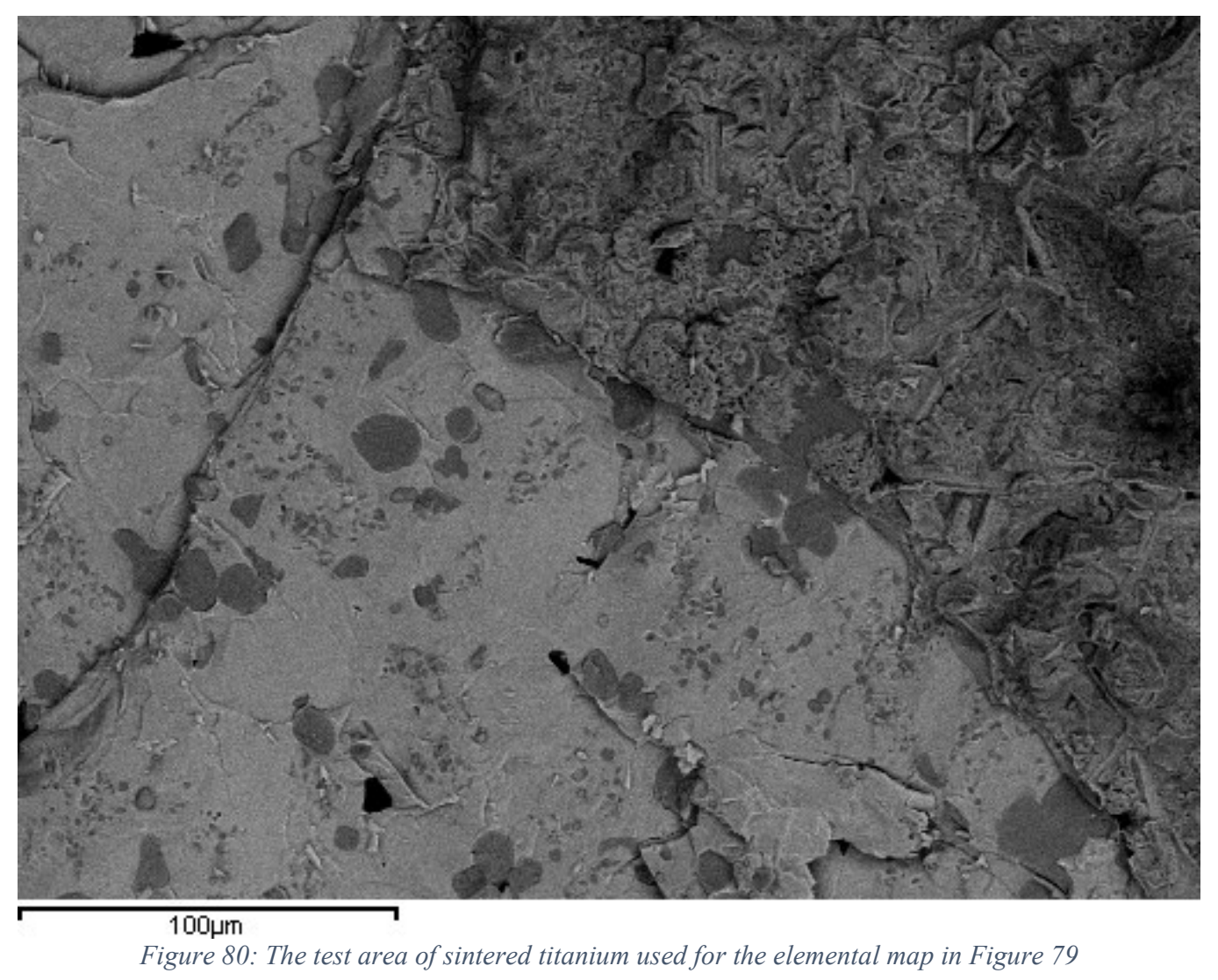




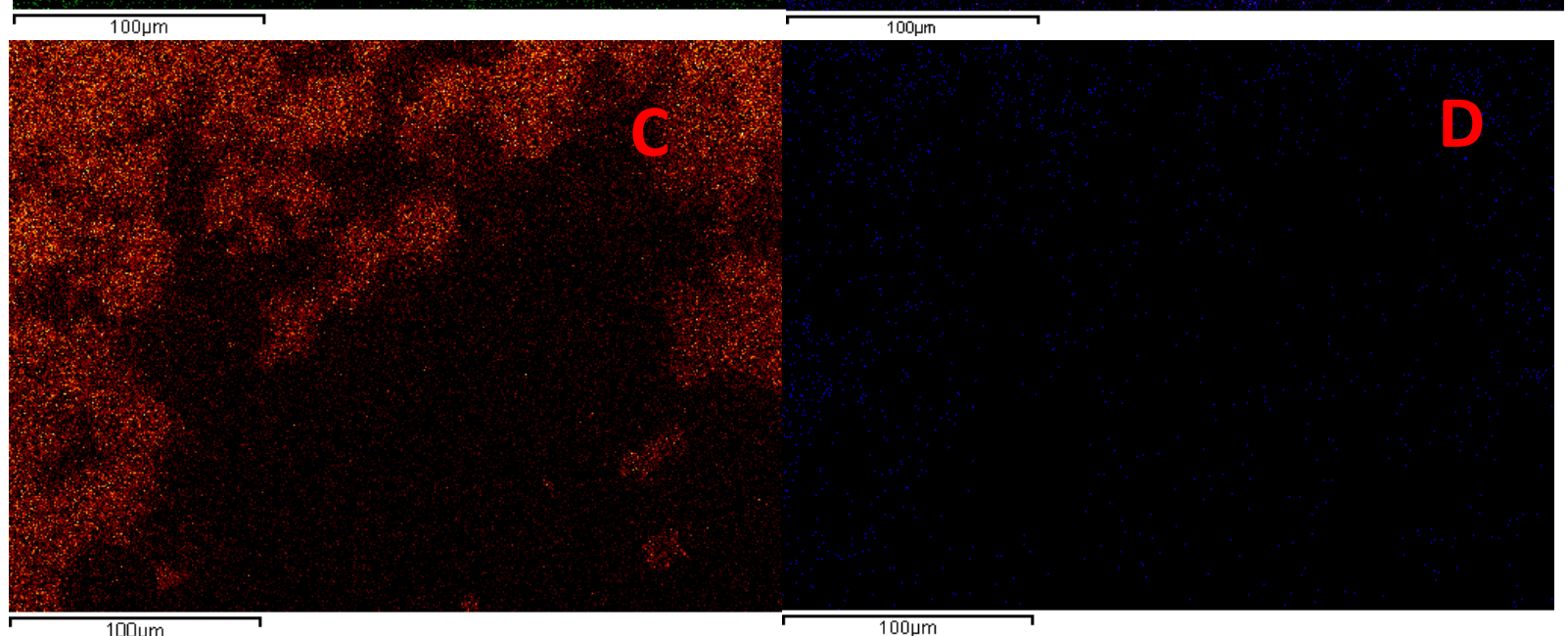

Figure 81: Elemental map of uncleaned sintered titanium and silver. A: Nitrogen, B: Oxygen, C: Titanium, D: Chromium, E: Cobalt, F: Silver

The elemental maps of the uncleaned sintered titanium and silver (Figure 81) show that nitrogen and oxygen are both present on the surface and are relatively evenly spread. There are lower levels of these elements in the area around the large silver structures, with 
higher levels surrounding regions with a greater concentration of titanium. This suggests that nitrogen and oxygen are present throughout the coatings but are more likely to interact with titanium. The area mapped was the edge of a cluster of silver structures (Figure 82).

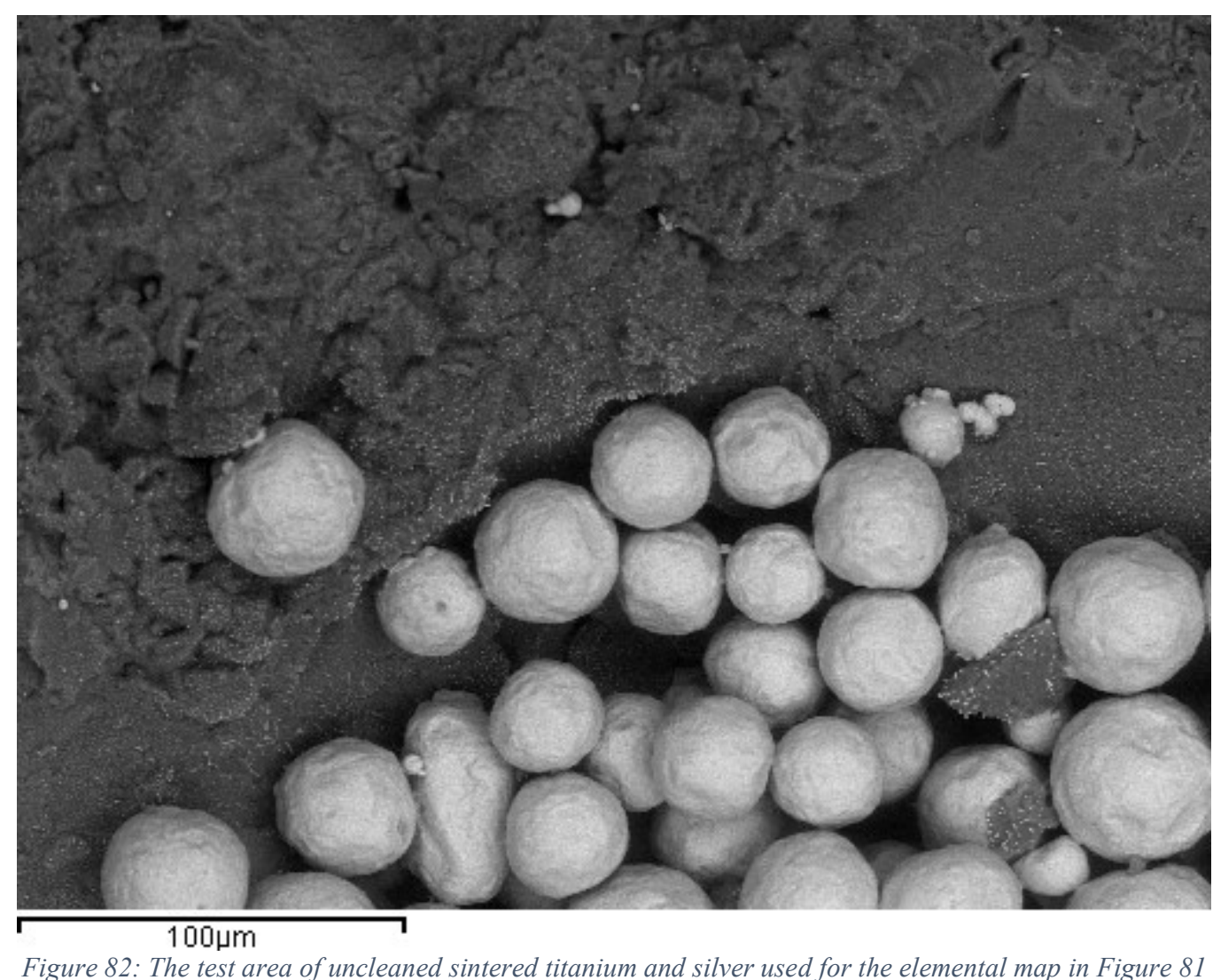



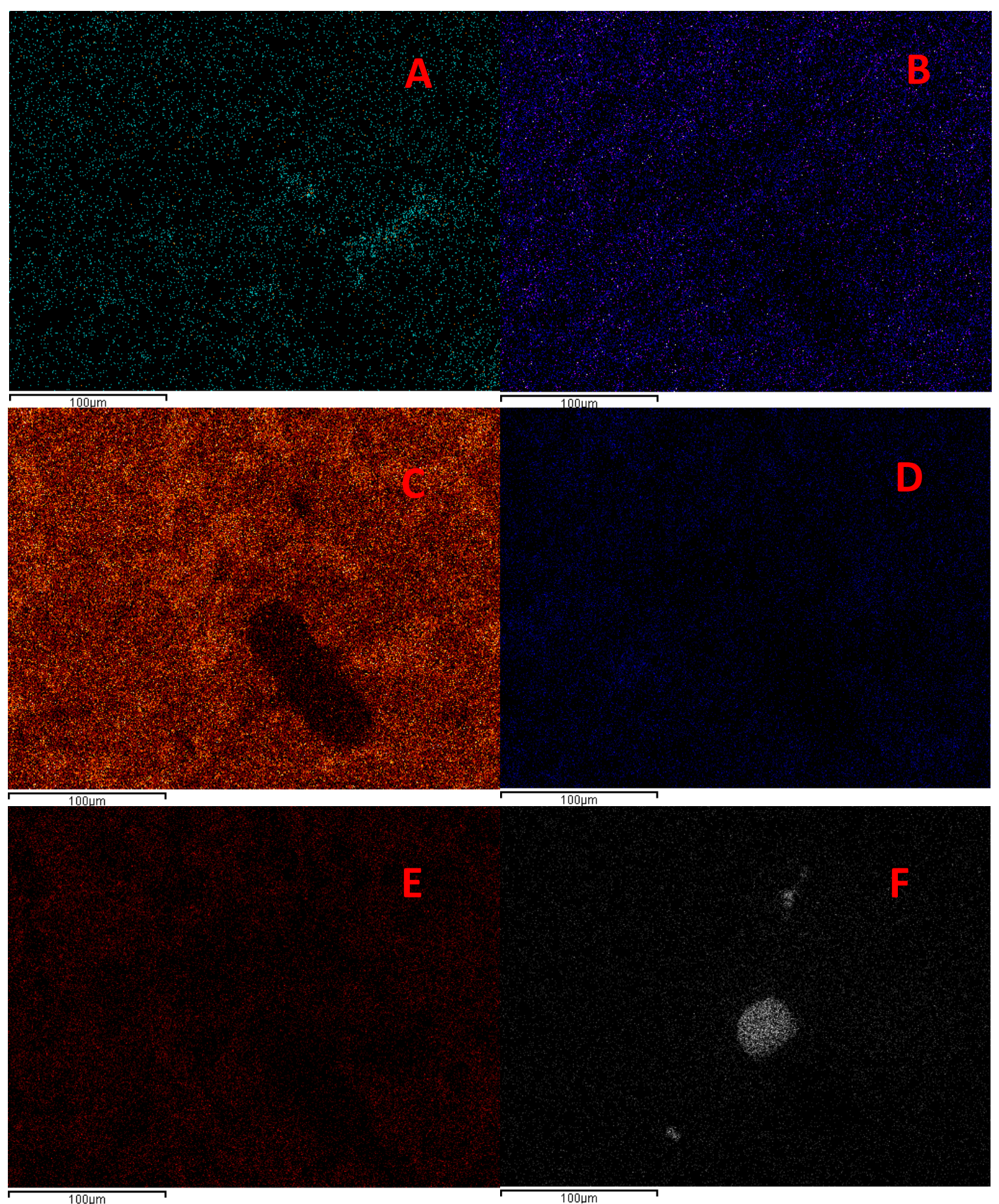

Figure 83: Elemental map of cleaned sintered titanium and silver. A: Sodium, B: Oxygen, C: Titanium, D: Chromium, E: Cobalt, F: Silver

The cleaned coating showed similar results (Figure 83), with the exception of significant amounts of sodium. The sodium likely originated from the liquid broth used to 
rinse the coatings during the bacterial testing, and it was not fully removed from the autoclave. The map shows a decrease in sodium levels around the silver structure, indicating little interaction between sodium and silver. Curiously, the silver structure left a shadow artifact in the titanium image (Figure 83C). The area mapped on this coating included large and small silver structures (Figure 84).

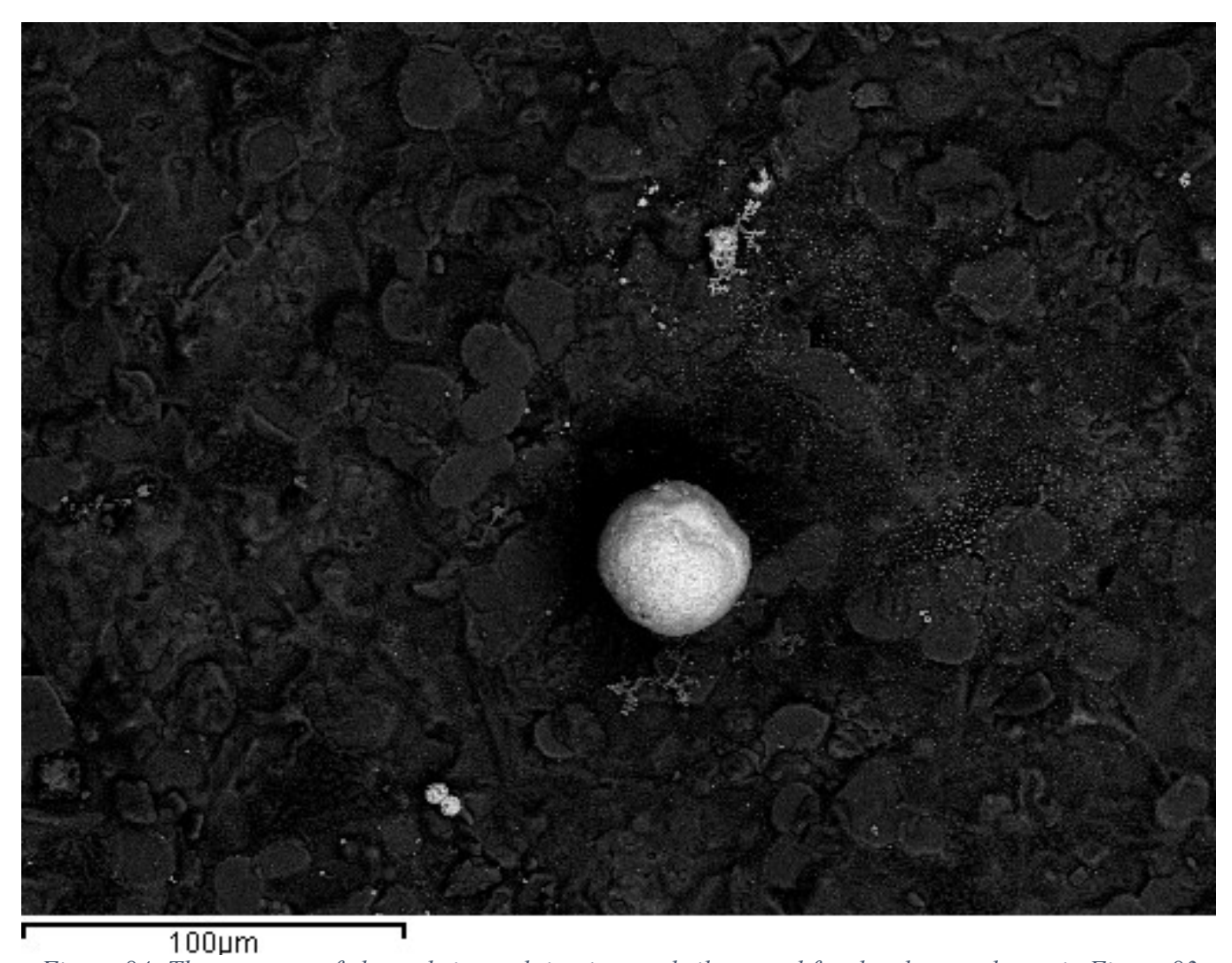

Figure 84: The test area of cleaned sintered titanium and silver used for the elemental map in Figure 83 


\subsubsection{Adhesion Strength}

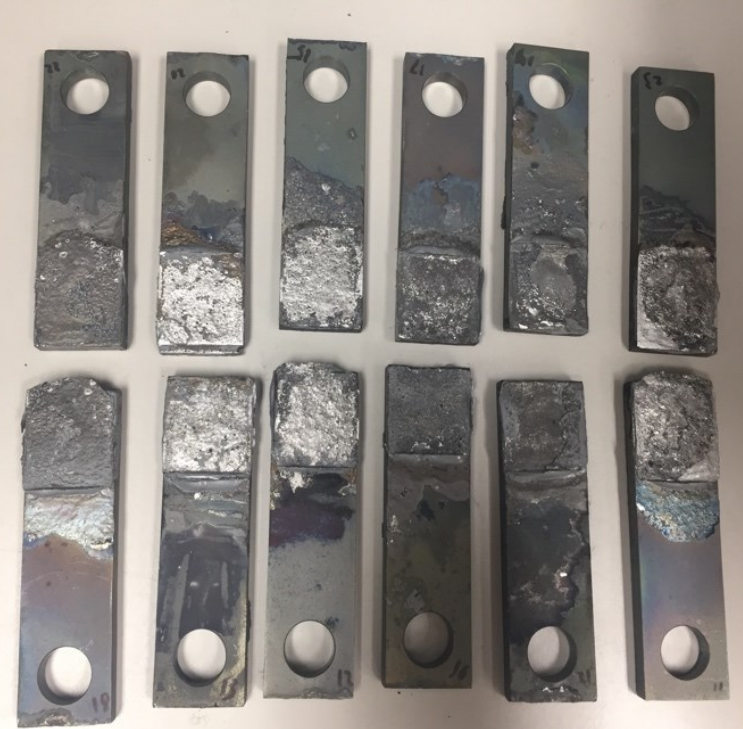

Figure 85: Sintered coupons after loading to failure according to ASTM F1044

Figure 85 shows the pairs of coatings after loading, where each column is a pair of coatings. The numbers visible correspond to the order that the specimens were placed in the furnace whereas the loading order was denoted on the reverse side. The average

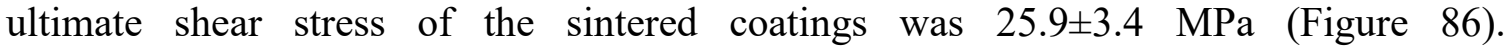

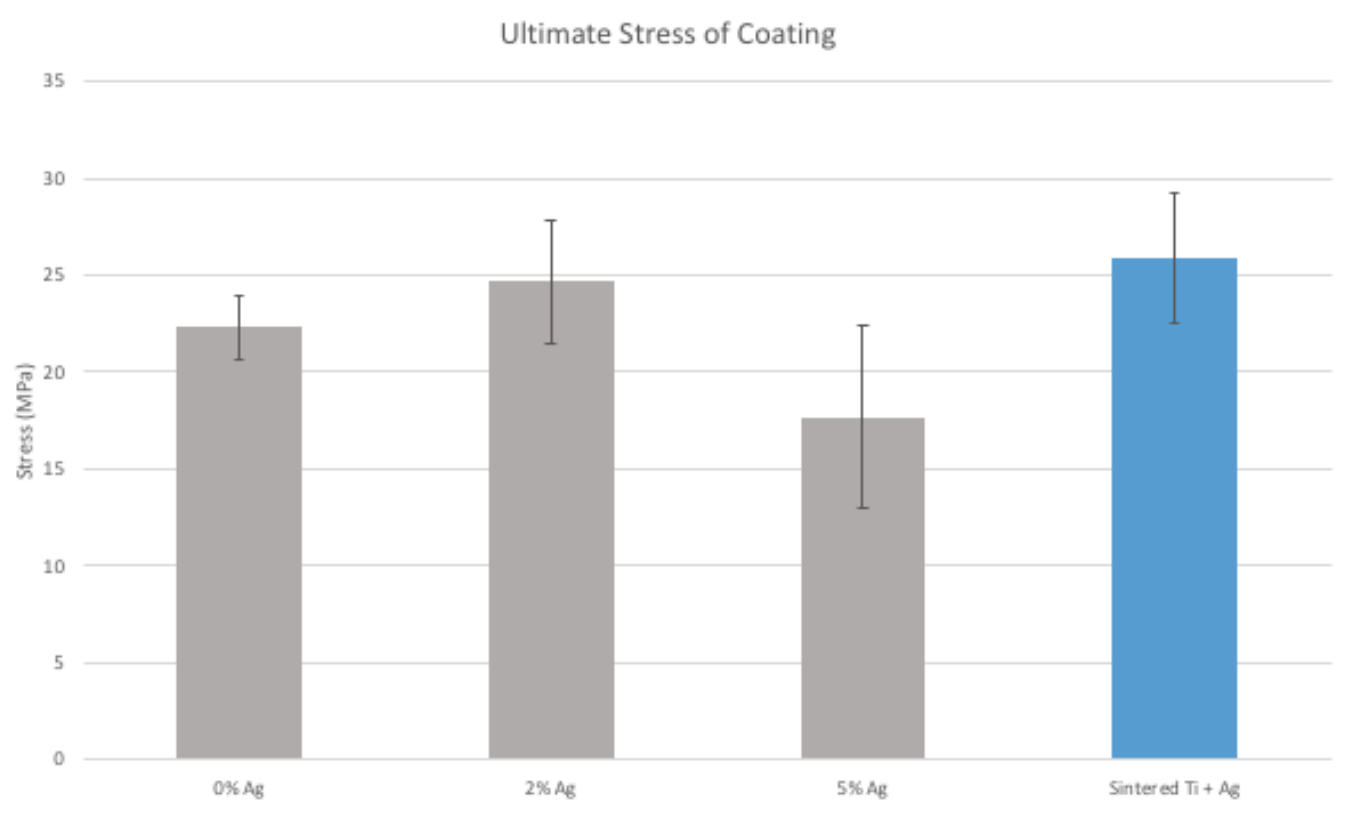

Figure 86: Average shear strength and standard deviation of sintered coatings (blue) compared to plasma-sprayed coatings (grey) 


\section{$\underline{\text { 4.3.3. Bacteria }}$}

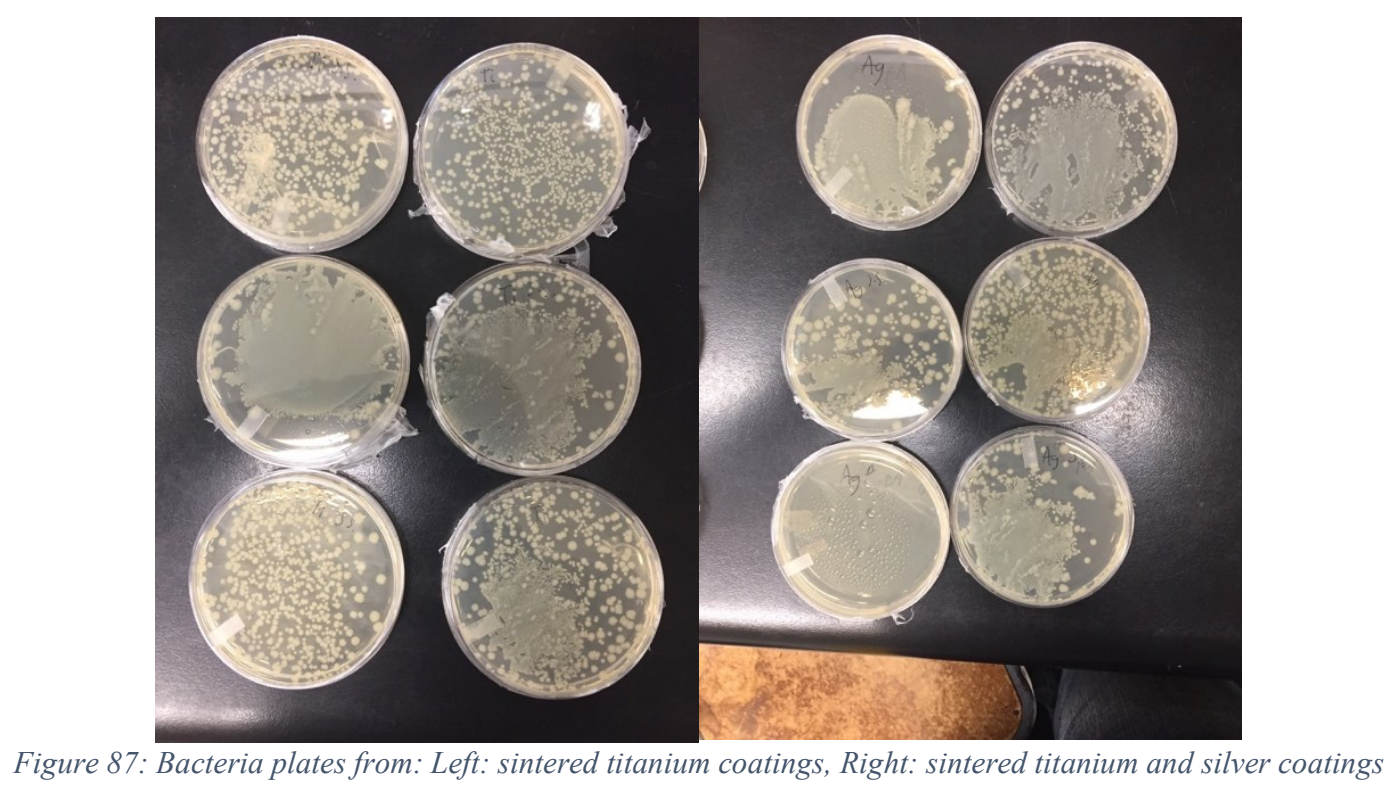

Figure 87 is an image of the plates corresponding to the sintered coatings. The order

of the plates in each group is in no particular order. The amount of bacteria present could not be determined quantitatively and is compared to the other groups qualitatively.

\subsection{Discussion}

\subsubsection{Scanning Electron Microscopy}

The SEM images show that the sintering process was able to produce a solid coating of titanium. The unsuccessful titanium compactions have a significantly different appearance than the successful compactions, showing that something was inherently different on the microscopic level. The microstructure of the sintered titanium specimens was as expected. The pressureless sintering should have resulted in a highly porous structure, which is visible in Figure 69. The microstructure of the sintered silver and titanium coatings was much different, with silver beads on a largely homogenous titanium surface. The second cycle of sintering was at a significantly cooler temperature, and the 
titanium necks were not expected to grow significantly. The sintered coatings containing silver are noticeably less porous than the coatings only containing titanium (Figure 67 Figure 68). It is possible that necks between grains of titanium continued to form at this lower temperature, resulting in a smoother surface.

The sintered titanium experienced high levels of oxidation, especially after the second stage of sintering. The argon was likely not fully able to displace all of the oxygen in the tube, resulting in the formation of oxides. In the future, vacuum sintering could be used to prevent oxidation.

\subsubsection{Revisit after Bacteria Testing}

After re-examining the sintered titanium and silver coatings, it is clear that significant amounts of silver were removed from the surface. Most remaining silver is concentrated in small pockets along the titanium surface. It is likely that some friction along the surface stripped away most of the silver on these surfaces, and the craters protected some silver. The smaller structures are also less common on the cleaned surface, but there is no distinct pattern in the structures that remain. This supports the hypothesis that the sintered coatings were unsuccessful in preventing bacterial proliferation due to the removal of silver from the surface. It is unclear when this silver reduction occurred, but it is likely the result of ultrasonic cleaning. The change in color seen in Figure 88 was believed to be from the removal of silver and this testing shows that silver was removed from the surface at some time during the processing. It remains unclear if the autoclaving process would also remove silver if most silver was removed from the surface beforehand. Further testing would be necessary to determine this. 
The elemental maps show the distributions of various elements in the scanned area. The expectation was that nitrogen and oxygen interacted with the silver, inhibiting its antimicrobial properties. The maps indicated a general tendency of nitrogen and oxygen to prefer titanium over silver, suggesting that silver oxides and nitrates were not formed as much as titanium oxides and nitrates. From this, it can be inferred that these silver compounds were not likely to have interfered with the potential antibacterial properties of the sintered coatings. The cleaning process was largely responsible and should be addressed in future studies. Either the coatings would need to be made to withstand the ultrasonic cleaning and autoclaving process, or alternative cleaning methods should be used that do not damage the silver layer.

\subsubsection{Adhesion Strength}

The adhesion strength test found that the sintered coatings were exceptionally strong, especially when compared to the plasma-sprayed coatings. The sintered coatings had a mean ultimate stress of approximately $25.86 \mathrm{MPa}$. This makes the sintered coatings slightly stronger than the strongest plasma-sprayed coating ( $2 \%$ silver at $24.66 \mathrm{MPa})$. The expectation was that the sintered coatings would fail under a weaker load, due to their porosity. The sintered titanium and silver produced by Chen et al. were sintered alloys and not coatings ${ }^{87}$, so the sintered coatings were compared to the plasma-sprayed coatings in this test. The plasma-sprayed coatings were considered successful; therefore, the sintered coatings can also be considered strong enough for their intended purpose.

In three of the six sintered titanium with silver coatings, low metallic noises were heard shortly before failure. The noises could be described as a "ping" and would occur 
once or twice, approximately 10 seconds before failure. The noises likely resulted from small failures occurring within the coating, before the entire coating failed. Two of the six sintered coatings also gave off small sparks when failing. Titanium powder is flammable ${ }^{111}$, and it is probable that small particles of titanium were ejected as the coating failed, and this was the source of the sparks. The sintered coatings appear to have failed within the coatings themselves, and not being removed from the surface of the substrate (Figure 85).

\section{$\underline{4.4 .3 . ~ B a c t e r i a ~}$}

The bacterial testing found that the sintered coatings were ineffective in preventing E. coli proliferation. The colonies overlapped, making it impossible to accurately count them. The amount of bacteria present on the plates indicates that that the bacteria were unaffected when compared to the controls.

One unexpected observation from the ultrasonic cleaning was that the sintered coatings containing silver had a slight change in color. As seen in Figure 88, the white coloring on the coating is less noticeable from after the process. The white area in Figure 88 is most likely the silver added. This is suggested from comparing the coatings from before and after the second round of sintering, as seen in Figure 59. It is possible that the silver was partially removed from the coating by the ultrasonic cleaning process, but this is speculation. The silver pockets found on the surface of the sintered coatings were significantly more globular than what was on the plasma sprayed coatings, so they could potentially be more easily removed. The $2 \%$ and $5 \%$ silver plasma-sprayed coatings did not appear to have the color change along the edges that was observed during the leaching 
test, despite being submerged in water. This color change was also not seen after autoclaving, even after repeated cycles. This suggests that the oxidation observed during the leaching process was related to the prolonged, continuous exposure to water, as the ultrasonic cleaning and autoclaving only lasted for an hour at a time.

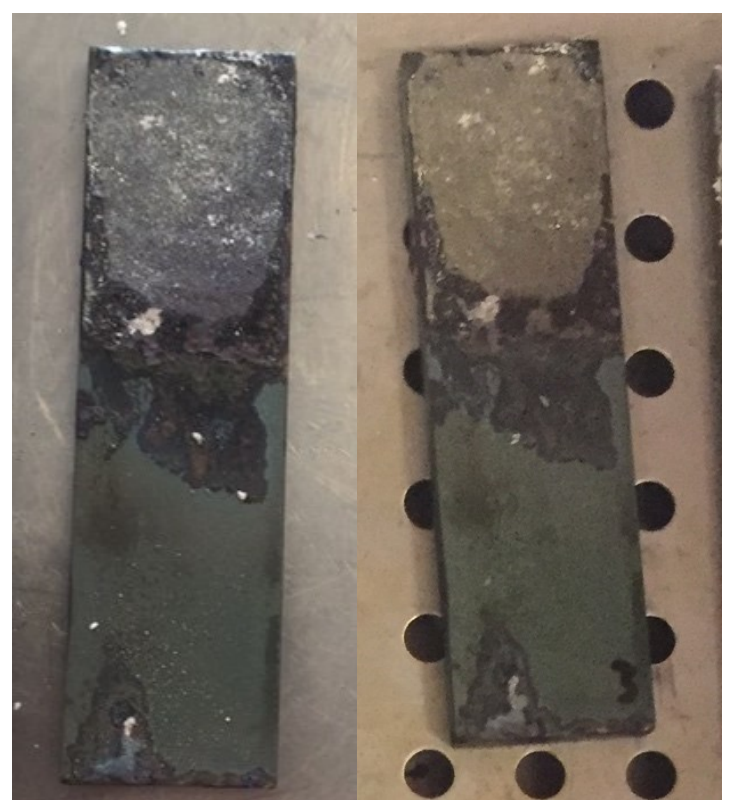

Figure 88: Left: Sintered titanium and silver coupon before ultrasonic cleaning, Right: same coupon after cleaning

Unlike the plasma-sprayed coatings, the sintered coatings did not appear to have any hydrophobic properties. The behavior of the culture on the sintered coatings was identical to when it was dripped onto the uncoated coupons.

After rinsing the sintered coatings with liquid broth, in some cases small metallic specks were found to be floating in the solution. The exact composition of these particles was unknown, but likely titanium and silver. These particles were avoided when collecting from the solution for the dilution process. 


\subsubsection{Uncoated Stellite vs. Sintered Titanium}

It is unclear exactly how much bacteria was on the sintered titanium plates relative to the uncoated Stellite, but the sintered titanium does not appear to have any reduction in bacteria (Figure 47 Figure 87). The sintered titanium was not expected to have any effect on the bacteria, as bacteria can proliferate on the surface of titanium ${ }^{100}$. Bacterial growth can be affected by the surface structure of titanium, but this does not prevent the growth of bacteria $^{112}$. The results show that the coating did not have any contaminants like the $0 \%$ plasma-sprayed coating was speculated to have at first. The sintered coatings were not tested with E. coli before being cleaned ultrasonically, so it is unclear if they would have had the same issues that the plasma-sprayed coatings did. All samples were ultrasonically cleaned to keep everything consistent between groups.

\subsubsection{Uncoated Stellite vs. Sintered Titanium + Silver}

The plates for both of the sintered groups are very similar in appearance (Figure 87). One of the silver plates saw no growth, but the culture on the surface was dry so this plate was not considered for analysis. Each of the sintered silver plates saw a large amalgamation of colonies, and four of the six titanium plates had this as well. Reviewing the original SEM images, the sintered silver coatings were hypothesized to be the most effective at preventing bacterial growth. Not only were the silver beads covering a larger percentage of the area, but the small, evenly spaced specs of silver covered the entire scanned area. The most likely reason for this was the ultrasonic cleaning. The coating became significantly whiter after the addition of the silver, however they seemed to lose this after the cleaning process. It is unconfirmed, but likely that the process loosened the 
silver from the surface of the sintered titanium. The autoclaving process could have also potentially done this, though this was not initially tested. The sintered silver coatings were not found to appear any different after the autoclaving process, but if the silver was already remove by the ultrasonic cleaner, the sintered coating would not have any notable changes. As seen in the SEM images (Figure 68 Figure 69), the sintered silver look to be spheres adhered to the titanium background. The plasma sprayed coatings had the silver more integrated into the surface, which is especially noticed in comparing the backscatter images to the secondary electron images (Figure 17 Figure 18). Though unconfirmed, the silver in the plasma-sprayed coatings would be difficult to remove without doing significant damage to the coatings.

While unlikely, it is possible that there was some variance between the two rounds of testing. The bacterial growth on the control surfaces were very similar, suggesting that there was no significant difference between the two rounds.

As with the plasma-sprayed coating tests, the study was limited by the fact that only one strain of bacteria was tested. Furthermore, only one sterilization process was tested. 


\section{Chapter 5: Discussion and Conclusions}

When testing for the mechanical properties of the plasma-sprayed coatings, it was found that they were comparable, if not stronger, with the plasma-sprayed coatings developed by Fielding et al. ${ }^{71}$, These coatings were designed for biomedical application and were determined to be strong enough for use, therefore the plasma-sprayed coatings developed in this thesis are also sufficiently strong. The sintered coatings had no direct analog for shear strength tests, however they were stronger than all plasma-sprayed coatings in this thesis. They were also stronger than the coatings developed by Fielding et $\mathrm{al}^{71}$, with both coatings being developed for the same purpose. The sintered coatings have the required adhesion strength and are considered a success in this aspect.

Of the plasma-sprayed coatings, only the $2 \%$ silver coating showed comparable results to what was seen in the literature ${ }^{71}$. The $0 \%$ silver and $5 \%$ silver coatings saw a decrease in bacteria colonies compared to the control, however these values are not considered successful compared to the threshold set by previous work. The sintered coatings showed no decrease in bacteria colonization, meaning that the current design is not viable as an antimicrobial coating.

Of all the coatings, the $2 \%$ silver plasma-sprayed coating showed the most promise. It was the strongest plasma-sprayed coating and had almost complete destruction of bacteria tested. For reasons unknown, the $5 \%$ silver plasma-sprayed was only able to slightly reduce the bacteria count compared to the $0 \%$ or uncoated coupons. Further testing of these coatings with bacteria should be done to determine how effective they are. This should be done with various species of bacteria, such as P. aeruginosa and C. difficile. This would show if the coatings are usable in broad-spectrum application. Testing with 
antibiotic-resistant strains would further suggest use as an all-purpose antimicrobial coating. Should development continue with a focus in food processing and water treatment, the surfaces would need to be tested to ensure that significant amounts of metal do not enter the food or water supply. The surfaces would need to pass government regulations in this respect. Further development as a biomedical coating would necessitate testing with human cell lines. This would be done to show that they are not significantly harmful if implanted in a patient. The $2 \%$ silver plasma-sprayed coatings should also be tested on more geometrically complex surfaces to demonstrate use in real world applications. This would be critical in proving that the plasma-spraying method used is effective in creating a relatively even coating on all desired parts of industrial machinery or implants.

The sintered coatings were marginally stronger than the $2 \%$ silver plasma-sprayed coating, however their lack of antimicrobial properties makes them unviable. It is possible that the sintered coatings would be effective at killing bacteria, and further testing should be done to find a sterilization process that does not strip the silver from the surface of the coating. This could potentially be done by immersing the coatings in a disinfectant solution such as sodium hypochlorite or only using the autoclave as a sterilization method. Should it be possible to clean the sintered coatings without removing the silver, a standardized method of production should be decided upon to ensure reliable coating consistencies. This could include using a specific amount of silver slurry per unit area or developing an automated compaction process that produces identical titanium compactions. Should the sintered coatings be found effective against E. coli, testing should continue with other species of bacteria and human cell lines. 


\section{Chapter 6: Contributions}

- Through the work done in this thesis, an effective antibacterial coating was developed. This coating can have potential application in industrial food and water processing and biomedical device design.

- The experiments performed characterized the plasma-sprayed coating. A minimum adhesion strength of $19.97 \mathrm{MPa}$ and anti-bacterial effectiveness of $99.9 \%$ were found.

- A two-step sintering process was developed to add silver to sintered titanium coatings, but it was shown that in this case silver was not effective in preventing the proliferation of E. coli. 


\section{$\underline{\text { References }}$}

1. Cecil JA. Gastrointestinal tract infections. Infectious Disease Advisor. https://www.infectiousdiseaseadvisor.com/hospital-infectioncontrol/gastrointestinal-tract-infections/article/598978/. Published 2013. Accessed June 28, 2018.

2. Roddick J, Higuera V. Open Wound: Types, Treatments, and Complications. Healthline. https://www.healthline.com/health/open-wound. Published 2017. Accessed June 28, 2018.

3. Cotter PD, Hill C. Surviving the acid test: responses of gram-positive bacteria to low pH. Microbiol Mol Biol Rev. 2003;67(3):429-53, table of contents. doi:10.1128/MMBR.67.3.429-453.2003

4. Public Health Agency of Canada. Public Health Notice - Outbreak of E. coli infections linked to romaine lettuce - Canada.ca. Government of Canada. https://www.canada.ca/en/public-health/services/public-healthnotices/2018/public-health-notice-outbreak-e-coli-infections-linked-romainelettuce.html. Published 2018. Accessed June 28, 2018.

5. Nutrition C for FS and A. Outbreaks - FDA Investigates Multistate Outbreak of E. coli O26 Infections Linked to Chipotle Mexican Grill Restaurants. https://www.fda.gov/food/recallsoutbreaksemergencies/outbreaks/ucm470410.htm. Accessed July 17, 2018.

6. Wattles J. E. coli recall affects major retailers across the U.S. CNN Money. https://money.cnn.com/2015/12/01/news/companies/e-coli-recall-walmart-costcoalbertsons/. Published 2015. Accessed June 28, 2018.

7. Canadian Food Inspection Agency. E. coli O157:H7 control in beef production Canadian Food Inspection Agency. Government of Canada. http://www.inspection.gc.ca/food/information-for-consumers/fact-sheets-andinfographics/products-and-risks/meat-and-poultry-products/beefproduction/eng/1361299193616/1361299285959. Accessed June 28, 2018.

8. CBC News. Inside Walkerton: Canada's worst-ever E. coli contamination $\mid \mathrm{CBC}$ News.https://www.cbc.ca/news/canada/inside-walkerton-canada-s-worst-ever-ecoli-contamination-1.887200. Published May 10, 2010. Accessed June 28, 2018.

9. CBC News. Listeriosis outbreak timeline / CBC News. $C B C$. https://www.cbc.ca/news/listeriosis-outbreak-timeline-1.694467. Published August 26, 2008. Accessed June 28, 2018.

10. CDC. Chicken and Food Poisoning. https://www.cdc.gov/features/salmonellachicken/index.html. Published 2017. Accessed June 28, 2018.

11. Eastaugh SR. Hospital specialization and cost efficiency: benefits of trimming product lines. Hosp Health Serv Adm. 1992;37(2):223-235.

http://www.ncbi.nlm.nih.gov/pubmed/10118589. Accessed June 28, 2018.

12. Weeks C. Better by design: How a hospital room can help patients heal - The Globe and Mail. The Globe and Mail. https://www.theglobeandmail.com/life/health-and-fitness/health/thehospital/better-by-design-how-a-hospital-room-can-help-patientsheal/article16748288/. Published February 7, 2014. Accessed July 17, 2018. 
13. Magill SS, Edwards JR, Bamberg W, et al. Multistate Point-Prevalence Survey of Health Care-Associated Infections. N Engl J Med. 2014;370(13):1198-1208. doi:10.1056/NEJMoa1306801

14. Mayo Clinic. C. difficile infection - Symptoms and causes - Mayo Clinic. https://www.mayoclinic.org/diseases-conditions/c-difficile/symptoms-causes/syc20351691. Published 2016. Accessed June 28, 2018.

15. Mayo Clinic. Staph infections. https://www.mayoclinic.org/diseasesconditions/staph-infections/symptoms-causes/syc-20356221. Published 2017. Accessed June 28, 2018.

16. Stryjewski ME, Corey GR. Methicillin-Resistant Staphylococcus aureus: An Evolving Pathogen. Clin Infect Dis. 2014;58(suppl 1):S10-S19. doi:10.1093/cid/cit613

17. Williamson R, Collatz E, Gutmann L. [Mechanisms of action of beta-lactam antibiotics and mechanisms of non-enzymatic resistance]. Presse Med. 1986;15(46):2282-2289. http://www.ncbi.nlm.nih.gov/pubmed/2949269. Accessed July 17, 2018.

18. Choo EJ, Chambers HF. Treatment of Methicillin-Resistant Staphylococcus aureus Bacteremia. Infect Chemother. 2016;48(4):267-273. doi:10.3947/ic.2016.48.4.267

19. Cetinkaya Y, Falk P, Mayhall CG. Vancomycin-resistant enterococci. Clin Microbiol Rev. 2000;13(4):686-707.

http://www.ncbi.nlm.nih.gov/pubmed/11023964. Accessed August 2, 2018.

20. Ribet D, Cossart P. How bacterial pathogens colonize their hosts and invade deeper tissues. Microbes Infect. 2015;17(3):173-183.

doi:10.1016/J.MICINF.2015.01.004

21. Ryu J-H, Kim H, Frank JF, Beuchat LR. Attachment and biofilm formation on stainless steel by Escherichia coli O157:H7 as affected by curli production. Lett Appl Microbiol. 2004;39(4):359-362. doi:10.1111/j.1472-765X.2004.01591.x

22. Johns Hopkins Medicine. Arthroplasty. https://www.hopkinsmedicine.org/healthlibrary/test_procedures/orthopaedic/arthro plasty_92,P07677. Accessed June 29, 2018.

23. Canadian Institute for Health Information. Hip and Knee Replacements in Canada, 2014-2015: Canadian Joint Replacement Registry Annual Report. Ottawa; 2015. https://secure.cihi.ca/free_products/cjrr-annual-report-2016-en.pdf. Accessed May $12,2018$.

24. Greengard S. Step-by-Step Explanation of Knee Replacement Surgery. Healthline. https://www.healthline.com/health/total-knee-replacement-surgery-step-by-step. Published 2012. Accessed June 29, 2018.

25. Tande AJ, Patel R. Prosthetic Joint Infection. Clin Microbiol Rev. 2014;27(2):302345. doi:10.1128/cmr.00111-13

26. Parvizi J, Aggarwal V, Rasouli M. Periprosthetic joint infection: Current concept. Indian J Orthop. 2013;47(1):10. doi:10.4103/0019-5413.106884

27. McHugh SM, Hill ADK, Humphreys H. Laminar airflow and the prevention of surgical site infection. More harm than good? Surg. 2015;13(1):52-58. doi:10.1016/j.surge.2014.10.003

28. Bischoff P, Kubilay NZ, Allegranzi B, Egger M, Gastmeier P. Effect of laminar airflow ventilation on surgical site infections: a systematic review and meta- 
analysis. Lancet Infect Dis. 2017;17(5):553-561. doi:10.1016/S14733099(17)30059-2

29. Richards MK, McAteer JP, Drake FT, Goldin AB, Khandelwal S, Gow KW. A National Review of the Frequency of Minimally Invasive Surgery Among General Surgery Residents. \{JAMA\} Surg. 2015;150(2):169.

doi:10.1001/jamasurg.2014.1791

30. Cheng T, Liu T, Zhang G, Peng X, Zhang X. Does Minimally Invasive Surgery Improve Short-term Recovery in Total Knee Arthroplasty? Clin Orthop Relat Res. 2010;468(6):1635-1648. doi:10.1007/s11999-010-1285-9

31. Ee WWG, Lau WLJ, Yeo W, Bing Y Von, Yue WM. Does Minimally Invasive Surgery Have a Lower Risk of Surgical Site Infections Compared With Open Spinal Surgery? Clin Orthop Relat Res. July 2013. doi:10.1007/s11999-013-31585

32. Del Pozo JL, Patel R. Clinical practice. Infection associated with prosthetic joints. N Engl J Med. 2009;361(8):787-794. doi:10.1056/NEJMcp0905029

33. Sculco TP, Martucci EA, eds. Knee Arthroplasty. Springer Vienna; 2001. doi:10.1007/978-3-7091-6185-2

34. S F, S MK, M J, R N, de Andrade J, AS L. Implementing 1-dose antibiotic prophylaxis for prevention of surgical site infection. Arch Surg. 2006;141(11):1109-1113. doi:10.1001/archsurg.141.11.1109

35. Dhammi IK, Ul Haq R, Kumar S. Prophylactic antibiotics in orthopedic surgery: Controversial issues in its use. Indian J Orthop. 2015;49(4):373-376.

doi:10.4103/0019-5413.159556

36. The Ottawa Hospital. Post-Anesthesia Care Unit. http://www.ottawahospital.on.ca/en/clinicalservices/deptpgrmcs/departments/anesthesiology/post-anesthesia-care-unit/. Published 2017. Accessed June 29, 2018.

37. van der Slegt J, Kluytmans JAJW, de Groot HGW, van der Laan L. Treatment of surgical site infections (SSI) IN patients with peripheral arterial disease: An observational study. Int J Surg. 2015;14:85-89. doi:10.1016/j.ijsu.2015.01.011

38. Schmolders J, Hischebeth GT, Friedrich MJ, et al. Evidence of MRSE on a gentamicin and vancomycin impregnated polymethyl-methacrylate (PMMA) bone cement spacer after two-stage exchange arthroplasty due to periprosthetic joint infection of the knee. BMC Infect Dis. 2014;14(1):144. doi:10.1186/1471-2334-14144

39. Moerman F, Partington E. MATERIALS OF CONSTRUCTION FOR FOOD PROCESSING EQUIPMENT AND SERVICES: REQUIREMENTS, STRENGTHS AND WEAKNESSES. http://www.jhed.mk/filemanager/JHED Vol 6/01. HED/02. Frank Moerman.pdf. Accessed July 18, 2018.

40. Bergmann G, Bender A, Dymke J, Duda G, Damm P. Standardized Loads Acting in Hip Implants. PLoS One. 2016;11(5):e0155612. doi:10.1371/journal.pone.0155612

41. Bergmann G, Bender A, Graichen F, et al. Standardized loads acting in knee implants. PLoS One. 2014;9(1):e86035. doi:10.1371/journal.pone.0086035

42. Chaturvedi TP. An overview of the corrosion aspect of dental implants (titanium and its alloys). Indian J Dent Res. 2009;20(1):91. doi:10.4103/0970-9290.49068 
43. Viennot S, Dalard F, Lissac M, Grosgogeat B. Corrosion resistance of cobaltchromium and palladium-silver alloys used in fixed prosthetic restorations. Eur $J$ Oral Sci. 2005;113(1):90-95. doi:10.1111/j.1600-0722.2005.00190.x

44. Niinomi M. Mechanical properties of biomedical titanium alloys. Mater Sci Eng A. 1998;243(1-2):231-236. doi:10.1016/s0921-5093(97)00806-x

45. Conti MC, Karl A, Wismayer PS, Buhagiar J. Biocompatibility and characterization of a Kolsterised®medical grade cobalt-chromium-molybdenum alloy. Biomatter. 2014;4(1):e27713. doi:10.4161/biom.27713

46. FARKAS-HIMSLEY H. KILLING OF CHLORINE-RESISTANT BACTERIA BY CHLORINE-BROMINE SOLUTIONS. Appl Microbiol. 1964;12(1):1-6. http://www.ncbi.nlm.nih.gov/pubmed/14106934. Accessed July 18, 2018.

47. Gaulin C, Lê M-L, Shum M, Fong D. Disinfectants and sanitizers for use on food contact surfaces. http://webprod.hc-sc.gc.ca/dpd-bdpp/index-.

48. Garibaldi BT, Reimers M, Ernst N, et al. Validation of Autoclave Protocols for Successful Decontamination of Category A Medical Waste Generated from Care of Patients with Serious Communicable Diseases. J Clin Microbiol. 2017;55(2):545-551. doi:10.1128/JCM.02161-16

49. Leary JT, Werger MM, Broach WH, et al. Complete Eradication of Biofilm From Orthopedic Materials. J Arthroplasty. 2017;32(8):2513-2518. doi:10.1016/j.arth.2017.03.050

50. Frough-Reyhani M, Ghasemi N, Soroush-Barhaghi M, Amini M, Gholizadeh Y. Antimicrobial efficacy of different concentration of sodium hypochlorite on the biofilm of Enterococcus faecalis at different stages of development. J Clin Exp Dent. 2016;8(5):e480-e484. doi:10.4317/jced.53158

51. Jennings MC, Ator LE, Paniak TJ, Minbiole KPC, Wuest WM. BiofilmEradicating Properties of Quaternary Ammonium Amphiphiles: Simple Mimics of Antimicrobial Peptides. ChemBioChem. 2014;15(15):2211-2215. doi:10.1002/cbic.201402254

52. Butterfield PW, Camper AK, Ellis BD, Jones WL. Chlorination of model drinking water biofilm: implications for growth and organic carbon removal. Water Res. 2002;36(17):4391-4405. doi:10.1016/S0043-1354(02)00148-3

53. Katti KS. Biomaterials in total joint replacement. Colloids Surfaces $B$ Biointerfaces. 2004;39(3):133-142. doi:10.1016/j.colsurfb.2003.12.002

54. Cheng $\mathrm{H}, \mathrm{Xu} \mathrm{M}$, Zhang $\mathrm{H}$, Wu W, Zheng M, Li X. Cyclic fatigue properties of cobalt-chromium alloy clasps for partial removable dental prostheses. $J$ Prosthet Dent. 2010;104(6):389-396. doi:10.1016/S0022-3913(10)60173-4

55. Maruyama N, Kawasaki H, Yamamoto A, Hiromoto S, Imai H, Hanawa T. Friction-Wear Properties of Nickel-Free Co-Cr-Mo Alloy in a Simulated Body Fluid. https://www.jim.or.jp/journal/e/pdf3/46/07/1588.pdf. Accessed July 18, 2018.

56. Bosshardt DD, Chappuis V, Buser D. Osseointegration of titanium, titanium alloy and zirconia dental implants: current knowledge and open questions. Periodontol 2000. 2017;73(1):22-40. doi:10.1111/prd.12179

57. Praxair Surface Technologies. Industrial Coating Services. http://www.praxairsurfacetechnologies.com/en/coating-services. Published 2018. Accessed July 18, 2018. 
58. Mantry S, Mishra BK, Chakraborty M. Parametric Appraisal of Process Parameters for Adhesion of Plasma Sprayed Nanostructured \{YSZ\} Coatings Using Taguchi Experimental Design. Sci World J. 2013;2013:1-8. doi:10.1155/2013/527491

59. SMART RF, ELLWOOD EC. Sintering of Tin Powder. Nature. 1958;181(4612):833-834. doi:10.1038/181833a0

60. Mashhadi M, Khaksari H, Safi S. Pressureless sintering behavior and mechanical properties of $\{\mathrm{ZrB}\} 2\{\mid$ textendash $\}\{\mathrm{SiC}\}$ composites: effect of $\{\mathrm{SiC}\}$ content and particle size. J Mater Res Technol. 2015;4(4):416-422. doi:10.1016/j.jmrt.2015.02.004

61. Chermant J-L, Coster M, Jernot J-P, Dupain J-L. Morphological analysis of sintering. J Microsc. 1981;121(1):89-98. doi:10.1111/j.1365-2818.1981.tb01201.x

62. Mangano F, Mangano C, Piattelli A, Iezzi G. Histological Evidence of the Osseointegration of Fractured Direct Metal Laser Sintering Implants Retrieved after 5 Years of Function. \{BioMed\} Res Int. 2017;2017:1-7. doi: $10.1155 / 2017 / 9732136$

63. Missiaen J-M. Solid-state spreading and sintering of multiphase materials. Mater Sci Eng A. 2008;475(1-2):2-11. doi:10.1016/j.msea.2007.01.160

64. Goutier F, Valette S, Vardelle M, Lefort P. Alumina plasma spraying on 304L stainless steel: Role of a wüstite interlayer. J Eur Ceram Soc. 2011;31(9):16851694. doi:10.1016/J.JEURCERAMSOC.2011.03.022

65. Delport HP. The BIOMET ReCap hip resurfacing prosthesis. Hip Resurfacing Handb. January 2013:69-77. doi:10.1533/9780857096203.1.69

66. Sinding KM, Orr A, Breon L, Tittmann BR. Effect of sintering temperature on adhesion of spray-on piezoelectric transducers. J Sensors Sens Syst. 2016;5(1):113-123. doi:10.5194/jsss-5-113-2016

67. FDA. Guidance Document for Testing Orthopedic Implants With Modified Metallic Surfaces Apposing Bone Or Bone Cement.; 1994. https://www.fda.gov/downloads/MedicalDevices/DeviceRegulationandGuidance/ GuidanceDocuments/ucm081247.pdf. Accessed July 18, 2018.

68. Clement JL, Jarrett PS. Antibacterial Silver. Met Based Drugs. 1994;1(5-6):467482. doi:10.1155/mbd.1994.467

69. Grass G, Rensing C, Solioz M. Metallic Copper as an Antimicrobial Surface. Appl Environ Microbiol. 2010;77(5):1541-1547. doi:10.1128/aem.02766-10

70. Paladini F, Pollini M, Sannino A, Ambrosio L. Metal-Based Antibacterial Substrates for Biomedical Applications. Biomacromolecules. 2015;16(7):18731885. doi:10.1021/acs.biomac.5b00773

71. Fielding GA, Roy M, Bandyopadhyay A, Bose S. Antibacterial and biological characteristics of silver containing and strontium doped plasma sprayed hydroxyapatite coatings. Acta Biomater. 2012;8(8):3144-3152. doi:10.1016/j.actbio.2012.04.004

72. Desrousseaux C, Sautou V, Descamps S, Traoré O. Modification of the surfaces of medical devices to prevent microbial adhesion and biofilm formation. $J$ Hosp Infect. 2013;85(2):87-93. doi:10.1016/j.jhin.2013.06.015

73. COOK SD, THOMAS KA, KAY JF, JARCHO M. Hydroxyapatite-Coated Titanium for Orthopedic Implant Applications. Clin Orthop Relat Res. 
1988; \{NA\} \$mat(232):225???243. doi:10.1097/00003086-198807000-00030

74. Petersen R. Titanium Implant Osseointegration Problems with Alternate Solutions Using Epoxy/Carbon-Fiber-Reinforced Composite. Metals (Basel). 2014;4(4):549569. doi:10.3390/met4040549

75. Wilkinson E. C difficile risk with prophylactic antibiotics during surgery. Lancet Infect Dis. 2008;8(7):412. doi:10.1016/S1473-3099(08)70144-0

76. Kuong E, Ng F-Y, Yan CH, Fang C, K Y Chiu P. Antibiotic prophylaxis after total joint replacements. Hong Kong Med J. 2009;15:458-462.

77. Otto-Lambertz C, Yagdiran A, Wallscheid F, Eysel P, Jung N. Periprosthetic Infection in Joint Replacement. Dtsch Arztebl Int. 2017;114(20):347-353. doi:10.3238/arztebl.2017.0347

78. Govindarajan T, Shandas R. A Survey of Surface Modification Techniques for Next-Generation Shape Memory Polymer Stent Devices. Polymers (Basel). 2014;6(9):2309-2331. doi:10.3390/polym6092309

79. Afzal M, Ahmed F, Khan AN, Anwar MY, Ali L, Ajmal M. Physical chemistry of WC-12\%Co coatings deposited by thermal spraying at different standoff distances. Int J Mater Res. 2015;106(9):988-995. doi:10.3139/146.111259

80. Cao M, Gitzhofer F, Gravelle D V, Henne R, Boulos MI. A torch nozzle design to improve plasma spraying techniques. Plasma Sources Sci Technol. 1997;6(1):3945. doi:10.1088/0963-0252/6/1/006

81. Beason Jr. G, McKechnie T, Power C. Plasma spray nozzle with low overspray and collimated flow. April 1995. https://patents.google.com/patent/US5573682A/en. Accessed September 15, 2018.

82. Karimi M, Jodoin B, Rankin G. Shock-Wave-Induced Spraying: Modeling and Physics of a New Spray Process. J Therm Spray Technol. 2011;20(4):866-881. doi:10.1007/s11666-011-9622-4

83. Luckey HA, Lamprecht EG, Walt MJ. Bone apposition to plasma-sprayed cobaltchromium alloy. J Biomed Mater Res. 1992;26(5):557-575. doi:10.1002/jbm.820260502

84. Yang CY, Chen CR, Chang E, Lee TM. Characteristics of hydroxyapatite coated titanium porous coatings on Ti-6Al-4V substrates by plasma sprayed method. $J$ Biomed Mater Res Part B Appl Biomater. 2007;82B(2):450-459. doi:10.1002/jbm.b.30750

85. Patel B, Inam F, Reece M, et al. A novel route for processing cobalt-chromiummolybdenum orthopaedic alloys. $J$ R Soc Interface. 2010;7(52):1641-1645. doi:10.1098/rsif.2010.0036

86. Champion E. Sintering of calcium phosphate bioceramics. Acta Biomater. 2013;9(4):5855-5875. doi:10.1016/J.ACTBIO.2012.11.029

87. Chen M, Zhang E, Zhang L. Microstructure, mechanical properties, bio-corrosion properties and antibacterial properties of Ti\{łtextendash\} Ag sintered alloys. Mater Sci Eng C. 2016;62:350-360. doi:10.1016/j.msec.2016.01.081

88. Ewald A, Hösel D, Patel S, Grover LM, Barralet JE, Gbureck U. Silver-doped calcium phosphate cements with antimicrobial activity. Acta Biomater. 2011;7(11):4064-4070. doi:10.1016/j.actbio.2011.06.049

89. Vaishya R, Chauhan M, Vaish A. Bone cement. J Clin Orthop Trauma. 2013;4(4):157-163. doi:10.1016/j.jcot.2013.11.005 
90. Donaldson AJ, Thomson HE, Harper NJ, Kenny NW. Bone cement implantation syndrome. Br J Anaesth. 2009;102(1):12-22. doi:10.1093/bja/aen328

91. Milić M, Leitinger G, Pavičić I, et al. Cellular uptake and toxicity effects of silver nanoparticles in mammalian kidney cells. J Appl Toxicol. 2015;35(6):581-592. doi:10.1002/jat.3081

92. Hadrup N, Lam HR. Oral toxicity of silver ions, silver nanoparticles and colloidal silver - A review. Regul Toxicol Pharmacol. 2014;68(1):1-7. doi:10.1016/J.YRTPH.2013.11.002

93. Ružić J, Vilotijević M, Božić D, Raić K. Understanding Plasma Spraying Process and Characteristics of DC-ARC Plasma Gun (PJ-100). Vol 18.; 2012. http://metall-mater-eng.com/index.php/home/article/view/203. Accessed September 15, 2018.

94. Specification for Cobalt-28 Chromium-6 Molybdenum Alloy Castings and Casting Alloy for Surgical Implants ( \{UNS\} R30075). doi:10.1520/f0075-12

95. Test Method for Shear Testing of Calcium Phosphate Coatings and Metallic Coatings. doi:10.1520/f1044

96. GOTMAN I. Characteristics of Metals Used in Implants. J Endourol. 1997;11(6):383-389. doi:10.1089/end.1997.11.383

97. Hryniewicz T, Rokosz K, Filippi M. Biomaterial Studies on \{AISI\} 316L Stainless Steel after Magnetoelectropolishing. Materials (Basel). 2009;2(1):129-145. doi:10.3390/ma2010129

98. Reade Advanced Materials. Silver Powder and Silver (Ag) Metal. 2018. https://www.reade.com/products/silver-powder-silver-metal. Accessed September 17, 2018.

99. Bosco R, Van Den Beucken J, Leeuwenburgh S, et al. Surface Engineering for Bone Implants: A Trend from Passive to Active Surfaces. Coatings. 2012;2(3):95119. doi:10.3390/coatings2030095

100. Rochford ETJ, Richards RG, Moriarty TF. Influence of material on the development of device-associated infections. Clin Microbiol Infect. 2012;18(12):1162-1167. doi:10.1111/j.1469-0691.2012.04002.x

101. the balance. Type 316/316L Stainless Steel Explained. 2018. https://www.thebalance.com/type-316-and-3161-stainless-steel-2340262. Accessed May 8, 2018.

102. Met, S.J.M Alloys \& Metals L. Cobalt alloys - SJM Alloys and Metals Ltd. http://www.sjmalloysandmetals.com/portfolio-items/cobalt-alloys/. Accessed May 12, 2018.

103. de Castro IA, Datta RS, Ou JZ, et al. Molybdenum Oxides - From Fundamentals to Functionality. Adv Mater. 2017;29(40):1701619. doi:10.1002/adma.201701619

104. Adhesives PE. PERMABOND ${ }^{\circledR}$ ES550 Technical Datasheet.; 2016.

105. Sanyal A, Gupta A, Bayraktar HH, Kwon RY, Keaveny TM. Shear strength behavior of human trabecular bone. J Biomech. 2012;45(15):2513-2519. doi:10.1016/j.jbiomech.2012.07.023

106. LBNL Pigment Database: [G04] Cobalt Chromite Blue-Green Spinel (iii). http://coolcolors.lbl.gov/LBNL-Pigment-Database/paints/G04.html. Accessed May 13, 2018.

107. Horst A. Antimicrobial Effects of Metal Oxide Nanoparticles.; 2009. 
https://www.nnin.org/sites/default/files/files/2009reura/2009NNINreuHorst.pdf.

108. Raza MA, Kanwal Z, Riaz S, Naseem S. Antibacterial Performance of Chromium Nanoparticles against Escherichia Coli, and Pseudomonas Aeruginosa.; 2016.

109. Arakha M, Pal S, Samantarrai D, et al. Antimicrobial activity of iron oxide nanoparticle upon modulation of nanoparticle-bacteria interface. Sci Rep. 2015;5(1):14813. doi:10.1038/srep14813

110. Reade Advanced Materials. 3D Printing Powders / Additive Manufacturing Powders. https://www.reade.com/products/3d-printing-powders. Published 2018. Accessed May 8, 2018.

111. Global Titanium Inc. Safety Data Sheet CP Titanium Powder, Dry (-325 Mesh). Detroit; 2015. http://www.globaltitanium.com/sds_cptipow-325.pdf. Accessed May 12, 2018.

112. Basim GB, Ozdemir Z, Karagoz A. Evaluation of Infection Resistance of Biological Implants through \{CMP $\}$ based Micro-Patterning. $\{M R S\}$ Proc. 2012;1464. doi:10.1557/opl.2012.1469 